\title{
A DESCRIPTIVE ANALYSIS OF THE PERCEIVED EFFECTIVENESS OF VIRGINIA TECH'S FACULTY DEVELOPMENT INSTITUTE
}

\author{
CLARETHA H. BANKS
}

Dissertation submitted to the Faculty of the Virginia Polytechnic Institute and State University in partial fulfillment of the requirements for the degree of

\author{
Doctor of Philosophy \\ in \\ Career and Technical Education
}

Patrick A. O'Reilly, Chair

K. Kurt Eschenmann

John Burton

Glen Holmes

Samuel Winchester

April 24, 2002

Blacksburg, Virginia

Keywords: Faculty Development, Computer technology, Motivational Theories, Met Expectation Hypothesis, Training

Copyright 2002, Claretha H. Banks 


\title{
A DESCRIPTIVE ANALYSIS OF THE PERCEIVED EFFECTIVENESS OF VIRGINIA
}

\section{TECH'S FACULTY DEVELOPMENT INSTITUTE}

\author{
by \\ Claretha H. Banks \\ Committee Chairman: Patrick A. O'Reilly \\ Teaching and Learning
}

(ABSTRACT)

Virginia Tech's Faculty Development Institute (FDI) was developed to address issues related to the computer technology revolution; training and education of faculty; faculty professional development; and the university adjusting to change. The purpose of this study was to identify and compare the goals, expectations, and perceived outcomes that the university, FDI developers, and the initial participants had for Virginia Tech's FDI initiative as originally implemented. Both qualitative and quantitative research methods were used in this study to identify the perceived outcomes for the developers and initial participants. The fundamental concepts of motivation theory, evaluation, personal recall, and self-perception theory are used help to describe and explain the findings of the study. Interview results from the five developers and historical document analysis were used to develop surveys for the 49 initial participants and the developers in order to provide validity for the results. Interviews, historical documents and the survey results show that initial participants, developers and the university had very similar expectations for the outcomes during and/or immediately following the initial FDI workshop. There were wider differences in expectations of long-term outcomes as a 
result of the FDI initiative. The results also differ in terms of the extent to which participants and developers believed that their expectations were met short and long term. 


\section{DEDICATION}

I would like to dedicate this dissertation to the memories of the following individuals: My brother, Eugene "Bo" Hughes, Jr., whose death reminded me that life is valuable and that we must pursue goals in the present time and not wait for a future date that we may not see; my cousin, James H. Hughes, who allowed me to be his "shadow" for years and who let me know by his actions that there are people who care and can lead by example without being over the age of 20; my grandmother, Fannie E. Felder, who enjoyed life and was content where she was, regardless of the advances of the world around her. Their deaths in 1997 and early 1998 gave me the inspiration to not settle for less than what I was capable of achieving. I realized that these were three people who inspired my life from the point that I can recollect their existence through today. They were all there when I needed them regardless of the circumstance and for the three of them to be taken away in such close proximity of each other made me wonder about my future without them. Upon pondering this question, I realized that they had prepared me to pursue my dream of obtaining a Ph.D. and any other goal.

I would also like to dedicate this to the memory of Mrs. Cora Allen whom when I did not even know what a Ph.D. was kept telling me that no matter how many degrees I earned, not to forget about "Dr. Jesus". Her sayings from when I was, seven or eight years old became reality to me the closer I came to obtaining my Ph.D.

I cannot begin to say enough about dedicating my success to the memory of my father-in-law, Richard Ervin Banks. His battle with Leukemia during the last two years of my studies was indeed an inspiration; no matter how bad things seemed, he kept moving and kept the faith. Regardless of the adversity that I was facing, just thinking of his "counting it all joy" kept me motivated. 


\section{ACKNOWLEDGMENTS}

I would like to first thank God for the gift of knowledge that He has provided me and the many people that He has placed in my life, which have allowed me to achieve all of my goals.

I would like to thank my husband, Richard L. Banks and daughter, Karla R. Banks who were supportive in numerous ways; especially enduring throughout the time it took for me to complete this degree. I would like to let Karla know that without her mature, independent spirit and personality, I would not have been able to leave her with babysitters and friends as much as I have. I also enjoyed the many car rides with her from Roanoke to Christiansburg and back.

I would like to thank my parents, Mr. and Mrs. Eugene (Rosa M.) Hughes who have supported and encouraged my interests throughout my life. I would like to especially thank my mother for continuously keeping my family and me in her prayers, and for doing everything within her power to make her children's lives better. I would like to thank all of my brothers and sisters who have always provided their support: Richard A. Hughes, John H. Hughes, Jerome Hughes, Jimmie L. Hughes, Terry W. Hughes, Bernice Smith, Levern M. Hughes, Alfonso Hughes, Margaret A. McFadden, and Roselind L. Hughes. Their families have also been very supportive.

I would like to offer most special support to Dr. Patrick A. O’Reilly, whom I will recognize as the best advisor at Virginia Tech. Regardless of the situation, he has been supportive. I just hope that he will have the energy to recover after the marathon finish that he has had to endure with this study. The traits that I would use to describe "Dr. O."

are supportive, knowledgeable, honest, open-minded, positive, time conscious, willing to help, direct, stable, willing to say he doesn't know but would find out, and a good sense of humor. These are also the traits that I look for in friends, so I would say he has also been a great friend as well as a superb advisor. 
Special thanks are also extended to the members of my doctoral committee: Drs. Kurt Eschenmann, John Burton, Glen Holmes and Samuel Winchester who all provided excellent support and professionalism.

I would like to specifically thank Dr. Winchester for his willingness to travel from Raleigh, NC to be here when needed and for his support over the past nine years during completion of my Master's and at present.

Special thanks also go to Dr. Lawrence Cross for reviewing and editing my survey instrument, Dr. Melanie Uttech for reviewing and editing the qualitative methodology of the study, and Drs. Sue Magliaro and Curtis Finch for assisting with research for this study. This study would not have been complete without their professional support.

An extra special thank you goes out to the following individuals who provided childcare support for Karla during this time, often at the last moment: Mr. and Mrs. Lewis (Deloris) Hayden, Mr. and Mrs. John (Sheila) Anderson, Mr. and Mrs. Kurt (Monica) Fultz, Mr. and Mrs. Bill (Katie) Jernigan, Mr. and Mrs. Robert (Mary) Smith and Ms. Arlene Berger and family. Without their support, often at no charge and at the oddest of hours, this study would not have been complete.

I would also like to thank several of my fellow graduate students for their friendship and understanding. They entertained Karla, purchased books along with completing other errands around campus that reduced my commute significantly. They are: Duanne Hoffler, Dr. Terence Lynch, Dr. David Robertson, Dr. Zulkifli Zakaria, Kathleen Carlisle, and Paul Dettman. Thanks for being there!

I would like to thank Mrs. Leah Coffman and her daughter Laura Coffman for their last minute editing of this document. It is great to have someone to call on at the ninth hour for support. 


\section{TABLE OF CONTENTS}

$\begin{array}{lll}\text { ABSTRACT } & \text { ii }\end{array}$

DEDICATION $\quad$ iv

ACKNOWLEDGEMENTS V v

TABLE OF CONTENTS vii

LIST OF TABLES $\quad$ xi

LIST OF FIGURES $\quad$ xiii

$\begin{array}{ll}\text { Chapter One } & 1\end{array}$

$\begin{array}{ll}\text { Background of the Problem } & 1\end{array}$

Computer Technology 1

$\begin{array}{ll}\text { Training and Education } & 2\end{array}$

Professional Development of Faculty $\quad 4$

$\begin{array}{lr}\text { Goals and Expectations } & 9\end{array}$

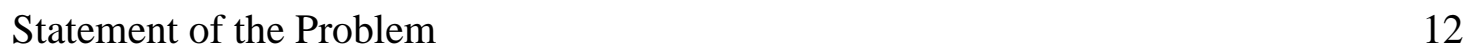

Research Questions 12

Basic Assumptions for the Study 12

Limitations for the Study $\quad 12$

Definition of Terms 13

$\begin{array}{ll}\text { Chapter Two } & 14\end{array}$

Review of Related Research 14

$\begin{array}{ll}\text { Introduction } & 14\end{array}$

Human Resource Development 14

$\begin{array}{ll}\text { Computer Training } & 15\end{array}$ 
$\begin{array}{ll}\text { Summary } & 16\end{array}$

$\begin{array}{ll}\text { Relevant Theories } & 16\end{array}$

$\begin{array}{ll}\text { Change Theory } & 16\end{array}$

$\begin{array}{ll}\text { Rogers’ Diffusion Theory } & 17\end{array}$

$\begin{array}{ll}\text { Theories of Motivation } & 19\end{array}$

$\begin{array}{ll}\text { Vroom’s Expectancy Model } & 21\end{array}$

$\begin{array}{ll}\text { Porter-Lawler Expectancy Model } & 21\end{array}$

Porter-Steers Met Expectations Hypothesis 22

$\begin{array}{ll}\text { Summary } & 24\end{array}$

$\begin{array}{ll}\text { Procedures } & 24\end{array}$

$\begin{array}{ll}\text { Evaluation } & 24\end{array}$

$\begin{array}{ll}\text { Personal Recall } & 25\end{array}$

$\begin{array}{ll}\text { Self-Perception Theory } & 26\end{array}$

$\begin{array}{ll}\text { Summary } & 26\end{array}$

$\begin{array}{ll}\text { Chapter Three } & 28\end{array}$

$\begin{array}{ll}\text { Methodology } & 28\end{array}$

$\begin{array}{ll}\text { The Design and Methods } & 28\end{array}$

$\begin{array}{lr}\text { Phase I } & 29\end{array}$

$\begin{array}{lr}\text { Participants } & 29\end{array}$

Data Collection $\quad 29$

Data Analysis $\quad 31$

Reliability and Validity 32 
Subjects

Data Collection

Data Analysis

Reliability and Validity

Chapter Four

Findings

Introduction

Phase I

Demographics

Data Collection

Research Question Results

Virginia Tech

FDI Developers

Initial Participants

Phase II

Demographics

Research Question Results

Virginia Tech

FDI Developers

Initial Participants

Phase III

Demographics 
Summary, Conclusions, and Discussion

Conclusions

Discussion

Implications

References

Appendix A: Banks Instructional Design Model 


\section{LIST OF TABLES}

Table 1: Rogers' Communication Channel Component and Study Example 19

Table 2: Interview Guide and Research Question(s) Answered 30

Table 3: Department/Area and Number of Subjects 33

Table 4: Outcomes developers expected to occur during and/or immediately following the initial FDI workshop

Table 5: Long-term outcomes developers expected to occur as a result of the initial FDI workshop

Table 6: Outcomes developers expected to occur during and/or immediately following the initial FDI workshop

Table 7: Long-term outcomes developers expected to occur as a result of the initial FDI workshop

Table 8: Outcomes developers agreed upon as not being long-term expectations for the initial FDI workshop

Table 9: Outcomes initial participants expected to occur during and/or immediately following the initial FDI workshop

Table 10: Long-term outcomes initial participants expected to occur as a result of the initial FDI workshop

Table 11: Outcomes initial participants did not agree upon as being expected to occur during and/or immediately following the initial FDI workshop

Table 12: Outcomes initial participants did not agree upon as being expected long-term outcomes for the initial FDI workshop

Table 13: Outcomes initial participants agreed upon as not being a long-term Expectation for the initial FDI workshop

Table 14: Comparison of outcomes not expected by the University, Developers, and Initial Participants

Table 15: Extent to which developers' expected outcomes were achieved during and/or immediately following the initial FDI workshop 
Table 16: Extent to which developers' long-term expected outcomes were achieved as a result of the initial FDI workshop

Table 17: Extent to which initial participants' expected outcomes were achieved during and/or immediately following the initial FDI workshop

Table 18: Extent to which initial participants' long-term expected outcomes were achieved as a result of the initial FDI workshop 


\section{LIST OF FIGURES}

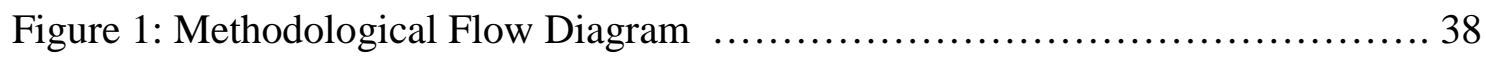




\section{CHAPTER 1}

\section{Background of the Problem}

Computer Technology

American society changes and grows as technology evolves. Often the majority of society is convinced to follow the initiatives of a few. The computer revolution that has evolved throughout the past half century is no exception. The computer technology development process began in earnest during World War II with mainframe computers being developed as university projects sponsored by the federal government. These computers were very expensive and used for business, research and military purposes. The introduction of personal computers in the 1980s and the explosion of chip technology transformed the computer revolution. Computers were dramatically reduced in size and cost, and increased in power.

Among the numerous applications of the computer are its important uses in education and training. The computer provides both a new core technology through which training can be organized and administered, and the computer and computer programs are themselves the content of an increasing number of training programs. In insurance, education, and other service industries, computer related expertise accounts for one of the largest performance needs addressed through training (Kelly, 1995).

The latest development in this revolution has been the expansion of the World Wide Web (WWW) in the last decade. The combination of computers and the WWW has transformed society, business, and research around the globe, as well as revolutionizing work and training methods (Kelly, 1995). Today, the majority of Americans of all ages have access to computers -- at home, work, school, public library, etc. In the university environment, essentially all faculty and students have access to computers in their office, 
lab or dorm room - most actually own one. Although faculty have moved rapidly to use computer and WWW technology in research and scholarly pursuits, they have typically been less interested in using them as teaching aids in a classroom setting. In recent years, faculty members have been asked to utilize computer technology within their professional work, primarily as instructional tools. The WWW has provided the platform for faculty members to incorporate technology into their instruction (Ball, 1995). Virginia Tech's Faculty Development Institute (FDI) was developed to assist faculty members with integrating technology into their instruction.

In today's technological environment, enhanced computer skills are a necessity for growth and survival throughout society. The university community has been affected by an increase in the number of students that need to be taught by faculty who have decreasing resources available. Computer technology has led to the rapid growth of knowledge acquisition and expansion and also provided numerous resources that were never available before to both faculty and students.

\section{Training and Education}

Training and education are processes or methods that are often used to introduce new technological innovations to individuals within organizations. According to Silberman, training is "a method of enhancing human performance. Whenever a person's ability to perform a job is limited by a lack of knowledge or skill, it makes sense to bridge that gap by providing the required instruction" (Silberman, 1998). Training is narrow in the sense that it focuses on the "gap" as described by Silberman or the assessed need of the individual to acquire some specific knowledge and/or skill. Training is often short-term and specific to a particular environment or task. It also focuses on the process 
and/or procedures needed to perform one or more tasks by providing specific 'need to know' information to the individual.

Education, much broader in nature than training, is designed to prepare individuals for future aspirations as opposed to current needs. It often provides general, as opposed to specific, knowledge and/or skills, and in contrast to training, is more longterm and general in nature. It is a more all-encompassing process of acquiring knowledge. Education focuses more on theory and background of applications as opposed to practical application. Training and education are different in many respects; however, they are similar with regard to their primary purpose, which is to transfer knowledge to an individual.

The process of how training and education are administered has an impact on the quality of the results that the individual(s) obtain from his/her experience(s). Training often identifies the problem through some type of needs analysis technique. Once the problem has been identified, a method to address it is determined through assessment techniques that can include interviews and observations. Once the appropriate method has been determined, proper development and execution of the training methodology(ies) and instruction designed to solve the problem for the learner becomes crucial. There are various models that can be used to assist with the development of the proper instruction and the selection and use of appropriate methodologies. A viable sequence of how training instruction could be designed can be found in Appendix A (ref. Banks Model).

Education often follows a prescribed curriculum that has been identified to address broad needs of the learner. Educators use methodologies that address the curriculum guidelines as opposed to learner specific guidelines. Their instructional 
materials often include a textbook as opposed to instructional materials developed for a specific need. Ultimately, education is a transfer of a body of knowledge and practice in a discipline or field of study; whereas training is learning and practicing activities and skills necessary to carry out a specific task or work practice.

Often, individuals benefit most from a combination of both education and training because training can build on what one has been taught in school environments and education can build upon and broaden an individual's knowledge in a specific skill area. Professional Development of Faculty

As the trend toward computer use escalated, faculty members, who are subject matter experts, but not necessarily adept with computer technology, realized they needed to acquire new knowledge and/or skills to use computer technology effectively. Computers and the WWW opened up the instructional setting to resources that were never before available. Although many, but not all, faculty recognized the potential benefits offered by computer technology and the opportunities that it would provide them, they may not have been willing to invest the time needed to develop and enhance their skills. They were faced with barriers that they were reluctant to address including: (a) the upfront time required to develop their materials using a new technology; (b) the lack of hardware and/or software resources; (c) the funds to update hardware and/or software; (d) the experience, technical assistance and support needed to succeed (Eifler, Greene, \& Carroll, 2001; Ndahi, 1998). When facing barriers, individuals often decide to participate in activities that are worthy of their effort or offer valuable return as a result of their effort. They seek a payoff that will enhance skills they already possess. For faculty, overcoming the barriers they faced in incorporating computer technology into their 
instruction may or may not have been perceived as too difficult for the payoff that was to be obtained.

Considerable learning occurs within organizations, but not all of it is planned. "Some of this learning is planned and formally sanctioned by the organization, but much of it is serendipitous, unplanned, and informal (e.g., learning from someone who has the inside 'track')" (Cascio, 1998). Traditionally, university faculty have acquired training and education through self-study, informal collaboration with peers, seminars, workshops, and professional conferences; however, those forms of skill acquisition techniques were often not specific in detail nor did they provide opportunities for faculty to develop their skills through practice. This training was often not directly related to the instructional roles of faculty. In an attempt to address specific faculty needs, Virginia Tech decided to enhance and build upon the idea of a formal faculty-training medium through the FDI. FDI was the first introduction of a large scale, formal faculty training program to the Virginia Tech environment. The changing culture of students who came to campus expecting to use their existing computer skills and the need to make the process of learning more efficient and effective were determinants for the development of a training entity that could help faculty acquire the computer skills they needed in a relatively short period of time.

The vision of FDI as initially implemented at Virginia Tech is as follows:

A major initiative in instructional computing will transform the academic lives of all students and faculty and change the nature of teaching and learning at Virginia Tech. Anticipated outcomes include courses with more emphasis on active and independent learning strategies, problem solving and collaboration; strengthened student competitiveness in the job market; improved student retention; improved quality of interactions among students and faculty; and improved use of computer skills by students and faculty throughout the entire academic enterprise. The University will gain from making a major commitment to its teaching mission that 
will enhance our competitiveness in student recruiting and placement while strengthening the long-term appreciation of alumni for the institution.

The anticipated outcomes that were expected four years after beginning the FDI initiative are as follows:

1. Sixteen key courses will have an improved quality of instruction resulting from formal course development projects. Faculty will receive release time and other significant support to infuse these courses with new approaches to teaching and learning that leverage emerging instructional technologies. All classroom used for these courses will have multimedia computers and projection systems permanently installed.

2. All students, regardless of major or economic status, will have greatly improved access to computers and software tools. Virginia Tech will have one of the best student-computer ratios among land-grant universities. There will be 20 student-access computer labs, housed in renovated classrooms (which will provide in-class computer support for teaching, and will also double as afterhours computer labs), new dormitory computer labs, the library, and other locations. Periodic replacement of these computers is included.

3. All faculty will receive a highly functional computer and an installed set of core software productivity programs (or a credit voucher towards a computer of even higher functionality). This will provide an equitable baseline of computing technology for all faculty. Periodic replacement of these computers is included.

4. All faculty will be better prepared to take advantage of computing technologies by participating in summer faculty development workshops, hands-on software training, and small-group faculty-led discussions on re-thinking instruction. Faculty will be encouraged to develop and assess alternative approaches that unlock courses from traditional formats by making increasing use of computeraided multimedia instruction, both in and out of classrooms.

5. Multimedia presentation systems will be permanently installed in 80 general classrooms (20 per year) to facilitate convenient and reliable use of computerbased teaching materials. These systems will include a computer, a color projection unit, and peripherals. Additionally, those faculty assigned to teach in classrooms not equipped with permanent computer projection system may borrow a portable laptop computer and LCD overhead display to be acquired from a loan pool. These systems will also prove invaluable for research presentations and meetings.

6. All students, beginning in freshman year, will receive specific training in the use of the computers through the campus cable system and in student-access labs. This training will insure that students know how to use a computer in the 
early stages of their academic careers. Students will gain valuable preparation for using collaborative workgroup software, creating computer-based presentations for classes, and accessing networks to tap campus and global information resources. The early training will enable faculty teaching lower division courses (e.g. core courses) to incorporate computer-based assignments with greater confidence.

7. There will be substantially different, and higher levels of contact between students and faculty, through greatly increased use of electronic mail, electronic discussion groups, and "24-hour electronic office hours."

8. All students and faculty will have 24-hour access to improved technical support and consulting on the common core of supported desktop software programs. Faculty will have enhanced access to professional staff and a support lab for help using new technologies in teaching. (Instructional computing proposal, 1992)

Although, all of the anticipated outcomes could be evaluated, the primary focus of this study will be outcomes three, four, seven, and eight as they relate to faculty use of technology in instruction.

Faculty were constantly in contact with students and were the ones who needed to become adept at providing these computer enabled resources to students. Faculty were considered to be in the optimum position for imparting new and evolving knowledge. Due to this, faculty were placed in situations that may not always have been comfortable for them and required that they acquire additional knowledge and/or skills to provide necessary information to their students. In the past, course materials primarily consisted of written documentation (i.e. books, papers, course handouts, etc...) and whatever the student could obtain through lectures, labs, workshops, etc. In order to enhance student comprehension of the subject matter being presented, faculty spent considerable time preparing and revising their materials. The addition of computer technology does not reduce the amount of time faculty members must spend preparing (Deden, 1998). They could not take for granted that the computer alone would enhance student learning. 
Course materials using computer technology needed to be well designed and much consideration given to how the materials were implemented into the instruction (Oliver, Omari, \& Herrington, 1998)

The organization of FDI resembled more of a formal training program than a traditional education program. It provided short-term, specific training focused on the task of computer technology utilization in instruction. It was based on a perceived need and specific objectives. Its focus was not on following traditional teaching or educational methods, but on specific skills training -- how faculty could use computer technology within their instructional process. It helped faculty develop skills in a learning by doing environment (e.g., Dewian). Faculty were provided an opportunity to be actively involved in their skill development and gained access to technical assistance resources that allowed them to work at their own pace. They were allowed the opportunity to build relationships with other participants and facilitators of the FDI workshops and to use these individuals and other peers as mentoring/coaching resources after leaving the workshop(s). They were also provided written documentation of training materials that were specifically designed to meet their needs during, and as a reference after, the workshop.

The literature suggested that computer technology was here to stay and that faculty must constantly remain up-to-date on the latest technologies available. To be effective FDI had to maintain a vision for growth and remain innovative so that it could sustain and meet the skill development needs of faculty members as technology changed. FDI serves as a resource for faculty to continuously upgrade their skills. Having been perceived as experts in their fields, these faculty members were expected to acquire, 
adapt, and perform new skills quickly. FDI currently provides the opportunity for upgrades on computers every four years and is seeking to reduce this to every three years. Faculty members must also remain actively involved in their own development (Hurst, 1994). They must not be intimidated by technology, but be willing to take on new challenges for their own, and their students' future development.

\section{Goals and Expectations}

New training programs are introduced to help individuals develop a skill or improve their knowledge of a particular topic. The training program's success in introducing and transferring new skills are often not measured or assessed during or after the program has been introduced. Expectations and goals are established whenever a training or education program is developed. Without assessment the extent to which the expectations and goals of the training program have been met is unknown.

Organizations establish programs to achieve specific goals and expectations. Often their goals are achieved over longer terms and their objectives are broader than the specific goals of individuals or developers. Individual and developers' goals and expectations are often determined from mission statements or visions of the organization and specific organizational problems. Developers create programs to achieve certain goals and expectations as outlined by their affiliated organization. The programs are

often designed to teach specific concerns. According to Silberman, developers should focus on the kind of learning goal that is dictated by the specific learning problem the organization is trying to address:

1. Cognitive goals are the priority when there is a lack of knowledge. This is often referred to as a "don't know" situation. 
2. Behavioral goals are the priority when there is a lack of skill. This is often referred to as a "can't do" situation.

3. Affective goals are the priority when there is a lack of desire or fear about using new knowledge or skills. This is often referred to as a "won't do" situation (Silberman, 1998).

Developers can target one or all of these three goals, and they may or may not be on target with the missions of the organization and/or the participants.

Individuals come to programs with personal expectations and goals. They come with personal goals that center around a 'what's in it for me' mentality. Often if the program meets their personal needs, the individual sees it as having been a success. According to Cascio, motivation of trainees to do well in training depends upon four factors:

Factor I a favorable work environment;

Factor II a belief in the soundness of the judgment by others that the trainee has strengths or weaknesses that training can improve on;

Factor III a personal belief in one's ability to master the content of the training (high self-efficacy); and

Factor IV a belief on the part of the trainee that successful completion of the program will lead to outcomes that he or she personally values (personal development, promotion, an increase in pay) (Cascio, 1998).

The outcomes of the goals and expectations of organizations, developers, and individuals may or may not match up. Key issues of whether these goals and expectations 
match up hinge on effective communication before, during, and after program implementation. If the goals and expectations for a program held by the organization, developers, and individuals involved are good matches, all stakeholders are usually satisfied and the program is often seen as a benefit - seen as having been valuable and successful for all involved. However, if there was a poor match between the goals and expectations of the stakeholders, they may not be satisfied and therefore perceive the program as ineffective, unsuccessful or a waste of resources.

The university, FDI developers, and the initial participants all had specific goals and expectations with regards to the FDI program. Their goals and expectations may or may not have aligned with each other and may or may not have been met. The degree to which they did align or were met was likely to be a determining factor in the extent to which all involved with the program viewed the program as having been effective and valuable. If they do not align, the effectiveness and value of the program may have been viewed as questionable. The extent to which the outcomes were valued affects the extent to which they were implemented. If the organization, developers, and the participants value the outcomes, it was likely to be continued and possibly expanded. Thus, the organization may choose to invest more resources; the developers may enhance workshops and /or add new workshops; and the participants may come back for further workshops and implement the acquired skills into their instruction. 


\section{Statement of the Problem}

The purpose of this study was to identify and compare the goals, expectations, and perceived outcomes that the university, FDI developers, and the initial participants had for Virginia Tech's FDI initiative as originally implemented. The focus of this study was to answer the following questions:

1. What organizational change initiatives influenced the development of objectives for the Faculty Development Institute (FDI)?

2. What were the goals and expectations of stakeholders: Virginia Tech, FDI developers, and initial participants?

3. In what ways were Virginia Tech, FDI developers', and initial participants' goals and expectations different?

4. In what ways, if any, have initial participants' professional roles changed as a result of FDI participation?

5. What were the perceived outcomes for the stakeholders: Virginia Tech, FDIdevelopers, and initial participants?

\section{Basic Assumptions for the Study}

A basic assumption of this study is that the initial participants of the study were early adopters of computer technology use in instruction.

\section{Limitations for the Study}

This study relies on the memory of the participants. Intervening events and respondent recall may limit the accuracy of information received. 


\section{Definition of Terms}

In order to clarify terms associated with this study, the following definitions are provided:

Adoption -- A decision to make full use of an innovation as the best course of action available. (Rogers, 1995)

Adoption Proneness - The measure of an individual's willingness to adopt an innovation. (Rogers, 1995)

Change Agent -- An individual who influences clients' innovation-decisions in a direction deemed desirable by a change agency. (Rogers, 1995)

Cognitive Learning - The acquisition of information and concepts related to course content.(Silberman, 1998)

Diffusion -- The process by which an innovation is communicated through certain channels over time among the members of a social system. It is a special type of communication in that the messages are concerned with new ideas. (Rogers, 1995)

Early adopters - Individuals who are the first to adopt a new innovation; they are often respected by their peers in an organization and can influence change.

(Rogers, 1995)

Innovation -- An idea, practice, or object that is perceived as new by an individual or other unit of adoption. (Rogers, 1995)

Motivation - An internal state that arouses us to action, pushes us in particular directions, and keeps us engaged in certain activities.

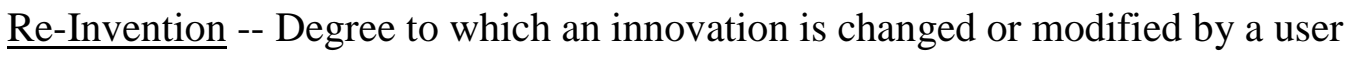
in the process of its adoption and implementation. (Rogers, 1995) 


\section{CHAPTER 2}

\section{Review of Related Research}

\section{Introduction}

This study focused upon an instance where computer technology was introduced into a new setting and evaluated and identified the expectations and perceived outcomes of the stakeholders. Theories and models including Porter and Steers' met expectations hypothesis, Rogers' diffusion theory, Vroom's expectancy theory, change and early adopter's theories were analyzed for relevance to the study. Literature regarding human resource development, training and recall were also reviewed for relevance to this study.

\section{Human Resource Development}

Human resource development (HRD) programs are found throughout most industries and within academia. Human resource departments within organizations are designed in part to assist employees in their professional development. Professional development of employees often consists of opportunities to attend training workshops and seminars and/or the opportunity to further one's education through the use of tuition aid programs. Training and development activities are "planned programs of organizational improvement undertaken to bring about a relatively permanent change in employee knowledge, skills, attitudes, or social behavior" (Cascio, 1998). HRD has access to various behavioral models to help guide training and development efforts including the individual differences model, principles of learning, motivation theory and behavioral modeling (Cascio, 1998).

HRD also focuses on the individual's ability to perform what he has learned in training and development activities when he has returned to the job. Performance, as defined by Cascio, is the "observable, measurable behavior from which we infer 
learning" (Cascio, 1998). HRD departments within organizations try to ensure that learning occurs whenever any training and development activity has been provided. The most prevalent area of focus for HRD training and development efforts throughout the past decade has been computer training and education as a result of the information technology revolution.

\section{Computer Training}

The information technology revolution that has evolved throughout the past decade has made training a vitally important component in an organization's success and expansion goals. Employee knowledge and performance has become a standard that organizations have started to evaluate more and value more. "Training programs are designed to modify or to develop abilities, skills, attitudes, or knowledge so that employees can acquire the competence that will enable them to better perform their jobs. The gamut of training programs available ranges from basic skill training and development for the hard-core unemployed, to supervisory training for the first-line supervisors, to extensive executive development programs for the managers" (Cascio, 1998).

Within organizations, there are training departments that provide knowledge and learning opportunities as a "commodity" to enhance learner development; however, the methods and processes used by training departments must match the needs of each individual learner as well as the organization's goals and objectives. As new technology and processes are developed or enhanced such as "the Internet, intelligent tutoring systems, learning objects and voice recognition" (Bassi, Cheney, \& Lewis, 1998), the providers of learning opportunities must be knowledgeable and able to assimilate those ideas into the workplace as needed. All trends that are developed may no longer be conducive to the growth of an organization as individuals develop new interests. 
Emerging trends such as corporate universities and learning organizations are the prevailing methods of choice for organizations that want to continuously provide computer training to their employees today. Historically, "early computer training was provided exclusively by computer manufacturers" (Kelly, 1995) because it was considered too technical for organizations.

\section{Summary}

The FDI initiative exemplifies the traditional training model of implementing a program to meet an identified need for human resource development i.e., some faculty members needed more enhanced computer technology skills in order to integrate technology into their instruction. Moreover, the developers chose to develop workshops and seminars as opposed to traditional education courses. Faculty members needed to apply their skills in current situations, which is what training is designed to achieve, as opposed to sometime in the future. Training addresses the immediate, applicable skill needs of the individual as opposed to the desire for education to use at a later date. Faculty needed practical, applicable, relevant information that they could apply in their current work.

\section{Relevant Theories}

\section{Change Theory}

There are numerous definitions that have been utilized to describe change. Moran and Brightman have identified five observations about change: (1) change is nonlinear: (2) effective change interweaves multiple improvement efforts; (3) change is top-down and bottom-up; (4) organizational change has an important personal dimension; and (5) measurement is key to successful and sustainable change (Moran \& Brightman, 2000). In order to manage change within organizations, leaders must understand the three most 
powerful drivers of work behavior: purpose, identity, and mastery in individuals. Leaders of change efforts must inspire individuals to align their purpose - what people desire and value; identity - a person's sense of who they are; and mastery - one's ability to manage oneself and the environment effectively with the necessary organizational change effort (Moran \& Brightman, 2000).

According to the literature, "the demand from the marketplace for speed, quality, customization, timeliness, and a variety of products and services has changed the landscape for doing business. The use of technology, the relentless speed of change, and the skills that working people need have changed the nature of work itself (Kunneman, Key, \& Sleezer, 2000) and have provided the platform for change within organizations. Organizations must provide learning that is equal to or greater than the pace of change in order to be successful and further develop both people and the organization for the future growth (Browell, 2000).

\section{Rogers Diffusion Theory}

Diffusion is a method used to measure and assess the change processes. Technological innovations are not always diffused and adopted rapidly, even when the innovation has obvious, proven advantages (Rogers, 1995). Diffusion investigations show that most individuals do not evaluate an innovation on the basis of scientific studies of its consequences, although such objective evaluations are not entirely irrelevant, especially to the very first individuals who adopt an innovation (Rogers, 1995). Diffusion theory has been used for years to explain how innovations are transferred throughout communities and organizations. The diffusion of programs throughout a specific community provides the foundation for studies of technological innovations. 
Rogers' diffusion theory consists of four elements: an innovation, communication channels, time, and social system. The first and second elements, an innovation and communication channels relate most closely to the study. The characteristics of innovations as perceived by individuals help to explain their different rates of adoption. The characteristics are defined as follows:

1. Relative advantage is the degree to which an innovation is perceived as better than the idea it supersedes.

2. Compatibility is the degree to which an innovation is perceived as being consistent with the existing values, past experiences, and needs of potential adopters.

3. Complexity is the degree to which an innovation is perceived as difficult to understand and use.

4. Trialability is the degree to which an innovation is perceived as difficult to understand and use.

5. Observability is the degree to which the result of an innovation are visible to others (Rogers, 1995).

Various studies have used Rogers' characteristics of innovations to explain the introduction of a technological innovation to an organization. Ndahi used Rogers' theory to help explain the introduction of distance learning technology to institutions, faculty and students (Ndahi, 1998). Falba used diffusion of innovation to help explain the innovation- decision process for faculty who were integrating technology into the curriculum of an undergraduate teacher preparation program (Falba, 1998). 
The components of the communication element include:

1. an innovation;

2. an individual or other unit of adoption that has knowledge of the innovation or experience with using it.;

3. another individual or other unit that does not yet have experience with the innovation; and

4. a communication channel connecting the two units. (Rogers, 1995)

The innovation for this study is the use of electronic technology in instruction.

The unit(s) with knowledge and/or experience is staff of FDI. The unit that does not have experience with the innovation is the faculty participants. The communication channels are FDI workshops and seminars.

The following table depicts how this study relates to Rogers' diffusion theory:

Table 1

Rogers' Communication Channel Component and Study Example

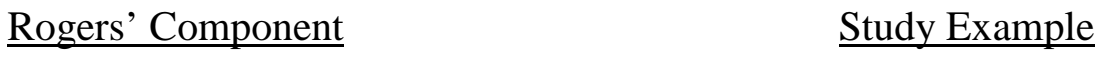

The Innovation Use of electronic technology in instruction

Unit with knowledge and/or experience Staff of FDI

Unit without knowledge and/or experience Faculty participants

\begin{tabular}{ll} 
Communication channel & FDI workshops and seminars \\
\hline
\end{tabular}

\section{Theories of motivation}

The theory of motivation deals with attitudes concerning needs, values, and satisfaction (Porter \& Lawler, 1968). Two of the most often-used motivation theories are drive and expectancy theory. Both theories focus on the concept that people have 
behavior response "expectations" or "anticipations" about future events. They indicate that in order for motivation to exist there must be both positive outcomes and some kind of connection between behavior and the outcomes. "The differences between the theories are that expectancy argues that the anticipation of the positively valent outcome functions selectively on actions which are expected to lead to it. Drive theory views the magnitude of goal as a source of general excitement - a nonselective influence on performance" (Porter \& Lawler, 1968). The drive theory concept of habit strength emphasizes past stimulus-response connections, and thus weights past learning heavily. Expectancy theory places a greater emphasis upon anticipation of the future than upon past learning (Porter \& Lawler, 1968).

Motivation has been studied for many years and there are many theories and definitions of motivation. Historically, psychologists have directed their studies of drive and expectancy towards filling in the missing empirical content of hedonism.

As in the hedonistic doctrine, people are assumed to behave in ways that maximize certain types of outcomes (rewards, satisfiers, positive reinforcements, and so on) and minimize other outcomes (punishments, dissatisfiers, negative reinforcements, and so on). However, some of the circularity of hedonism has been overcome by the development of more precisely stated models and by the linking of the concepts in these models to empirically observable events (Vroom, 1995).

Motivation has general effects:

- it increases an individuals energy and activity level;

- it directs an individual toward certain goals;

- it promotes initiation of certain activities and persistence in those activities; and

- it affects the learning strategies and cognitive processes an individual employs (Ormond, 1999).

Expectancy theory is the primary theory on which this study is based.

"Expectancy is defined as a momentary belief concerning the likelihood that a particular 
act will be followed by a particular outcome"(Vroom, 1995). Expectancy theory has been around for decades and is a decision theory of human motivation and choice in the work situation (House, Shapiro, \& Wahba, 1974).

\section{Vroom's Expectancy Model}

Vroom first proposed expectancy theory as an explanation of work behavior. He proposed three related models related to his theory. The models included a job satisfaction, work motivation and job performance (Vroom, 1995). His models were developed to address three phenomena within the interrelationship of work and motivation. They are as follows:

1. The choices made by persons among work roles.

2. The extent of their satisfaction with their chosen work roles.

3. The level of their performance or effectiveness in their chosen work roles (Vroom, 1995).

It states that the force on a person to perform an act is "a monotonically increasing function of the algebraic sum of the products of the valences of all outcomes and the strength of his expectancies that the act will be followed by an attainment of these outcomes" (House et al., 1974). The extent to which participants' expectations influenced the outcomes of a program could help answer questions of motivation for participating in a new innovation program. Vroom's model has been used primarily for the prediction of job satisfaction, occupational preference, the valence of good performance; however, it can be used to predict the valence of an outcome (Mitchell, 1974).

\section{Porter-Lawler Expectancy Model}

The Porter-Lawler model has been used primarily to measure supervisor effort, 
peer effort and self-effort. It is a modification of Vroom's model and it too is a consideration for this study. This model focused on the value of the reward, the perceived effort required relative to attaining the expected reward, the actual effort, abilities and traits, role perceptions, performance (accomplishment), rewards (fulfillment), perceived equitable rewards and satisfaction (Porter \& Lawler, 1968). Porter and Lawler's value of reward variable referred to the attractiveness of possible outcomes to individuals. The major focus of the model is that for any individual at the particular point in time there are a variety of potential rewards to which he/she attaches differential value. The value of the reward or rewards to an individual can be measured using several measures including asking an individual: (1) to make an actual choice among two or more alternatives in a situation in which he anticipates that the attainment of these outcomes will be affected by his behavior; (2) to rank or rate, on an attitude scaling device, the value of different rewards to himself; or (3) to complete some sort of projective device such as the Thematic Apperception Test (TAT) or a sentence completion test from which some other person (i.e., the tester) infers the values of different rewards for the individual under consideration (Porter \& Lawler, 1968; Vroom, 1995).

\section{Porter-Steers Met Expectations Hypothesis}

Porter-Steers Met Expectations Hypothesis is the modification of Vroom's Expectancy theory that is most relevant for this study. Porter and Steers described "three common denominators that characterize motivation: (1) what energizes human behavior; (2) what directs or channels such behavior; and (3) how this behavior is maintained or sustained" (Steers \& Porter, 1979).

In the context of training, this force influences enthusiasm for the training (energizer), keeps attention focused on training per se (director), and reinforces what is learned in training, even in the face of pressure back on the job to discard what has just been learned (maintainer) (Cascio, 1998). 
The various theories of motivation also have models that help to explain its characteristics. According to Porter \& Steers, "the basic building blocks of a generalized model of motivation are: (1) needs or expectations; (2) behavior; (3) goals; and (4) some form of feedback" (Steers \& Porter, 1979).

Porter and Steers were concerned with the potential role that "met expectations" may have on withdrawal behavior of an individual. Their concept of met expectations is described as the "discrepancy between what a person encounters on this job in the way of positive and negative experiences and what he expected to encounter" (Porter \& Steers, 1973). Using met expectations hypothesis, Porter and Steers predicted that when an individual's expectations - whatever they are - are not substantially met, his propensity to withdraw would increase. Irving and Meyer felt that met expectations hypothesis could be tested by utilizing difference scores reflecting the discrepancy between postentry experiences and pre-entry expectations and found problems related to the difference scores. The difference scores produced artificial relations with outcome variables. The use of direct measures generally requires respondents to indicate the extent to which they perceive that their pre-entry expectations concerning their jobs have been confirmed (Irving \& Meyer, 1995).

Thus, when direct measures of met expectations are used, it is implicitly assumed that respondent perform a mental comparison of their expectations and experiences and that scores on the measure reflect the "match" between these variables. If this is true, it should be possible to show that direct measures of met expectations reflect independently obtained measures of expectation and experiences approximately equally (Irving \& Meyer, 1995).

A weakness of direct measures of met expectations is that it requires individuals to recall their prior expectations after having been on the job for some time. Individual recollections of pre-entry expectations are filtered by more recent experiences and behaviors (Irving \& Meyer, 1995). 


\section{Summary}

Victor Vroom pioneered the development of expectancy theory for use in explaining work behavior. Since his initial study, many researchers have used expectancy theory to explain work behavior. Porter worked closely with Vroom and many others to enhance the theory for further use. From their studies many models have been designed, developed and modified to explain expectations, values and instrumentations. Components of Vroom, Porter \& Lawler, and Porter \& Steers studies are relevant to this study, but the most important component of their research that is useful for this study is the met expectation hypothesis. This study is seeking perceived outcomes for the individual as it relates to what he/she initially expected, which aligns most closely with the components of met expectation hypothesis.

\section{Procedures}

\section{Evaluation}

According to Kirkpatrick, "the reason for evaluating is to determine the effectiveness of a training program" (Kirkpatrick, 1994). Kirkpatrick developed four levels of an evaluation that have been extensively used by trainers and evaluators. They are: (1) Reaction - how those who participate in the program react to it; (2) Learning the extent to which participants change attitudes, improve knowledge, and/or increase skill as a result of attending the program; (3) Behavior - the extent to which change in behavior has occurred because the participant attended the training program; and (4) Results - the final results that occurred because the participants attended the program (1994). "Evaluation of a training program implies a dichotomous outcome (i.e., either a program has value or it does not)" (Cascio, 1998). 
Organizations have often performed evaluations of training programs to attain participant reactions immediately after completion of the program; however, there are other reasons that a program should be evaluated. According to Sackett and Mullen, there are at least four reasons to evaluate training:

1. to make decisions about the future use of a training program or technique (e.g., continue, modify, eliminate);

2. to make decisions about individual trainees (e.g., certify as competent, provide additional training);

3. to contribute to a scientific understanding of the training process; and

4. for political or public relations purposes (e.g., to increase the credibility and visibility of the training function by documenting success) (Sackett \& Mullen, 1993).

\section{Personal Recall}

The personal recall of the developers of FDI was used in this study during the interview phase. Therefore, it is important to know how personal memories are formed and how accurate they may be. The process of personal recall, an instance of long-term, episodic memory, involves two steps: (1) the individual begins by noting his or her present status on the attribute in question; (2) people may invoke an implicit theory of stability or change to guide their construction of the past. Implicit theories are schema like knowledge structures that include specific beliefs regarding the inherent stability of an attribute, as well as a set of general principles concerning the conditions likely to promote personal change or stability (Ross, 1989).

Weaknesses found with personal recall are that the prior response is likely to be biased when states (a) have changed and respondents are unaware of the change, (b) have changed and respondents uniformly miscalculate the degree or nature of the change, and 
(c) are stable and respondents assume that they have changed in a particular fashion; people exaggerated their consistency over time and inappropriately inferred that a prior response followed from their current state; people overestimated the extent to which their present state differed from an earlier state - they inferred a prior response that was too much at variance with their current status; and evidence was found that linked both of the above mentioned biases to people's implicit theories of stability and change for the attribute in question (Ross, 1989).

\section{Self-Perception Theory}

The first postulate of self-perception theory is that individuals come to "know" their own attitudes, emotions, and other internal states partially by inferring them from observations of their own overt behavior and/or the circumstances in which this behavior occurs. The second postulate states that to the extent internal cues are weak, ambiguous, or uninterpretable, the individual is functionally in the same position as an outside observer who must necessarily rely upon those same external cues to infer the individuals' inner states (Bem, 1972). Individuals use self-perception to explain their behavior by noting the conditions under which it occurs (Irving \& Meyer, 1995).

\section{Summary}

This study has focused primarily on level four of Kirkpatrick's model and reasons three and four of Sackett and Mullen's theory of why training is evaluated. This study is evaluating the final results of the impact of the training on the initial participants of FDI and their perceptions of the impact of the training on the university in general. It is also evaluating the expectations and goals that were considered by the developers of FDI as 
they made decisions about the future of their training program. This study will also contribute to the scientific understanding of the training process by evaluating the alignment of developer and participant expectations - whether they were met or not and how they affect perceived outcomes. The evaluation of FDI will depend on initial participants' recall and their self-perception of their experiences as they can recall from their initial participation in the program. The fundamental concepts of evaluation, personal recall and self-perception theory will all help to describe the process that occurred for the university, the developers', and initial participants. They will be used to help determine the expectations, goals, and perceived outcomes of FDI as initially implemented. 


\section{CHAPTER 3}

Methodology

\section{The Design and Methods}

The research design for this study is a mixed methodological approach. The design was chosen because it allowed the best opportunity to gain the necessary information for answering the research questions of this study. This study took place in two stages: Qualitative and Quantitative.

Qualitative methodology was chosen to address the portion of the study that deals with the goals of the university and the developers of FDI. The qualitative portion of this study adds research that is focused on discovery, insight, and understanding from the perspectives of those who participated in the program and offered the greatest promise of making significant contributions to the knowledge base and practice of education (Merriam, 1998).

The developers provided essential information since they were providing first person accounts of their perceptions of the goals and expected outcomes that the university and the developers had for FDI. The developers had the opportunity to describe their experiences and share their findings in an environment that was comfortable for them. Qualitative research allows opportunities for exploration. It is flexible, evolving, and emergent (Merriam, 1998). Through the use of interviews, the developer's goals and expectations were determined from their own words. In-depth interviewing is the way a qualitative researcher can understand "the experience of other people and the meaning they make of that experience" (Seidman, 1998). Pseudonyms were used according to appropriate research protocol (Seidman, 1998). Informed consent 
was utilized and was very important because when conducting in-depth interviews, the topic of inquiry, no matter how apparently innocent, is placed within the total life context of the participant, and that contextual exploration may at some point raise sensitive issues (Seidman, 1998). The procedures as identified by Merriam and Seidman were used in this study without deviation.

Proper protocol was used in this study through the researcher submitting an IRB form (see Appendix B) and gaining informed consent from all participants (see Appendix C). Quantitative methodology was chosen because this is a descriptive and ex post facto study. Quantitative data was gathered from survey questionnaires. The questionnaire addressed the topics as depicted in Appendix D, and was in part developed from the interviews with FDI developers.

Phase I

\section{Participants}

The participants in the qualitative phase of the study were the FDI developers. The developers of FDI were identified through meetings with current directors of the program. There were five developers who were interviewed for this study. Due to informed consent constraints, specific information about the developers was not included in this study.

\section{Data Collection}

Data were collected from interviews of the developers and historical analysis of documents relevant to the initiation and development of FDI. The qualitative data collection methods used in this study were content analysis of interviews with FDI developers and historical document analysis. The source documents used in this study 
included a FDI notebook obtained from developers and documents found as a result of interviews and university archive searches.

Semi-structured interviews of the developers were conducted at their convenience (see Appendix D for interview guide). The developers were interviewed to identify and confirm the original expectations of the university and FDI. Their narratives were used to identify themes and develop the survey. The information obtained from the interviews with the developers was compared to the results of the survey. During the interview itself, an interview guide that was developed specifically for this study was used. Open-ended questions were asked so that the interviewees were not limited in their response (Seidman, 1998). The questions were developed and used to answer the research questions of this study and can be found in Appendix D. The questions were used to answer research questions as follows:

Table 2

Interview Guide and Research Question(s) Answered

Interview Guide Topic

Computer Literacy

Goals of the University

Development Process

Work-related

Integration of Technology $\underline{\text { Research Question Answered }}$

2 and 3

1,2 , and 5

2

4 and 5

4

Pseudonyms were used to maintain confidentially and anonymity. Only the researcher's departmental advisor and research committee along with the researcher had 
access to the data. Pseudonyms are not included within the data package. This was important because the interviews were recorded and the identity of the participant, even disguised, is potentially discernible by someone who knows him or her and the potential vulnerability of the participant cannot be calculated ahead of time (Seidman, 1998).

Audio recordings of formal interviews with developers were utilized. The tapes served as a primary data source for this portion of the study. The audio recorders had counters on them and each tape was numerically coded such that data could be retrieved from them. The researcher scored and transcribed all of the tapes. The tapes were destroyed upon completion of the study unless participants requested that their personal tape be returned to them.

Within qualitative research, document analysis is used as an asset to the study. Document analysis was used because of the historical nature of the study; events could no longer be observed and informants may not have been able to recall all the events (Merriam, 1998). The historical document analysis was used to confirm the objectives of FDI, time frame for objectives, and the objectives of the university (university support) as reported by the FDI developers during interviews.

\section{Data Analysis}

The constant comparative method was utilized to analyze the data for this study. The researcher constantly compared the interview responses of developers to determine recurring themes within the data. The data was analyzed throughout the interview process. The researcher did not wait until all of the developers had been interviewed to begin the data analysis. The development of categories, properties, and tentative 
hypotheses through the constant comparative method (Merriam, 1998) allowed for the formation of emerging themes within the data. Once the themes were formed, then additional data was analyzed to support the theoretical framework developed. By constantly analyzing the data and organizing it in a manner that was easily retrievable, the researcher was able to focus more on the content of the data than on the collection process.

\section{Reliability and Validity}

The reliability and validity of the data in this study was affirmed through the use of triangulation, member checking and participatory or collaborative modes of research (Merriam, 1998). Triangulation involves the use of multiple investigators, multiple sources of data, or multiple methods to confirm emerging findings (Merriam, 1998). Triangulation within this study was conducted using multiple sources of data. The information provided by the developers has been reaffirmed or triangulated through analysis of documents related to the development of FDI and field notes of presentations given by the developers. The responses of the developers have also been compared against one another's and summarized since they were asked the same or very similar questions.

Member checking involves taking data and tentative interpretations back to the people from whom they were derived and asking them if the results are plausible (Merriam, 1998). Member checking was used to allow the developers to review the summary of their responses for accuracy throughout the study. They were allowed to make sure that the researcher conveyed what they meant in their responses. Participatory 
or collaborative modes of research mean involving participants in all phases of research from conceptualizing the study to writing up the findings (Merriam, 1998). A participatory or collaborative mode of research was used because the researcher met with the developers and obtained their assistance with gathering documents and finding participants throughout the study.

Phase II

\section{Subjects}

The subjects in phase II of the study were the developers and initial participants in the initial implementation of FDI. The participant group consisted of faculty members from various departments across the university. The departments represented and the number of subjects from each department is outlined in the following table:

Table 3

Department/Area and Number of Subjects

Departments/Area

Number of subjects

Art History

Black Studies

Communication Studies

Developers

English

FCD

Foreign Languages

History 
Departments/Area

Philosophy

Provost Office

Religion

Theatre Arts

Women's Studies
Number of subjects

4

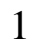

1

1

1

\section{Data Collection}

A Likert survey instrument was used to identify initial participants' expectations (see Appendix E) and measure the extent to which those were achieved through the FDI training. The initial participants were surveyed to identify the following:

1. their expectations for the training

2. outcomes of the training

3. job changes resulting from participation in FDI

Data Analysis

The following comparisons were made and evaluated within this study:

1. University Expectations vs FDI Expectations

2. University Expectations vs. University Outcomes

3. FDI Expectations vs. Initial participants' Expectations

4. FDI Expectations vs. FDI Outcomes

5. Initial participants Expectations vs. University Expectations

6. Initial participants' Expectations vs. Initial participants' Outcomes 
These comparisons were used to answer research questions two, three, and five as they relate to how the expectations and outcomes of the stakeholders relate and/or differ.

\section{Reliability and Validity}

The reliability and validity of the Likert survey used in this study was evaluated by the dissertation committee and faculty members from the EDRE program within Virginia Tech's Department of Leadership and Policy Studies. The survey was sent to various individuals for evaluation of readability and usability.

The literature suggests that expectancy theory surveys be developed using "the subject's own outcomes" (Mitchell, 1974) in order to provide more reliability and validity to the study. The decision to use the subject's outcomes is most often based on the amount of control that the investigator has over the experimental setting. Vroom's theory is based on a within subjects approach and theoretically that would mean that the subject should be asked to list his/her own outcomes, especially in settings where the experimenter has no control over the outcomes (Mitchell, 1974). One limitation to this approach is that the list of outcomes could be very extensive and would need to be reduced by the researcher. Another limitation is that subjects may not list negative outcomes, which may be important to the study.

In this study the researcher had some control by interviewing the developers and then developing the survey in order to reduce the list of potential outcomes had it been very extensive and include negative information, if applicable. Mitchell reviewed 23 studies that used expectancy theory and found "few problems with expectancy measures 
(Mitchell, 1974). The most prevalent concerns that he found with measurement methodologies as they relate to this study are as follows:

1. Investigators listing outcomes instead of each subject using his own outcomes is probably not the most accurate representation of what the theory would suggest. The impact of this problem is unknown.

2. Distinctions between positive and negative outcomes and intrinsic and extrinsic outcomes should probably be included and analyzed separately.

3. Long lists of outcomes, as opposed to short lists, are probably detrimental.

4. Important-unimportant is used most frequently as a measure of valence and yet valence is supposed to reflect anticipated satisfaction (Mitchell, 1974).

The above concerns have been considered and the study and instrumentation were designed with these concerns in mind. For example, important/unimportant are not choices for selection by survey participants.

The survey for this study was developed after interviewing the developers and after reviewing the results of the readability and usability evaluation.

The process for development of the survey was as follows (See Appendix F for the survey):

1. Interviewed developers

2. Analyzed responses to questions as they align with research questions

3. Developed a scale that is based upon the met expectations hypothesis

4. Presented survey to committee for review

5. Presented survey to selected EDRE program faculty for review

6. Field tested the survey with small group of individuals 
7. Made recommended and necessary changes to survey

8. Sent letter to subjects informing them of survey

9. Administered survey to developers and initial participants of FDI and provided them the option of responding electronically, via e-mail, or using a traditional pencil and paper format. 
Figure 1

Methodological Flow Diagram

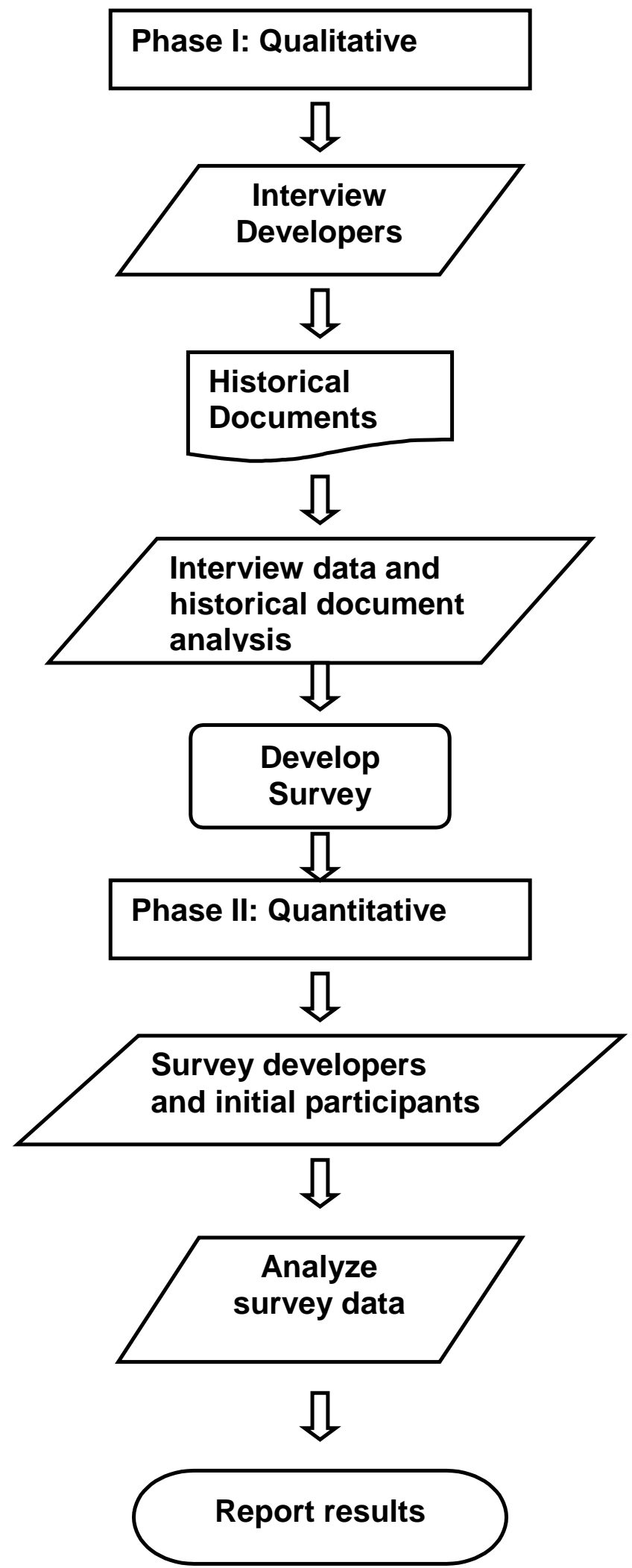




\section{CHAPTER 4}

\section{Findings}

\section{Introduction}

Virginia Tech's FDI was developed to address issues related to the computer technology revolution; training of faculty; faculty professional development; and the University adjusting to change. The purpose of this study was to identify and compare the goals, expectations, and perceived outcomes that the University, FDI developers, and the initial participants had for Virginia Tech's FDI initiative as originally implemented. Research was conducted in three phases (see Appendix G). Phase I consisted of interviewing the five developers of the FDI workshops and conducting a historical document analysis. The results of those efforts were used to develop surveys for the 49 initial participants and the 5 developers. Phase II was administration of the surveys to the developers and the initial participants. While administering the original survey, it was determined that a non-respondent survey was needed to assure that the respondents were representative of the initial participants. Phase III was the development and administration of a non-respondent survey.

Five research questions guided the study:

1. What organizational change initiatives influenced the development of objectives for the Faculty Development Institute (FDI)?

2. What were the goals and expectations of stakeholders: Virginia Tech, FDI developers, and initial participants?

3. In what ways were Virginia Tech, FDI developers', and initial participants' goals and expectations different? 
4. In what ways, if any, have initial participants' professional roles changed as a result of FDI participation?

5. What were the perceived outcomes for the stakeholders: Virginia Tech, FDI developers, and initial participants?

The findings of Phases I, II, and III are described separately in this chapter. 


\section{Phase I}

\section{Demographics}

The population for this phase of the study was the five developers of the Faculty Development Institute. Their experiences working within a university environment at the time that FDI was developed ranged from five to 20 years. They worked in areas including the Provost office, information systems, media services, adjunct faculty, and other areas of the university. Four of the five were male, three of the men held doctoral degrees.

\section{Data Collection}

Four of the developers were interviewed face-to-face by the researcher and one was interviewed via telephone using an interview guide (see Appendix D) developed by the researcher specifically for use in this study. All of the interviews were recorded and transcribed by the researcher. The qualitative software program Nudist was used to conduct text searches to identify themes and specific outcomes. Two surveys (see Appendices E and F) were developed based upon the identified themes and outcomes: the survey for the developers was developed and administered to triangulate the data gathered via structured interviews and from historical document analysis; the initial participant survey was developed from the same themes and outcomes to determine the participants' expectations and perceived outcomes.

\section{Research Question Results}

Interview question results and historical document analysis were used to answer research questions one and two. The results are reported by research question: 
1. What organizational change initiatives influenced the development of objectives for the Faculty Development Institute (FDI)? Specifically, the following questions were asked of the developers from interview guide topics "Goals of the University" and "Development Process"(see Appendix D):

- What were the goals of the University as related to FDI?

- What did the University plan to achieve, overall, as a goal for FDI?

- What were the expected outcomes for the University?

- What was the policy memorandum that established FDI?

- In what ways did the organizational change concepts such as early adopter's theory play a role in selection of objectives for FDI?

- In what ways were faculty members provided technical support prior to FDI? After implementation of FDI?

- How were the goals of FDI developed

- What role did you play, if any, in the development of the goals for FDI? Initial participants?

- What were the goals of FDI?

The organizational change initiatives that influenced the development of objectives for the Faculty Development Institute were as follows:

a) Curriculum change within departments

b) Departments with very large student enrollments: English, Humanities and Math

c) Improving undergraduate student education 
d) Change from mainframe to distributed computing environment

e) Low (60\%) percentage of faculty using computer technology

Examples of how each of the organizational change initiatives impacted the development of FDI are provided here: (a) Curriculum change within departments: according to the developers

the goal of FDI is curriculum change and so we knew English, Mathematics, and Humanities were already engaged in some curricular planning; they were identified as early adopters and were amenable to participating in carrying out change within their departments, so we did not pick departments that were resistant...

the third goal was looking at specific curriculum throughout the university to pilot workshops; mathematics was upgrading their curriculum, changing their curriculum; humanities, English, all three of those departments really were looking on their own how they could integrate things like Mathematica for example into the math curriculum and we saw these workshops as an opportunity for those departments to take the time, get together with their colleagues, get some resources in terms of getting a modern computing system on their desk and go from there to see how we could help them in implementing their curricula changes.

...without FDI then each department and each college would have to do this on their own. There would not be any uniform, consistent software and hardware upgrades or not too may will learn how they could integrate this into the curriculum.

(b) Departments with very large student enrollments: English, Humanities and

Math: Math and English were specifically chosen to participate in the initial workshop

because the

early focus was on departments that taught large numbers of freshmen and core curriculum subjects. This was done I suspect to improve the effectiveness and efficiency of reaching large numbers of students early on ...

Both those departments have very large enrollments, basically every student takes freshman English and then other course, and many students practically all students have to take some kind of mathematics so again we wanted to have an impact on departments that were dealing with a lot of students. 


\section{(c) Improving undergraduate student education:}

The focus was not on graduate education or research because faculty, many faculty [were] well advanced in doing their own research and using computers in that way. This was on undergraduate instruction primarily.

...my own focus on and interest in improving undergraduate education led to those $[\mathrm{FDI}]$ objectives rather than anything else.

The single most important goal is the improvement of student learning and analyzing how the integration of technology along with changing teaching methods could improve student learning.

...this program coupled with a lot of other activity at the university in the early 90's was a, was a re-emphasis on undergraduate teaching...

(d) Change from mainframe to distributed computing environment:

This was more of an information systems goal, but it played a role in the development of FDI. The university was changing systems and faculty needed to be able to use the new technologies.

...we were at that point moving from a mainframes centralized to a distributed environment and we wanted to use this program to, to facilitate, to help get faculty that were computer literate that had a dependency on mainframe computing ... and the applications they were using over into a distributed computing environment.

We were transitioning off the mainframe computer so we needed to go to the distributed computer environment and that required that all faculty basically have a desktop computer that was up to date with current software, that was one of the main goals.

(e) Low (60\%) percentage of faculty using computer technology:

of the reasons I was given was that access to technology at Virginia Tech was very much related to what departments had resources, operating dollars and resources to invest in computing and versus those that did not...the second thing that we knew was true was that of those faculty that actually used computers and the network a very, very small percentage, miniscule percentage actually used it in anyway to support teaching... But very little in terms of support for instruction and so the idea was to put together a program that would be initially aimed at these have not areas; people that had no access at all and to get computers and network access into their hands ... There was a realization that computer technology was not being utilized by a large number of faculty members. Sixty percent usage was considered to be a low usage number for the university and 
there were several reasons I started pushing for some sort of large-scale investment in our faculty to learn how to use the technology. One of the biggest was that we had actually been a fairly computer intensive university for a number of years and yet only, I think it was around 62 or 60 percent of our faculty used computers ...And it wasn't much different from like 4 or 5 years previous. ... $60 \%$ [I] started asking questions about why we were not going any higher in the percentages...

... we asked the provost what success [would] be early on... he was saying a reasonably high amount of participation by faculty. We thought perhaps $80 \%$ in the program; being able to walk down a hallway and see people using technology in the classroom would be another desirable outcome.

(2) What were the goals and expectations of stakeholders: Virginia Tech, FDI developers, and initial participants?

\section{Virginia Tech}

The goals and expectations for Virginia Tech were identified through historical document analysis and interviews with the developers. Virginia Tech had eleven broad goals as identified in The University Plan: 1991-1996. The goals were as follows:

a. To enhance the quality of undergraduate education.

b. To enhance the quality of graduate and professional education.

c. To enhance the quality of the University's programs of research, scholarship, creative expression and artistic performance.

d. To enhance the quality of the University's programs of public service, continuing education, and cooperative extension.

e. To enhance the University's international programs and curriculum.

f. To enhance the quality of life for students, faculty, and staff.

g. To increase the diversity of the student body, the faculty, and the staff through effective recruiting and retention programs. 
h. To establish a comprehensive program of human resource development for faculty, staff, and administrators.

i. To increase the effectiveness and the efficiency of administrative and support service operations.

j. To enhance the quality and accessibility of library and other information resources and advanced computing and communication technologies.

k. To develop the physical facilities necessary to support the fulfillment of the University's mission. (The University Plan: 1991-1996, 1991)

The ones that directly impacted the development of the FDI initiative are $h$ and $j$.

The University identified the following objectives as key to accomplishing goal h, "to establish a comprehensive program of human resource development for faculty, staff, and administrators" (The University Plan: 1991-1996, 1991); however, only item i relates specifically to FDI:

i. To strengthen and expand faculty development programs related to teaching effectiveness, advising, and the applications of advanced computing and communications technologies in the teaching-learning environment.

ii. To provide classified staff employees with education and training opportunities that support both career advancement and the development of job-related skills.

iii. To enhance opportunities for professional renewal for faculty members by expanding the existing study and research leave programs. 
iv. To implement comprehensive programs for leadership, management, and supervisory development throughout the University. (The University Plan: $\underline{1991-1996}, 1991)$

The other goal of the University that impacted FDI development was "to enhance the quality and accessibility of library and other information resources and advanced computing and communication technologies" (The University Plan: 1991-1996, 1991).

The following objectives associated with that goal all impacted the expectations for FDI.

i. To increase access to library and other information resources, regardless of format or location.

ii. To promote the application of advanced computing and communications technologies in the teaching-learning environment.

iii. To provide students, faculty, and staff with access to the computing and communications capabilities needed to support their activities.

iv. To develop and implement a comprehensive plan for upgrading and replacing administrative information systems and related data bases. To provide for the timely replacement of the University's computing and communications infrastructure. (The University Plan: 1991-1996, 1991)

These two goals as identified by the University and approved by the Board of Visitors influenced the development of the Instructional Development Initiative and specifically the development of FDI at Virginia Tech. 


\section{FDI Developers}

The goals and expectations of the FDI developers were identified through historical document analysis, interviews with the developers, and a survey of developers (see Appendix F). Many of the goals of the developers were found through historical document analysis and are reported here. "The primary goal of the workshops was to provide an opportunity for faculty to reexamine curriculum issues and instructional methods which would allow them to adapt to the changing needs of students"(Faculty Development Project, 1993). Another goal of the developers was that the pilot workshops "be scaled up to a University-wide instructional development program which would involve all faculty over a four-year cycle"(Faculty Development Project, 1993).

The developers themselves identified four specific goals: 1) Increase facultydriven teaching effectiveness; 2) Increase learning efficiency; 3) Enhance ability of faculty to meet professional responsibilities; and 4) Enhance student opportunities beyond the academy. The goals are outlined such that each goal is associated with the objectives and the tools/processes that were intended to facilitate accomplishment of the goal. Following are the three FDI developers' goals that specifically relate to FDI (First Draft Goals and Objectives):

a. Increase faculty driven teaching effectiveness

i. Improve quality of interactions among faculty and students

a) Electronic mail

b) Discussion lists

c) Multimedia tutorials and help sessions 
d) Other instructional communication strategies

ii. Foster critical reexamination of teaching methods and curricula at a fundamental level

a) Promote faculty collaboration to develop course materials

b) Develop courses with more emphasis on active and independent learning strategies

c) Develop courses with more emphasis on problem-solving, synthesis, and critical thinking skills

d) Develop courses with more emphasis on collaboration

e) Promote students' ability to construct knowledge and develop insights

iii. Generate a sense of excitement about curricular information

a) Deal with more realistic issues by using live databases and real-time simulation

b) Promote a higher level of understanding of complex phenomena by establishing links between disciplinary information

c) Involve students with curricular information through hands-on research, analysis and presentation

b. Increase learning efficiency

i. Offer 24-hour access to pertinent course information

a) Ability to access materials, assignments, and discussions from dorm room, apartment, or open lab

b) Ability to e-mail messages to and from faculty and other students from dorm room, apartment, or open lab 
c. Enhance ability of faculty to meet professional responsibilities.

i. Teaching

a) Access to new resources for teaching

b) Access to new resources for testing and grading

c) Ability to creatively present material in new ways

d) Use of courseware and simulations

e) Enhance ability to work with diverse group of students

f) Enhance ability to help students experiencing problems

g) Enhance enjoyment of teaching

ii. General

a) Time/meeting management

b) Classroom/office management

c) Project management (First Draft Goals and Objectives)

Interviews with developers confirmed the above-mentioned goals. Examples of statements made by developers that helped to confirm those goals are:

proposed our initiating a program that would be aimed at, a faculty development program that would be aimed at $100 \%$ of our faculty over several years

There were two goals: one was to at the end of four years instead of being 60 some percent 100 percent of our faculty were computer and network literate and would have the computer, have access to computers and good network access and the second goal was to see if we couldn't have a more notable percentage that were actually using computers and networking in some way to support teaching ... improve the teaching of whatever discipline they taught... we were at that point moving from a mainframes centralized to a distributed environment and we wanted to use this program to facilitate... to help get faculty that were computer literate that had a dependency on mainframe computing, we wanted to get those faculty and the applications they were using over into distributed 
computing environment at the least and in most cases into their personal computing environment. That was the Information Systems goal that was, it was secondary to the university goals, but you know, I think we played a role in creating all three of those goals. But one had a very information systems orientation to it, the other two were very much university enhancement kinds of goals.

Although the complete compilation of the developers' perceived outcomes are expressed in the 41 items on the developer survey (see Appendix F) and 41 of 42 items on the initial participant survey (see Appendix E), many expectations for FDI were confirmed during the interviews. Examples of these in the developers' own words are:

the university would be competitive in the use and integration of technology not just in teaching but in research across the whole institution in the use of administrative systems outcome was to improve student to faculty communication, principally through e-mail greater faculty understanding and greater faculty use of technology in their courses either as supplements or as online courses

$100 \%$ of our faculty technology literate, $100 \%$ of our faculty with reasonably... up to date technology

uniform, consistent software and hardware upgrades

The expectations the developers held for the initial FDI workshop were also identified through survey responses and are described by descriptive statistics in the following tables: 
The developers unanimously agreed that the following 10 items from the questionnaire were among the outcomes they expected to occur during and/or immediately following the initial FDI workshop:

Table 4

Outcomes developers expected to occur during and/or immediately following the initial FDI workshop

$\underline{\text { Outcomes }}$

$\underline{\% \text { Yes }}$

All participating faculty would have desktop computers installed in their offices with necessary hardware and software available. $(\mathrm{n}=5)$

Participants would receive specific training in how to use computers more effectively in their teaching role. $(n=5)$

FDI would enhance participants' knowledge and skills to interact with students outside the classroom using computer technology. $(n=5)$

Participants would acquire the knowledge and skills necessary to integrate computer technology into their instruction. $(\mathrm{n}=5)$

Participants would be encouraged and motivated to re-think how they were teaching. $(\mathrm{n}=5)$

Participants would enhance their computer skills to make their work with students more efficient and effective. $(n=5)$ 
$\underline{\text { Outcomes }}$

$\underline{\% \text { Yes }}$

The computer technology workshop would help participants

become more effective in their teaching role. $(n=5)$

Participation in this workshop would be a positive experience for faculty. $(n=5)$

Participants' ideas and needs would be addressed within FDI workshops. $(\mathrm{n}=5)$

Participants would improve their communication with students by learning to use e-mail. $(n=5)$ 100

The developers also unanimously agreed upon the following eight items from the questionnaire as being among their long-term expectations as a result of the initial FDI workshop:

Table 5

Long-term outcomes developers expected to occur as a result of the initial FDI workshop

$\underline{\text { Outcomes }}$

\% Yes

Improved undergraduate student education. $(n=5)$ 100

Curriculum change within disciplines would occur through implementation of formal course development for targeted courses. $(n=5)$ 100

FDI would become a forum for faculty to re-think their teaching strategies and how they were teaching. $(n=5)$ 
Faculty could develop new ways to use technology to help students learn. $(n=5)$

Faculty would be provided with an opportunity to explore new approaches to instruction. $(\mathrm{n}=5)$

All faculty would develop higher levels of computer literacy and skills. $(\mathrm{n}=5)$

The quality of interaction among students and faculty would improve. $(n=5)$

Virginia Tech would become a national leader in the use and integration of computer technology in teaching and research. $(n=5)$ 
The following tables contain the short and long-term expectations that were not unanimously agreed upon by the developers but were determined to be expectations for the initial FDI workshop. Expectations that had a frequency rating of "Yes" at sixty percent or greater are listed as developer expectations.

Table 6

Outcomes developers expected to occur during and/or immediately following the initial FDI workshop

$\underline{\text { Outcomes }}$

\% Yes

Collaborative communication regarding teaching strategies would

be encouraged and facilitated during the workshop among participating faculty. $(n=5)$

Participants would acquire an enhanced understanding of administrative classroom uses of computers. $(n=5)$

Faculty would become more productive in their jobs as a result of computer technology skills learned in the workshop. $(n=5)$

Following the workshop, participants would receive support with course development techniques. $(n=5)$

Students would become more active in, and take more responsibility for, their own learning as a result of participants using computer technology skills to provide information to them inside and outside the classroom. $(n=5)$ 
$\underline{\text { Outcomes }}$

\% Yes

Participants would receive personalized technical support with computer technology use in instruction. $(n=5)$

More classrooms across campus would be equipped with computer technology. $(\mathrm{n}=5)$

Table 7

Long-term outcomes developers expected to occur as a result of the initial FDI workshop

$\underline{\text { Outcomes }}$

\% Yes

The University would provide students adequate access to

computers. $(n=5)$

All students would have access to computer technology and know how to use it effectively. $(n=5)$

All faculty would become technology literate and have access to computer technology. $(n=5)$

The mainframe computing system would be replaced with a distributive, personal computing environment. $(n=5)$

The number of courses taught online and using distance learning technology would increase. $(n=5)$

An increased number of students would be served while maintaining the quality of instruction and costs. $(n=5)$ 
$\underline{\text { Outcomes }}$

$\%$ Yes

The emphasis on active and independent learning strategies,

problem solving and collaboration would increase. $(n=5)$

The University would provide the classroom computer systems needed by faculty to enhance their access to technology. $(\mathrm{n}=5)$

Faculty would transition smoothly from the mainframe environment to personal computing environment. $(n=5)$

A majority of faculty would use the computer technology in the classroom as a supplement to their teaching. $(n=5)$

The Virginia Tech computer technology infrastructure would become leading edge technology. $(n=5)$

Students would develop higher levels of computer literacy and skills. $(\mathrm{n}=5)$

The use of class contact hours as a determinate of credit hours would decrease. $(n=5)$

Virginia Tech would become a national leader in the use and integration of computer technology in teaching and research. $(n=5)$

The developers agreed upon all seventeen of the items listed in the questionnaire as expectations during and/or immediately following the initial FDI workshop. They also 
agreed that three of the items listed as long-term expected outcomes were actually not expectations of the initial FDI workshop. Items that were rated 'Yes' with a frequency of forty percent or lower were determined to not be expectations of the initial FDI workshops.

Table 8

Outcomes developers agreed upon as not being long-term expectations for the initial FDI workshop

Outcomes

$\underline{\% \text { Yes }}$

Use of computer technology in instruction would become an important factor in promotion, tenure and salary evaluations. $(n=5)$

Computer literacy requirements would be developed and required of all students across the university. $(n=5)$

Enhanced instructional, research, administrative and outreach computing resources would be made available to faculty. $(n=5)$

\section{Initial Participants}

The expectations of the initial participants were determined as agreed upon if they were rated as 'Yes' at a frequency of $65 \%$ or higher on the questionnaire. They were rated as not agreed upon if they were rated 'Yes' at frequency between 35-65\%. Items were determined to not be an expectation if fewer than $35 \%$ of the participants included 
them among their expectations. Their expectations as identified through survey responses are as depicted in the following tables:

Table 9

Outcomes initial participants expected to occur during and/or immediately following the initial FDI workshop

Outcomes

$\%$ Yes

I would receive specific training in how to use computers more effectively in their teaching role. $(n=28)$

I would earn a state of the art desktop computer, installed in my office, with necessary hardware and software to incorporate computer technology in my teaching. $(\mathrm{n}=28)$

I would enhance the knowledge and skills necessary to integrate computer technology into my instruction. $(\mathrm{n}=28)$

I would be encouraged and motivated to re-think how I was teaching. $(\mathrm{n}=28)$

Participation in this workshop would be a positive experience for me. $(\mathrm{n}=27)$

The computer technology workshop would help me become more effective in my teaching role. $(\mathrm{n}=28)$

More classrooms across campus would be equipped with computer technology. $(\mathrm{n}=28)$ 
$\underline{\text { Outcomes }}$

\% Yes

Collaborative communication regarding teaching strategies would

be encouraged and facilitated during the workshop among

participating faculty. $(\mathrm{n}=28)$

78.6

I would enhance my computer skills to make my work with students more efficient and effective. $(n=28)$

Following the workshop, I would receive support with course

development techniques. $(n=28)$

I would enhance my knowledge and skills to interact with

students outside the classroom using computer

technology. $(n=28)$

75

My ideas and needs would be addressed within FDI workshops.

$$
(n=28)
$$

Table 10

Long-term outcomes initial participants expected to occur as a result of the initial FDI workshop

$\underline{\text { Outcomes }}$

\% Yes

Faculty could develop new ways to use technology to help students learn. $(\mathrm{n}=28)$ 
$\underline{\text { Outcomes }}$

$\%$ Yes

Faculty would be provided with an opportunity to explore new approaches to instruction. $(\mathrm{n}=28)$

The University would provide the classroom computer systems needed by faculty to enhance their access to technology. $(n=28)$

Enhanced instructional, research, administrative and outreach computing resources would be made available to faculty. $(n=28)$

Students would develop higher levels of computer literacy and skills. $(n=28)$

The University would provide students adequate access to computers. $(n=28)$

All faculty would develop higher levels of computer literacy and skills. $(n=28)$

The mainframe computing system would be replaced with a distributive, personal computing environment.

All students would have access to computer technology and know how to use it effectively. $(n=28)$ 


\section{Table 11}

Outcomes initial participants did not agree upon as being expected outcomes during and/or immediately following initial FDI workshop

I would receive personalized technical support with computer technology use in instruction. $(n=28)$

I would become more productive in my job as a result of computer technology skills learned in the workshop. $(n=28)$

I would improve my communication with students by learning to use e-mail. $(n=28)$

I would acquire an enhanced understanding of administrative classroom uses of computers. $(n=28)$

Students would become more active in, and take more responsibility for, their own learning as a result of participants using computer technology skills to provide information to them inside and outside the classroom. $(n=28)$ 
Table 12

Outcomes initial participants did not agree upon as being expected long-term outcomes for the initial FDI workshop

\section{$\underline{\text { Outcomes }}$}

\% Yes

All faculty would become technology literate and have access to computer technology. $(\mathrm{n}=28)$

FDI would become a forum for faculty to re-think their teaching strategies and how they were teaching. $(n=28)$

The number of courses taught online and using distance learning technology would increase. $(n=28)$

The emphasis on active and independent learning strategies, problem solving and collaboration would increase. $(n=28)$

Improved undergraduate student education. $(n=28)$

Curriculum change within disciplines would occur through implementation of formal course development for targeted courses. $(n=27)$

Computer literacy requirements would be developed and required of all students across the university. $(n=28)$

The Virginia Tech computer technology infrastructure would become leading edge technology. $(n=28)$ 
$\underline{\text { Outcomes }}$

\% Yes

Virginia Tech would become a national leader in the use and integration of computer technology in teaching and research. $(n=28)$

The quality of interaction among students and faculty would improve. $(\mathrm{n}=28)$

Faculty would transition smoothly from the mainframe environment to personal computing environment. $(n=28)$

\section{Table 13}

Outcomes initial participants agreed upon as not being a long-term expectation for the initial FDI workshop

$\underline{\text { Outcomes }}$

$\underline{\% \text { Yes }}$

A majority of faculty would use the computer technology in the

$$
\text { classroom as a supplement to their teaching. }(n=28)
$$

An increased number of students would be served while

$$
\text { maintaining the quality of instruction and costs. }(n=28)
$$

The use of class contact hours as a determinate of credit hours

$$
\text { would decrease. }(n=28)
$$

Use of computer technology in instruction would become an important factor in promotion, tenure and salary evaluations.

$$
(n=28)
$$




\section{Phase II}

\section{Demographics}

Data relevant to research questions three through five were gathered during Phase II of the study in which surveys were administered to the five developers and the 42 initial participants who were a part of the available population for the study. The developers survey response rate was $100 \%$. The response rate for the initial participants was a raw response rate of $88.09 \%$ with a usable response rate of $66.67 \%$. Twenty-eight of the 42 initial participants completed the full survey.

\section{Research Question Results}

3. In what ways were Virginia Tech, FDI developers', and initial participants' goals and expectations different?

According to the survey responses there was a clear difference in some of the goals and expectations for the University, FDI Developers and the initial participants. The survey was an instrument that was developed by the researcher that listed the goals and expectations for the FDI as determined from semi-structured, face-to-face interviews with the developers and historical document analysis. All of the outcomes listed in the instrument were a direct result of information obtained during Phase I of the study.

Table 14 shows that there were differences in what the developers identified as being expected outcomes during the interviews and their responses to the questionnaire. The University, developers' and initial participants' goals and expectations were different. There were also differences in the items that were agreed upon by both the developers and the initial participants as not being expected outcomes. 
Table 14

Comparison of outcomes not expected by the University, Developers, and Initial Participants.

$\underline{\text { Not an Outcome }} \quad \underline{\text { The }} \frac{\text { FDI }}{\text { University }} \frac{\underline{\text { Initial }}}{\frac{\text { Developers }}{(n=5)}} \quad \frac{\underline{\text { Participants }}}{(\mathrm{n}=28)}$

Use of computer technology in

instruction would become an

important factor in promotion,

tenure and salary evaluations.

X $\quad X$

Computer literacy requirements

would be developed and required

of all students across the

university.

$\mathrm{X}$

Enhanced instructional, research,

administrative and outreach

computing resources would be

made available to faculty.

$\mathrm{X}$

A majority of faculty would use the

computer technology in the

classroom as a supplement to

their teaching.

$\mathrm{X}$ 
Not an Outcome

\begin{tabular}{|c|c|c|}
\hline The & $\underline{\text { FDI }}$ & $\underline{\text { Initial }}$ \\
\hline University & $\frac{\text { Developers }}{(\mathrm{n}=5)}$ & $\frac{\text { Participants }}{(\mathrm{n}=28)}$ \\
\hline
\end{tabular}

An increased number of students would

be served while maintaining the

quality of instruction and costs.

The use of class contact hours as a

determinate of credit hours would

decrease.
$\mathrm{X}$

$\mathrm{X}$

There was also a clear distinction in items that were not agreed upon by the initial participants. The developers all agreed upon goals and outcomes as being either expectations or not for FDI, long and short-term. However, the initial participants had numerous items that they did not agree upon as being expected goals and outcomes for FDI (see tables 10 and 11).

4. In what ways, if any, have initial participants' professional roles changed as a result of FDI participation?

Twenty-four of the 28 survey participants responded to the qualitative question of the initial participant survey, question 18 (see Appendix E). There were two main themes that emerged from responses to this question that included: the use of computer technology in the classroom and the use e-mail/websites to communicate with students. These were areas identified by initial participants in which their professional roles were 
impacted by their participation in FDI.

Examples of how initial participants felt that their professional role had changed in regards to the use of computer technology in the classroom in the initial participants' own words are:

Although, my classes were always filled with discussion, instructional technology allowed me to tailor discussions in different ways and forced me to question my own role as guide in a set-up that can be overlyhierarchical.

Used more computer demonstrations in classroom

More hands on participation with students

I am able to cover some aspects of the course, directions, clarifications, elaborations and extra assignments without the restrictions of class periods or of copying/printing procedures. Much more time involved in creating classroom exercises and in managing materials (emails, online conversations) generated during and after class periods - i.e. I became more of a "manager of materials" than I had been before. I had to take a more passive role in the classroom (often a good thing), since my voice had been transformed into text on the screen (assignments, instructions for class activities).

I have been able to make courses more hands-on and process oriented.

I am less the center of attention in the classroom [, and] I feel more confident using technology in the classroom.

I regularly include computer assignments in my classes.

Examples of how initial participants felt that their professional role had changed in regards to the use e-mail/websites to communicate with students in the initial participants' own words are:

FDI helped me understand that I could communicate with students beyond the parameters that I had been confined previously. E-mail allowed me to converse with students throughout the week instead of only during class time. I posted lecture notes so that students 
could access them and review them at their own pace in their own time. I was also able to set up group discussions...

Ease of communication with students via e-mail has me to make real my role as a consultant in the students' work to develop their own skills.

With a course website, I can make much of the administrative structure of the course available to the students $24 / 7 \ldots$

... now that students can submit their work electronically, I find that my role as a provider of writing advice is enhanced and changed... each paper goes back to the student as a document with both the student's work and my comment, as soon as I finish it. A much livelier dialog takes place because the student can return the document to me with further questions right away.

A few respondents felt that they received tenure track positions, not necessarily at Virginia Tech, as a result of their participation in FDI.

5. What were the perceived outcomes for the stakeholders: Virginia Tech, FDI developers, and initial participants?

Each of the outcomes that were determined from the stakeholders as being an expected outcome, either through their respective survey data or historical document analysis, was further evaluated to determine the extent to which the stakeholders believed the outcome was achieved. The extent to which the stakeholders' perceived outcomes were achieved is documented in the following sections:

\section{Virginia Tech}

In 1996, the University Plan: Progress Toward 1991-1996 Goals report confirmed that the University felt that FDI had played a role in helping the University be successful in achieving its goals to "establish a comprehensive human resources development program" and "enhance the quality and accessibility of library and 
information systems." The perceived outcomes for Virginia Tech that were impacted by the development of FDI as identified through a historical document analysis are:

(a) The Instructional Development Initiative will provide an opportunity for all faculty members over a four-year period with a state-of-the art computer and an intensive workshop focused on the integration of advanced computing and communications technology into the curriculum. Over 650 faculty members, almost half of the faculty, have participated in this program; (b) The University has leveraged the communications infrastructure, enhanced through network technology and resources, allowing the development of hundreds of WWW home pages on campus (The University Plan: Progress Toward 1991-1996 Goals, 1996).

\section{FDI Developers}

The extent to which developers' seventeen perceived outcomes were achieved during and/or immediately following the initial FDI workshop was identified by having them rate each as having been fully achieved, somewhat achieved or not achieved. Five of the outcomes were rated by at least $60 \%$ of the developers as fully achieved. Eleven of the outcomes were rated by at least $60 \%$ of the developers as somewhat achieved. There was disagreement among the developers on the exact level of achievement of one expectation. The specific results of the extent to which the developers' perceived the outcomes were achieved are found in the following table: 
Table 15

Extent to which developers' expected outcomes were achieved during and/or immediately following the initial FDI workshop $F A=$ Fully Achieved $; S A=$ Somewhat Achieved NA = Not Achieved

Extent Achieved \%

Perceived Outcomes

$\underline{\mathrm{FA}} \quad \underline{\mathrm{SA}} \quad \underline{\mathrm{NA}}$

All participating faculty would have desktop computers installed

in their offices with necessary hardware and software

available. $(n=5)$

$92.9 \quad 7.1$

Participation in this workshop would be a positive experience for faculty. $(n=5)$

Participants would improve their communication with students by learning to use e-mail. $(n=5)$

Participants would receive specific training in how to use computers more effectively in their teaching role. $(n=5)$

FDI would enhance participants' knowledge and skills to interact with students outside the classroom using computer technology. $(\mathrm{n}=5)$

Participants would be encouraged and motivated to re-think how they were teaching. $(n=5)$

Participants would enhance their computer skills to make their work with students more efficient and effective. $(n=5)$

The computer technology workshop would help participants become more effective in their teaching role. $(n=5)$ 


\section{$\underline{\text { Perceived Outcomes }}$}

Participants' ideas and needs would be addressed within FDI workshops. $(\mathrm{n}=5)$

Collaborative communication regarding teaching strategies would be encouraged and facilitated during the workshop among participating faculty. $(\mathrm{n}=5)$

Participants would acquire an enhanced understanding of administrative classroom uses of computers. $(n=5)$

Faculty would become more productive in their jobs as a result of computer technology skills learned in the workshop. $(n=5)$

Following the workshop, participants would receive support with course development techniques. $(n=5)$

Students would become more active in, and take more responsibility for, their own learning as a result of participants using computer technology skills to provide information to them inside and outside the classroom. $(n=5)$

Participants would receive personalized technical support with computer technology use in instruction. $(n=4)$

More classrooms across campus would be equipped with computer technology. $(n=5)$ $\underline{\text { Extent Achieved }}$ $\underline{\%}$

$\underline{\mathrm{FA}} \quad \underline{\mathrm{SA}} \quad \underline{\mathrm{NA}}$

$40 \quad 60$

$20 \quad 80$

100 
The extent to which the developers' twenty long-term perceived outcomes were achieved was determined by having them rate each expectation as fully achieved, somewhat achieved or not achieved. Only two of the outcomes were identified by at least $60 \%$ of the developers as fully achieved. Fourteen of the outcomes were determined by at least $60 \%$ of the developers as somewhat achieved. The developers disagreed upon the extent of achievement of four expected outcomes. The specific results of the extent to which the developers' perceived the outcomes were achieved are found in the following table:

Table 16

Extent to which developers' long-term expected outcomes were achieved as a result of the initial FDI workshop $F A=$ Fully Achieved $; S A=$ Somewhat Achieved $; A=$ Not Achieved

Extent Achieved

$\underline{\text { Perceived Outcomes }}$

$\underline{\text { FA } \quad \underline{\%}} \quad \underline{\text { NA }}$

All faculty would develop higher levels of computer literacy and skills. $(\mathrm{n}=5)$

All faculty would become technology literate and have access to computer technology. $(n=5)$

The University would provide students adequate access to computers. $(n=5)$ $60 \quad 20 \quad 20$

Improved undergraduate student education. $(n=5)$ 
Perceived Outcomes

Curriculum change within disciplines would occur through

implementation of formal course development for targeted courses. $(n=5)$

FDI would become a forum for faculty to re-think their teaching strategies and how they were teaching. $(\mathrm{n}=5)$

Faculty could develop new ways to use technology to help students

learn. $(n=5)$

Faculty would be provided with an opportunity to explore new

approaches to instruction. $(\mathrm{n}=5)$

40

60

The quality of interaction among students and faculty would improve. $(\mathrm{n}=5)$

The number of courses taught online and using distance learning technology would increase. $(n=5)$

$40 \quad 60$

An increased number of students would be served while maintaining the quality of instruction and costs. $(n=4)$ $25 \quad 75$

The emphasis on active and independent learning strategies, problem solving and collaboration would increase. $(n=4)$ $25 \quad 75$

The University would provide the classroom computer systems needed by faculty to enhance their access to technology. $(n=4)$
Extent Achieved

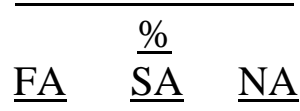


$\underline{\text { Perceived Outcomes }}$

A majority of faculty would use the computer technology in the classroom as a supplement to their teaching. $(n=3)$

The Virginia Tech computer technology infrastructure would become leading edge technology. $(n=4)$

The use of class contact hours as a determinate of credit hours would decrease. $(n=4)$

All students would have access to computer technology and know how to use it effectively. $(n=5)$

The mainframe computing system would be replaced with a distributive, personal computing environment. $(n=5)$

Faculty would transition smoothly from the mainframe environment to personal computing environment. $(n=4)$ Students would develop higher levels of computer literacy and skills. $(n=4)$ $\underline{\text { Extent Achieved \% }}$

$\underline{F A} \quad \underline{\mathrm{SA}} \quad \underline{\mathrm{NA}}$

$33.3 \quad 66.7$

Initial Participants

The extent to which the initial participants' twelve perceived outcomes were achieved during and/or immediately following the initial FDI workshop was identified by having them rate each as having been fully achieved, somewhat achieved or not achieved. Only one of the outcomes was rated as fully achieved by at least $65 \%$ of the participants. A second outcome was rated by at least $65 \%$ of the participants as having been somewhat 
achieved. The initial participants were unable to agree upon the exact level of achievement of ten expected outcomes, although they did agree that they were at least somewhat achieved. The specific results of the extent to which the initial participants' perceived the outcomes were achieved are found in the following table:

\section{Table 17}

Extent to which initial participants' expected outcomes were achieved during and/or immediately following the initial FDI workshop

\section{$F A=$ Fully Achieved $; S A=$ Somewhat Achieved $; A=$ Not Achieved}

Extent Achieved \%

Perceived Outcomes

$\underline{\text { FA }} \quad \underline{\mathrm{SA}} \quad \underline{\mathrm{NA}}$

I would earn a state of the art desktop computer, installed in my

office, with necessary hardware and software to incorporate computer technology in my teaching. $(n=28)$

$92.9 \quad 7.1$

More classrooms across campus would be equipped with computer technology. $(n=28)$

I would enhance the knowledge and skills necessary to integrate computer technology into my instruction. $(n=28)$

I would be encouraged and motivated to re-think how I was teaching. $(n=28)$

Participation in this workshop would be a positive experience for me. $(n=27)$

The computer technology workshop would help me become more effective in my teaching role. $(n=28)$ 
$\underline{\text { Perceived Outcomes }}$

Extent Achieved \%

$\underline{F A} \quad \underline{\mathrm{SA}} \quad \underline{\mathrm{NA}}$

Collaborative communication regarding teaching strategies would

be encouraged and facilitated during the workshop among

participating faculty. $(\mathrm{n}=28)$

$32.1 \quad 60.7$

I would enhance my computer skills to make my work with

students more efficient and effective. $(n=28)$

$21.4 \quad 50 \quad 21.4$

Following the workshop, I would receive support with course

development techniques. $(n=28)$

$32.1 \quad 42.9 \quad 17.9$

I would enhance my knowledge and skills to interact with students outside the classroom using computer technology. $(n=28)$

$\begin{array}{lll}42.9 & 39.3 & 7.1\end{array}$

My ideas and needs would be addressed within FDI workshops.

$(n=28)$

32.1

50

7.1

The extent to which the initial participants' nine long-term expected outcomes were perceived to have been achieved as a result of the initial FDI workshop was identified through their ratings of each expected outcome as fully achieved, somewhat achieved or not achieved. One of the outcomes was rated by at least $65 \%$ of the initial participants as fully achieved. Two of the outcomes were identified by at least $65 \%$ of the initial participants to have been somewhat achieved. The initial participants did not agree upon the exact level of achievement for the remaining six expected outcomes. The specific 
results of the extent to which the initial participants' perceived the outcomes were achieved are found in the following table:

Table 18

Extent to which initial participants' long-term expected outcomes were achieved as a result of the initial FDI workshop $F A=$ Fully Achieved; SA = Somewhat Achieved NA = Not Achieved

\section{$\underline{\text { Perceived Outcomes }}$}

The mainframe computing system would be replaced with a

distributive, personal computing environment. $(n=26)$

Faculty could develop new ways to use technology to help

students learn. $(n=28)$

$21.4 \quad 71.4 \quad 7.1$

All students would have access to computer technology and

know how to use it effectively. $(n=27)$

$22.2 \quad 66.7 \quad 7.4$

The University would provide students adequate access to

$$
\text { computers. }(\mathrm{n}=28)
$$

$42.9 \quad 46.4 \quad 7.1$

Faculty would be provided with an opportunity to explore

new approaches to instruction. $(\mathrm{n}=28)$

$42.9 \quad 46.4 \quad 7.1$

The University would provide the classroom computer

systems needed by faculty to enhance their access to

technology. $(n=28)$

$21.4 \quad 60.7 \quad 17.9$

Enhanced instructional, research, administrative and outreach

computing resources would be made available to

faculty. $(n=28)$
$\underline{\mathrm{FA}} \quad \underline{\mathrm{SA}} \quad \underline{\mathrm{NA}}$

$84.6 \quad 11.5$ 
Extent Achieved \%

\section{Perceived Outcomes}

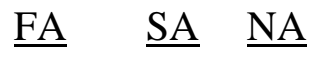

Students would develop higher levels of computer literacy and skills. $(n=27)$

$44.4 \quad 51.9$

All faculty would develop higher levels of computer literacy and skills. $(\mathrm{n}=28)$ 


\section{Phase III}

\section{Demographics}

At the deadline for completion of Phase II of the study, there were 12 of 49 initial participants that had not completed the full survey. There were also eight anonymous responses. Hence, a non-respondent survey of the 20 initial participants was conducted. A non-respondent survey containing eight questions from the original survey (see Appendix J) was developed in order to conduct the non-respondent survey. Upon completion of the non-respondent survey, there was a $50 \%$ response rate -- five of ten non-respondents. Two of the 12 non-respondents completed the full survey after the deadline. The answers of the non-respondents to the eight questions were not significantly different from those of the respondents. See Appendix J for specific results. 


\section{Chapter 5}

\section{Summary, Conclusions, and Discussion}

Virginia Tech's FDI was developed to address issues related to the computer technology revolution; training of faculty; faculty professional development; and the University adjusting to change. The purpose of this study was to identify and compare the goals, expectations, and perceived outcomes that the University, FDI developers, and the initial participants had for Virginia Tech's FDI initiative as originally implemented.

Theories and models including Porter and Steers' met expectations hypothesis, Rogers' diffusion theory, Vroom's expectancy theory, change and early adopter's theories were analyzed for relevance to the study. A review of literature regarding human resource development, training and recall were also reviewed for relevance to this study.

Data for the study was collected from historical documents relevant to FDI, the development of FDI and from the developers of FDI and the initial participants. All five of the developers participated in the study by responding to the interview questions and the survey. There were 42 initial participants available to participate in the study. Surveys were sent to them via e-mail and traditional mail. Post card reminders were mailed to non-respondents to the first round. Those who did not respond following the post card reminder were sent a second copy of the survey via e-mail and regular mail. A nonrespondent survey was administered via telephone to those who did not respond after the third contact. A response rate of $88.09 \%$ was obtained although the usable response rate was $66.67 \%$. Twenty-eight of the initial 42 participants completed and returned the full survey. 
The findings of this study were based on the analysis of data as they relate to the research questions. Frequency tables for all of the data are provided in Appendices $\mathrm{H}$ and I for further review.

\section{Summary of Findings}

\section{University Expectations vs. FDI Expectations}

The University and FDI had different expectations regarding the probable outcomes of the initial FDI workshop. The University had 11 broad strategies, goals and expectations for meeting the challenges brought on by technological change and changes in the university environment. Of those, FDI had the potential to directly and significantly impact two. The first of those was the University's goal "to establish a comprehensive program of human resource development for faculty, staff, and administrators". The FDI initiative was in alignment with the University objective "to strengthen and expand faculty development programs related to teaching effectiveness, advising, and the applications of advanced computing and communications technologies in the teaching-learning environment".

The second goal of the University relevant to FDI was "to enhance the quality and accessibility of library and other information resources and advanced computing and communication technologies" (The University Plan: 1991-1996, 1991). FDI made that one of their expectations and assisted with providing faculty with the technological hardware and software necessary to meet this University goal.

The FDI initiative may have impacted most, or even all, of the University goals to some extent; however, the these two goals were those most compatible with the focus of FDI as initially conceived and implemented. 


\section{University Expectations vs. University Outcomes}

Through historical document analysis information, the University expectations in regards to FDI were met and achieved according to the University Plan: Progress Toward 1991-1996 Goals (The University Plan: 1991-1996, 1991). FDI was a part of a larger Instructional Development Initiative and the outcomes that impacted on the broader university goals were achieved. According to findings from FDI developer interviews, FDI provided the capability for the accomplishment of many changes to help the University achieve a number of goals. For example one of the FDI developers made the following comments to illustrate how FDI sparked a transformation in the University environment:

The faculty development program has produced faculty ...[driven] ideas. It was faculty out of the faculty development program that came up with the idea for the math emporium and pushed us to help them implement the math emporium. It was faculty that had gone through the [FDI] that established something called the Cyber School, which was an early sort of online university pilot... It was faculty ... who realized we really need to know that students had a certain high level of computing capability ... and based on that proposed the requirement for everyone to have computers ... [at] Virginia Tech...

\section{FDI Expectations vs. Initial Participants' Expectations}

The developer's expectations were presented to the initial participants via a survey instrument, which listed the 41 expectations. The initial participants only identified 21 of the 41 potential short and long-term expectations as being an outcome they expected to occur as a result of the initial FDI initiative. On the other hand, the developers identified 39 of the 41 potential outcomes as being something that they expected would occur as a result of participating in the initial FDI workshop. The FDI developers and the initial participants had some similar expectations; they agreed on 13 of the 17 short-term expectations but only on eight of the 24 long-term expectations. The 
expectations and goals of these stakeholders did not all match, but both of the stakeholder groups came away with most of what they expected. The FDI program met the needs of the stakeholders on an individual basis, but from a within group perspective, neither the developers nor the initial participants agreed on the effectiveness of the program. Neither did they agree across groups.

\section{FDI Expectations vs. FDI Outcomes}

Sixteen of the seventeen short-term and twenty-one of twenty-four long-term expectations were seen as achieved by the developers. The extent to which individual developers believed each expectation was achieved differed. The difference can be explained based on the viewpoint from which the developers were measuring achievement. They all came from different areas of the university and were looking at the program from different perspectives and came to the project with different expectations.

\section{Initial Participants' Expectations vs. University Expectations}

The initial participants' expectations did align with the University's expectations of having faculty receive specific computer technology training and receiving a state of the art desktop computer. They were also provided the software to communicate more effectively, locally and globally. The extent to which such communication occurred, increased or was more efficient and effective was not measured by the University. 


\section{Initial Participants' Expectations vs. Initial Participants' Outcomes}

The extent to which initial participants' perceived that the outcomes they held as expectations for the workshop were achieved varied. Of the 12 short-term and nine longterm expectations held by at least $65 \%$ of the initial participants, only two were rated as having been fully achieved. Participants did not agree on the extent of achievement for the remaining ten outcomes.

\section{Conclusions}

After reviewing and summarizing this study's findings, there were four University goals that FDI sought to meet as determined from the expected short and long-term outcomes evaluated in this study. The researcher has drawn the following conclusions:

1. FDI developers designed the FDI initiative to align with the University's short and long-term initiatives. However, participants did not enter the program with expectations identical to those of the developers. The developers' and participants' short-term expectations were more often in agreement than were their long-term expectations.

There were many organizational change initiatives occurring within the University before the development of FDI. The major ones included curriculum change within departments; changing from the mainframe to distributed computing environment; improving undergraduate student education; and increasing the use of computer technology by faculty. These changes were a part of the University Plan 1991-1996 (The University Plan: 1991-1996, 1991). The developers of FDI, because of their previous roles within the university, were aware of these initiatives. They saw them as an opportunity for 
action. They used these changes to develop a platform from which they could leverage an idea that would meet professional goals and influence the achievement of the University goals. According Kunneman, Key, and Sleezer, the use of technology, the relentless speed of change and the skills needed by working people have provided the platform for change within organizations (2000). Interview findings show that developers saw the opportunity, were in positions to influence change and made the decision to so. FDI evolved out of that decision. Developers stated:

...you know the argument was made, we talked about it as a good idea and I agreed and told people to go ahead with it... I was central to the executive decision that yes we should go ahead, it was a good idea

I went to the University Provost and proposed our, initiating a program that would be aimed at, a faculty development program that would be aimed at $100 \%$ of our faculty over several years, then I indicated that I would be willing to reallocate internal resources... to support personnel and operating costs associated with this program, but that I would need support in winning a reallocation of some of the equipment trust fund monies to pay for the equipment that would be allocated to faculty...

a. University goal: to enhance the quality of undergraduate education (The University Plan: 1991-1996, 1991)

FDI and the initial participants tended to agree upon the short-term expectations and at least partially agreed as to the extent they were achieved. They disagreed more in regards to the long-term expectations related to this goal of the University and the extent to which those were achieved. The University did not hold FDI solely accountable for the achievement of this goal (The University Plan: 1991-1996, 1991), but the findings of this study suggest that FDI developers felt that FDI could positively influence the attainment of this goal. 
b. University goal: to establish a comprehensive program of human resource development for faculty, staff, and administrators (The University Plan: 1991$\underline{1996}, 1991)$

FDI and the initial participants, again, tended to agree upon the short-term expectations related to this University goal and partially agreed as to the extent they achieved. They disagreed more in regards to the long-term expectations and the extent to which those were achieved.

c. University goal: to increase the effectiveness and the efficiency of administrative and support operations (The University Plan: 1991-1996, 1991)

FDI and the initial participants did not agree upon either the short or longterm expectations related to this University goal. Also, they disagreed regarding the extent to which the short and long-term expectations were achieved.

d. University goal: to enhance the quality and accessibility of library and other information resources and advanced computing and communications technologies (The University Plan: 1991-1996, 1991)

FDI and the initial participants did not agree upon the long-term expectations related to this University goal. They partially agreed as to the extent to which they were achieved. 
2. The initial FDI initiative was successful in meeting the expectations of the stakeholders.

Although the FDI developers and initial participants did not hold identical short or long-term expectations for the workshop, both groups did agree that all of their expectations were at least somewhat achieved. The perceived outcomes for Virginia Tech are:

(a) The Instructional Development Initiative will provide an opportunity for all faculty members over a four-year period with a state-of-the art computer and an intensive workshop focused on the integration of advanced computing and communications technology into the curriculum. Over 650 faculty members, almost half of the faculty, have participated in this program; (b) The University has leveraged the communications infrastructure, enhanced through network technology and resources, allowing the development of hundreds of WWW home pages on campus (The University Plan: Progress Toward 1991-1996 Goals, 1996).

3. Neither the FDI developers nor the participants believed that FDI would change the criteria used to evaluated faculty performance or propel Virginia Tech into a position of national leadership.

With regards to items that were a part of the list of outcomes that were not a stated University goal/objective, FDI and the initial participants were in agreement that the use of computer technology in instruction would become an important factor in promotion, tenure, and salary evaluations was not expectation and not achieved. They did not agree that 'Virginia Tech will become a national leader in the use and integration of computer technology in teaching and research' was an expectation but agreed that it was at least partially achieved. 
4. The FDI initiative expanded the capabilities of faculty to communicate with, and teach, their students

The findings show that faculty saw their professional roles most affected by their enhanced ability to use computer technology in the classroom and the use of e-mail/websites. Faculty were equipped to provide students with 24-hour access to course materials and students had more options for obtaining class notes and communicating with faculty, but this did not guarantee that quality learning would occur. Students still were accountable for the knowledge they obtained. Technology provided an additional tool for faculty and students to use.

5. This study provides trainers with another perspective from which to enhance evaluations of training programs.

Taking time to find out what individual participants expectations are before a program is developed should lead to a better utilization of resources when implementing a program. There would be better measurement of the transfer of training because what individuals expect to receive from training would have been clearly identified and documented. This method would allow trainers to use direct measures in which respondents would indicate the extent to which they perceived their pre-entry expectations concerning the training to have been confirmed (Irving and Meyer, 1995).

\section{Discussion}

Overall, there was a distinct difference in the perceived outcomes and the extent achieved for the University, the developers, and the initial participants. There was total agreement on only two items out of the 41 expectations. The two that were agreed upon 
are: 1) Faculty would received a state of the art desktop computer, installed in their office with necessary hardware and software to incorporate computer technology into their teaching; and 2) Faculty could develop new ways to use technology to help students learn. The first of these was a very tangible and visible outcome; the second was less so, but an almost unavoidable outcome of the workshop was that faculty would know more about using technology than when they entered.

The findings indicate that although goals and expectations were communicated by the developers to some of the initial participants before the workshop for them to communicate to others in their departments, the initial participants still came in with their own perceptions. Their personal perceptions were evaluated to determine the perceived effectiveness of FDI. FDI met some needs and expectations of the individual participants; however, the developers did not know exactly what those needs and expectations were prior to developing the program. Therefore, they would not have been able to assess the extent to which they were achieved. According to Bassi, Cheney and Lewis, the methods and processes used by training departments must match the needs of each individual learner as well as the organization's goals and objectives (Bassi, Cheney \& Lewis 1998).

A needs analysis and assessment of the individual participants' needs might have positively affected the FDI development process. The time frame, in which FDI was developed, within six months, did not provide a window of opportunity for this to occur. According to the developers:

we did it rather quickly because we first started meeting in October, November 1992 and the first workshops occurred June of 1993, so basically, we had six months. It was relatively fast for a University. 
Actually, I think for a University initiative, it happened pretty quickly. I think one of the reasons why FDI was so successful was that there was a period of planning that extended for ... three to six months before each workshop that happened with the representative or representatives of the groups that were going to be coming through and I think that made the workshops more meaningful for people who came...it was a workshop that was tailored to the needs of the group.

The theoretical models that were utilized in this study support the researcher's finding that the individual differences occurred because a pre-program assessment of individual needs was not conducted. Met expectation hypothesis supports that there would be a discrepancy between what the person actually experienced and what the person expected to encounter often occur in such situations (Porter \& Steers, 1973). Rogers' (1995) diffusion theory stresses the importance of communication to the success of efforts such as FDI. Diffusion theory played a role in the development of FDI (reference Table 1). The findings from the interview guide (Appendix D) question Tell me about the steps you went through to integrate the use of technology into the University community through FDI, of this study indicate the developers of FDI used Rogers' communication channel to diffuse FDI throughout the University community. As stated by developers:

We worked through the deans, we worked through the department heads and a number of the steering committees, that was a major channel of information to people ... We worked through, kind of traditional academic channel to get the message out. We also relied on people who had been through the program to be a source of information that became more and more important as we progressed through the initial four-year program...

... there was the FDI piece which was the workshop piece, there was the classroom piece, which was identifying classrooms on campus that were set up as computer classrooms ... the third piece was the deployment of computers in faculty offices for participants...

Many other forces drive whether technology was integrated into the classroom and how much some FDI and initial participants' expectations were achieved after the 
initial workshop. According to the research of Steers, Porter (1979) and Cascio (1998)

enthusiasm for the training; reinforcement of what is learned in training; and how the behavior change as a result of training is maintained and sustained influences the perceived success or effectiveness of that training for the individual involved. Examples of how two of the initial participants were impacted in this way follow:

From my perspective the FDI initiative has been a resounding success at helping faculty become computer literate; however, few faculty incorporate technology in their classroom instructional strategies. I have been using technology in my classes for years. The FDI initiative has given me updated hardware, which I greatly appreciate; however, the integration of technology in my classroom behavior more or less comes from my professional interests. How do students learn? How can technology enhance this learning?

The "course" materials that we were supposed to be introduced to was a program developed for Classical Studies, called Perseus, which I never figured out. Since I do not teach Classical Studies, this was irrelevant as well as intensely frustrating.

These comments show that individuals had widely, variable skills coming into the program and may not have had the motivation or enthusiasm for the training (Cascio, 1998). Furthermore, the comments support Silberman's theory that programs should address the

a) cognitive goals- lack of knowledge or 'don't know' situations;

b) behavioral goals - lack of skill or 'can't do situations; or

c) affective goals - lack of desire or fear about using new knowledge or skills or 'won't do' situations (Silberman, 1998)

within organizations. The developers of FDI faced all three of these situations and developed FDI to meet those needs for faculty who did not understand how to use a computer for instructional purposes; who could not manipulate the new software applications or use a personal computer; and/or were afraid of or was not interested in changing their teaching methods. 
As a part of the development of the survey instrument, the developers were asked if early adopter's theory play a role in their selection of objectives for FDI. They felt that early adopter's did play a role in the sense that the initial participants were seen as "early adopters and were amenable to participating in carrying out change within their departments." This was in keeping with the concept of change agents as identified in the literature review concerning how an innovation is diffused through an organization. The initial participants could be viewed as change agents.

Another comment from a developer was that:

...there was no question in some cases that early adopters [were] among those departments, were in the first group we worked with.

One element that was not measured in this study was time. However, in response to survey item 36, "An increased number of students would be served while maintaining the quality of instruction and costs," a faculty member provided the following insights:

... there can be no such thing as more with less. MORE always equals MORE. Technology is enabling me to teach in new ways that I find better than the old, though they require more work. Technology will NOT enable us to teach more students for the same cost. I think it is an uninformed and unethical deception to propose that it will.

The use of qualitative and quantitative research methodology for this study, proved to be advantageous. The researcher obtained information from each method that was complimentary to the other methodology. Had the researcher not interviewed the developers and conducted a historical document analysis, a lot of information may have been missed. A significant portion of the historical documentation was obtained from or via conversation with the developers. Using their interview information as suggested 
from the Mitchell (Mitchell, 1974) was also invaluable. The researcher was able to triangulate information to provide validity to the findings of the study.

As a follow-up to this study, the following questions could be considered:

1. Are the initial participants expectations and outcomes the same as those of faculty members who participated in FDI following the initial workshop?

2. The measure of implementation of technology in instruction was beyond the focus of this study; however, an extension of this study could be to measure the extent of implementation of technology in instruction since the inception of FDI. To what extent are faculty members using technology within instruction? 


\section{References}

Ball, W. (1995). Using the Internet as a teaching tool: why wait any longer? PS: Political Science \& Politics, 28(4), 718-723.

Bassi, L., Cheney, S., \& Lewis, E. (1998). Trends in workplace learning: supply and demand in interesting times. Training and Development, 52(11), 51-75.

Bem, D. J. (1972). Self-perception theory. In L. Berkowitz (Ed.), Advances in experimental and social psychology (Vol. 6, pp. 1-62). New York: Academic Press.

Browell, S. (2000). Staff development and professional education: a cooperative model. Journal of Workplace Learning: Employee Counseling Today, 12(2), 57-65.

Cascio, W. F. (1998). Applied psychology in human resource management (5th ed.). Upper Saddle River, NJ: Prentice Hall.

Deden, A. (1998). Computers and systemic change in higher education. Communications of the ACM, 41(1), 58-64.

Eifler, K. E., Greene, T. G., \& Carroll, J. B. (2001). Walking the talk is tough: From a single technology course to infusion. The Educational Forum, 65, 366-375.

Falba, C. J. (1998). Technology use by a college of education faculty and factors influencing integration of technology in undergraduate teacher preparation program. Unpublished doctoral dissertation, University of Nevada, Las Vegas.

First Draft Goals and Objectives. (Draft). Blacksburg, VA: Virginia Tech.

House, R. J., Shapiro, H. J., \& Wahba, M. A. (1974). Expectancy theory as a predictor of work motivation and attitude: A re-evaluation of empirical evidence. Decision Science, 5, 581-586. 
Hurst, D. (1994). Teaching technology to teachers. Educational Leadership, 52(7), 74-77. Instructional computing proposal. (Draft)(1992). Blacksburg, VA: Virginia Tech. Instructional development initiative: interim report on this phase II initiative. (Report)(1993). Blacksburg, VA: Virginia Tech.

Irving, P. G., \& Meyer, J. P. (1995). On using direct measures of met expectations: a methological note. Journal of Management, 21(6), 1159-1176.

Kelly, L. (1995). The ASTD technical and skills training handbook. New York: McGrawHill, Inc.

Kirkpatrick, D. L. (1994). Evaluating training programs. San Francisco, CA: BerrettKoehler Publishers, Inc.

Kunneman, D. E., Key, J. P., \& Sleezer, C. M. (2000). Management training activities and training needs within selected business and industry organizations in Oklahoma. Journal of Career and Technical Education, 16(2), 51-56.

Merriam, S. (1998). Qualitative research and case study applications in education. California: Jossey-Bass Inc.

Mitchell, T. (1974). Expectancy models of job satisfaction, occupational preference and effort: A theoretical, methodological, and empirical appraisal. Psychological Bulletin, 81(12), 1053-1077.

Moran, J. W., \& Brightman, B. K. (2000). Leading organizational change. Journal of Workplace Learning: Employee Counseling Today, 12(2), 66-74.

Ndahi, H. B. (1998). A study of industrial and technical teacher education faculty acceptance of distance learning technology. Unpublished doctoral dissertation, Oklahoma State University, Stillwater. 
Oliver, R., Omari, A., \& Herrington, J. (1998). Investigating implementation strategies for WWW-based learning environments. International Journal of Instructional Media, 25(2), 121-136.

Ormond, J. E. (1999). Human learning (3rd ed.). Upper Saddle River, NJ: Prentice-Hall Inc.

Porter, L. W., \& Lawler, E. E. (1968). Managerial attitudes and performance. Homewood, Il: Richard D. Irwin, Inc.

Porter, L. W., \& Steers, R. M. (1973). Organizational, work, and personal factors in employee turnover and absenteeism. Journal of Management, 80, 151-176.

Rogers, E. M. (1995). Diffusion of innovations (4th ed.). New York: The Free Press.

Ross, M. (1989). Relation of implicit theories to the construction of personal histories. Journal of Management, 96, 341-357.

Seidman, I. (1998). Interviewing as qualitative research: A guide for researchers in education and the social sciences (2nd ed.). New York: Teachers College Press.

Silberman, M. (1998). Active training (2nd ed.). San Francisco: Jossey-Bass/Pfeiffer.

Steers, R. M., \& Porter, L. W. (1979). Motivation and work behavior. New York: McGraw-Hill Book Company.

The University Plan: 1991-1996 (1991, April 29, 1991). [Report]. Virginia Polytechnic Institute and State University. Retrieved, from the World Wide Web: http://Www.provost.vt.edu/sp/uni_plan91-96.htmI

The University Plan: Progress Toward 1991-1996 Goals (1996). [Report]. Virginia Tech. Retrieved, from the World Wide Web: http://www.provost.vt.edu/sp/UnivPlanUpdate.html 
Vroom, V. H. (1995). Work and Motivation. San Francisco: Jossey-Bass. 


\section{Appendix A: Banks Instructional Design Model}
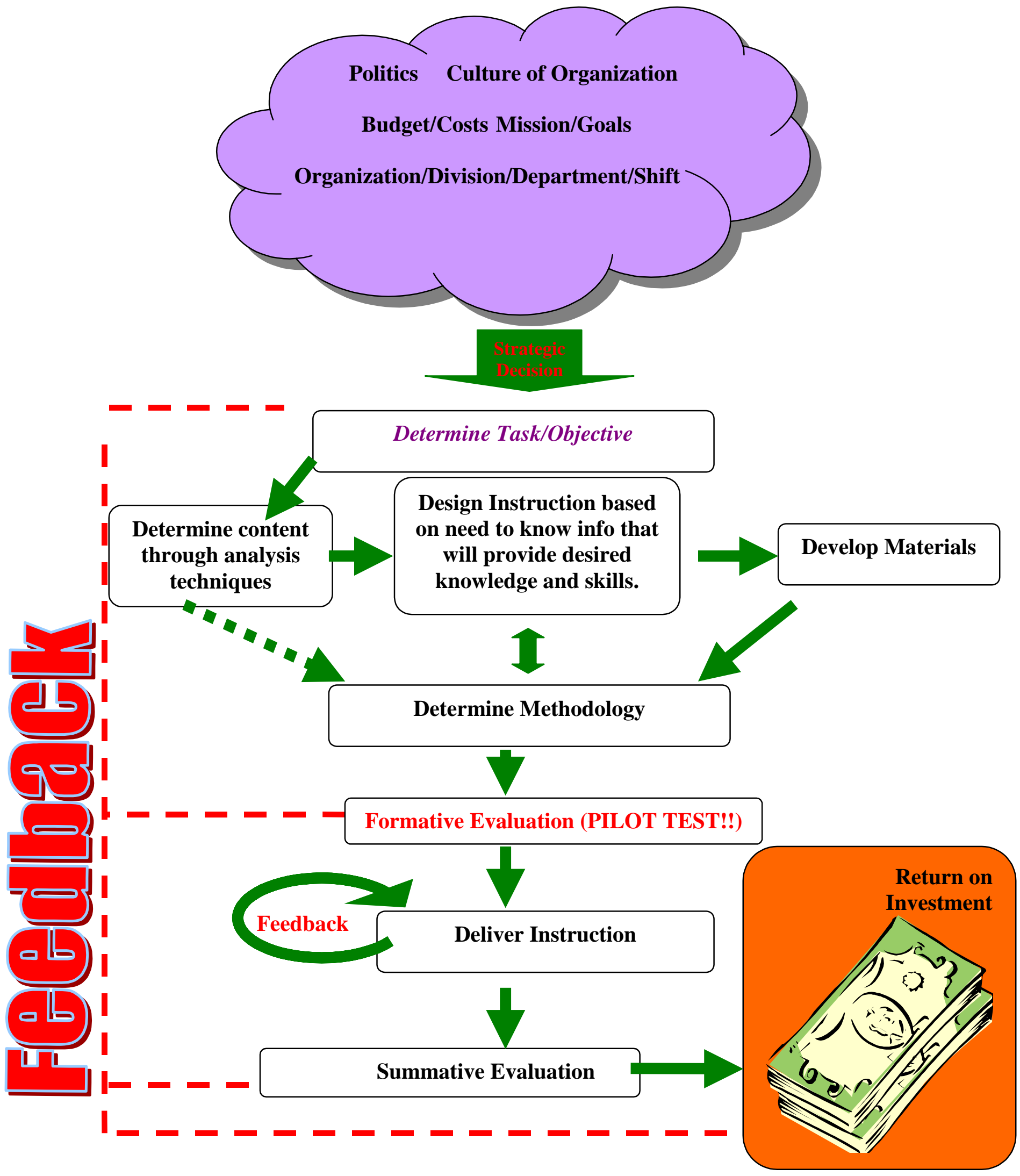


\section{Appendix B: IRB Form}

\section{Justification of Project}

The purpose of this study is to identify and compare the goals, expectations, and perceived outcomes that the university, FDI developers, and the initial participants had for Virginia Tech's FDI initiative as originally implemented. The goals, expectations, and perceived outcomes of the stakeholders involved within the FDI initiative as originally implemented at Virginia Tech are unknown.

The purpose for involving human subjects as a part of this study is the need to determine what the developers and the university's goals, expectations and outcomes were. If the developer's information is not included in his or her own words, the true reason for FDI development may never be known. The theory that is being used in this study (expectancy theory) requires a within subject approach in order to add validity to the study and reliability to the data. Also, the data that will be obtained from the developers will be used to triangulate the historical document review results. The triangulated results will then be used to develop a survey for the initial participants of FDI and the developers. If the interview is not conducted, there will be no foundation for the study to occur.

\section{Procedures}

The subject pool will consist of five developers of Virginia Tech's FDI. Four of them are male and one female. 
The subjects will be asked to respond honestly to open-ended questions in a semistructured interview format. The interview questions will primarily come from an interview guide that the interviewees will be able to review. The subjects will be interviewed once, but will have an opportunity to review transcribed data. The interviews are not expected to last more than two hours. There will be one interview conducted via telephone due to distance if a suitable location to meet cannot be determined. The interviews will be conducted in a location that is convenient for the interviewee, be it their office, home, etc...

\section{Risks and Benefits}

The risks to the interviewee are that individuals other than the researcher and the researcher's committee members may determine their identity. All precautions will be utilized to minimize risk to the subjects.

\section{Confidentiality/Anonymity}

The anonymity or confidentiality of the identity of each subject will be preserved through the use of pseudonyms and the destruction of recorded media unless the subject requests the media. The researcher and researcher's committee will have access to the data. The interviews will be tape recorded because the developers are the only individuals who can provide the reasoning for the development of FDI. Audio recordings of formal interviews with FDI developers will be utilized. The tapes will serve as a primary data source for my study. I will be trying to ascertain goals, expectations, and outcomes of FDI and only through the developers' voices can their stories be properly told. The audio recorders will have counters on them and each tape will be numerically coded such that 
data can be retrieved from them. I will have the only access to the tapes. I will keep the tapes in a locked storage cabinet within my home. I will score and transcribe all of the tapes. The tapes will be erased and destroyed upon completion of the study unless participants would like to have their personal tape.

\section{Informed Consent}

See attachments

\section{Biographical Sketch}

I am a Ph. D. candidate at Virginia Tech in the Department of Vocational/Technical Education specializing in Training and Development/Instructional Technology. I have professional experience as an Internal Training Consultant in which I train and develop 150 employees, managers, and supervisors. I have observed FDI workshop sessions and witnessed faculty participation with the skills being taught. I have completed course work in qualitative research and will have access to experts in the field for advice on the subject. I have also completed an extensive literature review of my topic and am confident that I am qualified to conduct this study. 


\section{Appendix C: Informed consent application:}

\section{VIRGINIA POLYTECHNIC INSTITUTE AND STATE UNIVERSITY \\ Informed Consent for Participants of Investigative Projects}

Title of Project A DESCRIPTIVE ANALYSIS THE PERCEIVED EFFECTIVENESS OF VIRGINIA TECH'S FACULTY DEVELOPMENT INSTITUTE USING EXPECTANCY THEORY.

Investigator(s)__Claretha $\mathrm{H}$. Banks

\section{The Purpose of this Research/Project}

The purpose of this study is to identify and compare the goals, expectations, and perceived outcomes that the university, FDI developers, and the initial participants had for Virginia Tech's FDI initiative as originally implemented. The goals, expectations, and perceived outcomes of the stakeholders involved within the FDI initiative as originally implemented at Virginia Tech are unknown. There will be total number of five subjects involved in the interview process of this study.

\section{Procedures}

The subjects will be asked to respond honestly to open-ended questions in a semistructured interview format. The interview questions will primarily come from an interview guide that the interviewees will be able to review. The interview will be taperecorded. The subjects will be interviewed once, but will have an opportunity to review transcribed data. The interviews are not expected to last more than two hours. There will be one interview conducted via telephone due to distance if a suitable location to meet 
cannot be determined. The interviews will be conducted in a location that is convenient for the interviewee, be it their office, home, etc...

\section{Risks}

The risks to the interviewee are that individuals other than the researcher and the researcher's committee members may determine their identity. All precautions will be utilized to minimize risk to the subjects. Only the researcher and the researcher's committee will have access to the data. The researcher will transcribe all the tapes and will keep them in a located cabinet of her home.

\section{Benefits of this Project}

The intangible benefits of this study are that FDI will have research data to use to expand its services to the Virginia Tech faculty community. There is no promise or guarantee that the results of this study will be a direct benefit to the subject for his or her participation.

All subjects may contact the researcher at a later time for a summary of the research results.

\section{Extent of Anonymity and Confidentiality}

The anonymity or confidentiality of the identity of each subject will be preserved through the use of pseudonyms and the destruction of recorded media unless the subject requests the media. The researcher and researcher's committee will have access to the data. The interviews will be tape recorded because the developers are the only individuals who can 
provide the reasoning for the development of FDI. Audio recordings of formal interviews with FDI developers will be utilized. The tapes will serve as a primary data source for my study. I will be trying to ascertain goals, expectations, and outcomes of FDI and only through the developers' voices can their stories be properly told. The audio recorders will have counters on them and each tape will be numerically coded such that data can be retrieved from them. I will have the only access to the tapes. I will keep the tapes in a locked storage cabinet within my home. I will score and transcribe all of the tapes. The tapes will be erased and destroyed upon completion of the study unless participants would like to have their personal tape.

At no time will the researchers release the results of the study to anyone other than individuals working on the project without your written consent.

In some situations, it may be necessary for an investigator to break confidentiality. If child abuse is known or strongly suspected, investigators are required to notify the appropriate authorities. If a subject is believed to be a threat to herself/himself or others, the investigator should notify the appropriate authorities.

\section{Compensation}

There will be no compensation provided the subject for participation in this study.

\section{Freedom to Withdraw}

Subjects are free to withdraw from a study at any time without penalty. Subjects are free not to answer any questions or respond to experimental situations that they choose without penalty.

There may be circumstances under which the investigator may determine that a subject should not continue as a subject. 


\section{Approval of Research}

This research project has been approved, as required, by the Institutional Review Board for Research Involving Human Subjects at Virginia Polytechnic Institute and State University, by the Department of Vocational and Technical Education.

\section{Subject's Responsibilities}

I voluntarily agree to participate in this study. I have the following responsibilities:

1. Participate in the interview

2. Answer questions honestly

\section{Subject's Permission}

I have read and understand the Informed Consent and conditions of this project. I have had all my questions answered. I hereby acknowledge the above and give my voluntary consent for participation in this project.

If I participate, I may withdraw at any time without penalty. I agree to abide by the rules of this project.

Signature

Date

Should I have any questions about this research or its conduct, I may contact:

Claretha H. Banks

Investigator(s)

Dr. Patrick O'Reilly

Faculty Advisor

E. R. Stout

Chair, IRB,

Research Division $\underline{540-427-2805}$

Phone

540-231-8204

Phone

Phone 


\section{Appendix D: Interview Guide (FDI Developer):}

\section{Interview with FDI Developer}

\section{Background}

1. How many years have you been a faculty member or an administrator at Virginia Tech?

2. In what college of the university do you teach or work as an administrator?

3. Note gender.

4. What was your role in the development of FDI?

\section{Computer Literacy}

1. Describe any experience that you have with the use of a computer prior to your experience at Virginia Tech. (training, other work, etc.)

2. Tell me how that experience has helped you while developing FDI.

3. In what way has FDI added to your computer use knowledge?

\section{Goals of the University}

1. What were the goals of the University?

2. What did the University plan to achieve?

3. What were the expected outcomes for the University?

4. What was the policy memorandum that established FDI?

\section{Development Process}

1. In what ways did the organizational change concepts, such as early adopter's theory, play a role in selection of objectives for FDI? 
2. In what way were faculty members provided technical support prior to FDI? After implementation of FDI?

3. How were the goals of FDI developed?

4. What role did you play, if any, in the development of the goals for FDI? Initial participants?

5. What were the goals of FDI?

\section{Work-related}

1. Do you have any teaching experience in which you utilized technology within your instruction?

2. Was the use of technology a benefit? If so, how?

3. What barriers did you encounter when using technology in your instruction?

4. How did your teaching role change with the use of computer technology?

5. In what way has FDI helped you to modify/change your role at the university?

6. How have your job duties changed since helping with the development of FDI?

7. In what ways did that first experience motivate you to continue/discontinue your association with FDI?

\section{$\underline{\text { Integration of Technology }}$}

1. Tell me about the steps you went through to integrate the use of technology into the university community through FDI. 
2. How did you feel about the time it took to develop FDI?

3. Describe for me the benefits of integrating technology into traditional instruction.

4. What role was FDI to play in enhancing communication between faculty members and students?

\section{The Future}

1. Describe for me how you would use FDI to enhance your use of technology in future.

2. If you had the opportunity to change anything about FDI, what would you change and why?

3. Were the anticipated outcomes measured five years after the implementation of FDI? 


\section{Appendix E: Initial Participant Survey:}

Directions: Please indicate for each of the following statements whether they represented an expected outcome and then whether your expectation was realized. Please respond to the following survey based on your expectations prior to attending the initial FDI workshop. Your candid feedback is essential to the success of this study. Click on the gray area to select your response. Thank you.

\section{Outcomes during and/or immediately following initial FDI workshop}

1. I would earn a state of the art desktop computer, installed in my office, with necessary hardware and software to incorporate computer technology in my teaching.

Was this an outcome you expected? $\square$ Yes $\square$ No To what extent was this outcome achieved?

\begin{tabular}{|l}
$\square$ Fully Achieved \\
\hline$\square$ Somewhat Achieved \\
\hline$\square$ Not Achieved \\
\hline$\square$ Not Addressed
\end{tabular}

2. Collaborative communication regarding teaching strategies would be encouraged and facilitated during the workshop among participating faculty. Was this an outcome you expected? $\square$ Yes $\square$ No To what extent was this outcome achieved?

\begin{tabular}{l}
$\square$ Fully Achieved \\
\hline$\square$ Somewhat Achieved \\
\hline$\square$ Not Achieved \\
\hline$\square$ Not Addressed
\end{tabular}

3. I would receive specific training in how to use computers more effectively in my teaching role.

Was this an outcome you expected? $\square$ Yes $\square$ No To what extent was this outcome achieved?

\begin{tabular}{|l}
\hline Fully Achieved \\
\hline$\square$ Somewhat Achieved \\
\hline$\square$ Not Achieved \\
\hline$\square$ Not Addressed
\end{tabular}

4. I would acquire an enhanced understanding of administrative classroom uses of computers.

Was this an outcome you expected? $\square$ Yes $\square$ No

To what extent was this outcome achieved?

\begin{tabular}{|l}
$\square$ Fully Achieved \\
\hline$\square$ Somewhat Achieved \\
\hline$\square$ Not Achieved \\
\hline$\square$ Not Addressed
\end{tabular}

5. I would enhance my knowledge and skills to interact with students outside the classroom using computer technology. Was this an outcome you expected? $\square$ Yes $\square$ No To what extent was this outcome achieved?

\begin{tabular}{|l}
$\square$ Fully Achieved \\
\hline$\square$ Somewhat Achieved \\
\hline$\square$ Not Achieved \\
\hline$\square$ Not Addressed
\end{tabular}


6. I would enhance the knowledge and skills necessary to integrate computer technology into my instruction. Was this an outcome you expected? $\square$ Yes $\square$ No To what extent was this outcome achieved?

\section{$\square$ Fully Achieved $\square$ Somewhat Achieved Not Achieved Not Addressed}

7. I would be encouraged and motivated to re-think how I was teaching. Was this an outcome you expected? $\square$ Yes $\square$ No To what extent was this outcome achieved?

\begin{tabular}{|l}
$\square$ Fully Achieved \\
\hline$\square$ Somewhat Achieved \\
\hline$\square$ Not Achieved \\
\hline$\square$ Not Addressed
\end{tabular}

8. I would enhance my computer skills that would make my work with students more efficient and effective.

Was this an outcome you expected? $\square$ Yes $\square$ No

To what extent was this outcome achieved?

\begin{tabular}{|l}
$\square$ Fully Achieved \\
\hline$\square$ Somewhat Achieved \\
\hline$\square$ Not Achieved \\
\hline$\square$ Not Addressed
\end{tabular}

9. I would become more productive in my job as a result of computer technology skills learned in the workshop.

Was this an outcome you expected? $\square$ Yes $\square$ No To what extent was this outcome achieved?

\begin{tabular}{l}
$\square$ Fully Achieved \\
\hline$\square$ Somewhat Achieved \\
\hline$\square$ Not Achieved \\
$\square$ Not Addressed
\end{tabular}

10. The computer technology workshop would help me become more effective in my teaching role.

Was this an outcome you expected? $\square$ Yes $\square$ No

To what extent was this outcome achieved?

\begin{tabular}{|l}
$\square$ Fully Achieved \\
\hline$\square$ Somewhat Achieved \\
\hline$\square$ Not Achieved \\
$\square$ Not Addressed
\end{tabular}

11. Following the workshop, I would receive support with course development techniques.

Was this an outcome you expected? $\square$ Yes $\square$ No To what extent was this outcome achieved?

\begin{tabular}{|l}
$\square$ Fully Achieved \\
\hline$\square$ Somewhat Achieved \\
\hline$\square$ Not Achieved \\
\hline$\square$ Not Addressed
\end{tabular}

12. Students would become more active in, and take more responsibility for, their own learning as a result of my using computer technology skills to provide information to them inside and outside the classroom. 
Was this an outcome you expected? $\square$ Yes $\square$ No To what extent was this outcome achieved?

\section{$\square$ Fully Achieved Somewhat Achieved $\square$ Not Achieved $\square$ Not Addressed}

13. I would receive personalized technical support with computer technology use in instruction.

Was this an outcome you expected? $\square$ Yes $\square$ No

To what extent was this outcome achieved?

\begin{tabular}{|l}
$\square$ Fully Achieved \\
\hline$\square$ Somewhat Achieved \\
\hline$\square$ Not Achieved \\
\hline$\square$ Not Addressed
\end{tabular}

14. Participating in this workshop would be a positive experience for me. Was this an outcome you expected? $\square$ Yes $\square$ No To what extent was this outcome achieved?

\begin{tabular}{|l}
$\square$ Fully Achieved \\
\hline$\square$ Somewhat Achieved \\
\hline$\square$ Not Achieved \\
$\square$ Not Addressed
\end{tabular}

15. My ideas and needs would be addressed within FDI workshops. Was this an outcome you expected? $\square$ Yes $\square$ No To what extent was this outcome achieved?

\begin{tabular}{|l}
$\square$ Fully Achieved \\
\hline$\square$ Somewhat Achieved \\
\hline$\square$ Not Achieved \\
$\square$ Not Addressed
\end{tabular}

16. More classrooms across campus would be equipped with computer technology. Was this an outcome you expected? $\square$ Yes $\square$ No To what extent was this outcome achieved?

\begin{tabular}{l}
$\square$ Fully Achieved \\
\hline$\square$ Somewhat Achieved \\
\hline$\square$ Not Achieved \\
$\square$ Not Addressed
\end{tabular}

17. I would improve my communication with students by learning to use e-mail. $\square$ Yes $\square$ No To what extent was this outcome achieved?

$\square$ Fully Achieved
$\square$ Somewhat Achieved
$\square$ Not Achieved
$\square$ Not Addressed

18. Please provide at least three examples of how your teaching role has changed as a result of your initial participation in the FDI? 
$\underline{\text { Long term outcomes as a result of the FDI initiative }}$

19. The university would provide students adequate access to computers. Was this an outcome you expected? $\square$ Yes $\square$ No To what extent was this outcome achieved? $\square$ Fully Achieved Somewhat Achieved $\square$ Not Achieved $\square$ Not Addressed

20. The university would provide the classroom computer systems needed by faculty to enhance their access to computer technology. Was this an outcome you expected? $\square$ Yes $\square$ No To what extent was this outcome achieved?

\begin{tabular}{|l}
$\square$ Fully Achieved \\
\hline$\square$ Somewhat Achieved \\
\hline$\square$ Not Achieved \\
\hline$\square$ Not Addressed
\end{tabular}

21. All students would have access to computer technology and know how to use it effectively. Was this an outcome you expected? $\square$ Yes $\square$ No To what extent was this outcome achieved?

\begin{tabular}{|l}
$\square$ Fully Achieved \\
\hline$\square$ Somewhat Achieved \\
\hline$\square$ Not Achieved \\
$\square \square$ Not Addressed
\end{tabular}

22. Computer literacy requirements would be developed and required of all students across the university.

Was this an outcome you expected? $\square$ Yes $\square$ No To what extent was this outcome achieved?

23. Improved undergraduate student education. Was this an outcome you expected? $\square$ Yes $\square$ No To what extent was this outcome achieved?

\begin{tabular}{|l}
$\square$ Fully Achieved \\
\hline$\square$ Somewhat Achieved \\
\hline$\square$ Not Achieved \\
\hline$\square$ Not Addressed
\end{tabular}

\begin{tabular}{|l}
$\square$ Fully Achieved \\
\hline$\square$ Somewhat Achieved \\
$\square$ Not Achieved \\
$\square$ Not Addressed
\end{tabular}

24. Curriculum change within disciplines would occur through implementation of formal course development for targeted courses. Was this an outcome you expected? $\square$ Yes $\square$ No To what extent was this outcome achieved?

\author{
$\square$ Fully Achieved \\ Somewhat Achieved \\ Not Achieved \\ Not Addressed
}


25. FDI would become a forum for faculty to re-think their teaching strategies and how they were teaching.

Was this an outcome you expected? $\square$ Yes $\square$ No

To what extent was this outcome achieved?

\begin{tabular}{l}
$\square$ Fully Achieved \\
\hline$\square$ Somewhat Achieved \\
\hline$\square$ Not Achieved \\
\hline$\square$ Not Addressed
\end{tabular}

26. All faculty would become technology literate and have access to computer technology.

Was this an outcome you expected? $\square$ Yes $\square$ No To what extent was this outcome achieved?

\begin{tabular}{|l}
$\square$ Fully Achieved \\
\hline$\square$ Somewhat Achieved \\
\hline$\square$ Not Achieved \\
\hline$\square$ Not Addressed
\end{tabular}

27. Faculty could develop new ways to use technology to help students learn. Was this an outcome you expected? $\square$ Yes $\square$ No To what extent was this outcome achieved?

\begin{tabular}{l}
$\square$ Fully Achieved \\
\hline$\square$ Somewhat Achieved \\
\hline$\square$ Not Achieved \\
\hline$\square$ Not Addressed
\end{tabular}

28. Faculty would be provided with an opportunity to explore new approaches to instruction.

Was this an outcome you expected? $\square$ Yes $\square$ No

To what extent was this outcome achieved?

\begin{tabular}{|l}
$\square$ Fully Achieved \\
\hline$\square$ Somewhat Achieved \\
\hline$\square$ Not Achieved \\
\hline$\square$ Not Addressed
\end{tabular}

29. Faculty would transition smoothly from the mainframe environment to a personal computing environment. Was this an outcome you expected? $\square$ Yes $\square$ No To what extent was this outcome achieved?

\begin{tabular}{|l}
$\square$ Fully Achieved \\
\hline$\square$ Somewhat Achieved \\
\hline$\square$ Not Achieved \\
\hline$\square$ Not Addressed
\end{tabular}

30. The mainframe computing system would be replaced with a distributive, personal computing environment. Was this an outcome you expected? $\square$ Yes $\square$ No To what extent was this outcome achieved?

\begin{tabular}{l}
$\square$ Fully Achieved \\
\hline$\square$ Somewhat Achieved \\
\hline$\square$ Not Achieved \\
$\square$ Not Addressed
\end{tabular}


31. A majority of faculty would use the computer technology in the classroom as a supplement to their teaching.

Was this an outcome you expected? $\square$ Yes $\square$ No

To what extent was this outcome achieved?

\begin{tabular}{|l}
$\square$ Fully Achieved \\
\hline$\square$ Somewhat Achieved \\
\hline$\square$ Not Achieved \\
\hline$\square$ Not Addressed
\end{tabular}

32. All faculty would develop higher levels of computer literacy and skills. Was this an outcome you expected? $\square$ Yes $\square$ No To what extent was this outcome achieved?

\begin{tabular}{|l}
$\square$ Fully Achieved \\
\hline$\square$ Somewhat Achieved \\
\hline$\square$ Not Achieved \\
$\square$ Not Addressed
\end{tabular}

33. The Virginia Tech computer technology infrastructure would become leadingedge technology.

Was this an outcome you expected? $\square$ Yes $\square$ No

To what extent was this outcome achieved?

\begin{tabular}{|l}
$\square$ Fully Achieved \\
\hline$\square$ Somewhat Achieved \\
\hline$\square$ Not Achieved \\
$\square$ Not Addressed
\end{tabular}

34. The number of courses taught online and using distance learning technology would increase.

Was this an outcome you expected? $\square$ Yes $\square$ No To what extent was this outcome achieved?

\begin{tabular}{|l}
$\square$ Fully Achieved \\
\hline$\square$ Somewhat Achieved \\
\hline$\square$ Not Achieved \\
\hline$\square$ Not Addressed
\end{tabular}

35. Enhanced instructional, research, administrative and outreach computing resources would be made available to faculty. Was this an outcome you expected? $\square$ Yes $\square$ No To what extent was this outcome achieved?

\begin{tabular}{|l}
$\square$ Fully Achieved \\
\hline$\square$ Somewhat Achieved \\
\hline$\square$ Not Achieved \\
$\square$ Not Addressed
\end{tabular}

36. An increased number of students would be served while maintaining the quality of instruction and costs.

Was this an outcome you expected? $\square$ Yes $\square$ No To what extent was this outcome achieved?

\author{
$\square$ Fully Achieved \\ Somewhat Achieved \\ Not Achieved \\ $\checkmark$ Not Addressed
}


37. Virginia Tech would become a national leader in the use and integration of computer technology in teaching and research.

Was this an outcome you expected? $\square$ Yes $\square$ No

To what extent was this outcome achieved?

\begin{tabular}{|l}
$\square$ Fully Achieved \\
\hline$\square$ Somewhat Achieved \\
\hline$\square$ Not Achieved \\
\hline$\square$ Not Addressed
\end{tabular}

38. Students would develop higher levels of computer literacy and skills. Was this an outcome you expected? $\square$ Yes $\square$ No To what extent was this outcome achieved? $\square$ Fully Achieved $\square$ Somewhat Achieved $\square$ Not Achieved $\square$ Not Addressed

39. The quality of interaction among students and faculty would improve. Was this an outcome you expected? $\square$ Yes $\square$ No To what extent was this outcome achieved?

\begin{tabular}{|l}
$\square$ Fully Achieved \\
\hline$\square$ Somewhat Achieved \\
\hline$\square$ Not Achieved \\
\hline$\square$ Not Addressed
\end{tabular}

40. The emphasis on active and independent learning strategies, problem solving and collaboration would increase. Was this an outcome you expected? $\square$ Yes $\square$ No To what extent was this outcome achieved?

\begin{tabular}{|l}
$\square$ Fully Achieved \\
\hline$\square$ Somewhat Achieved \\
\hline$\square$ Not Achieved \\
\hline$\square$ Not Addressed
\end{tabular}

41. The use of class contact hours as a determinate of credit hours would decrease. Was this an outcome you expected? $\square$ Yes $\square$ No To what extent was this outcome achieved?

\begin{tabular}{|l}
$\square$ Fully Achieved \\
\hline$\square$ Somewhat Achieved \\
\hline$\square$ Not Achieved \\
\hline$\square$ Not Addressed
\end{tabular}

42. Use of computer technology in instruction would become an important factor in promotion, tenure and salary evaluations. Was this an outcome you expected? $\square$ Yes $\square$ No To what extent was this outcome achieved?

$\square$ Fully Achieved
$\square$ Somewhat Achieved
$\square$ Not Achieved
$\square$ Not Addressed




\section{Appendix F: Developer Survev:}

Directions: Please indicate for each of the following whether they were an expectation for FDI and the extent to which each was achieved. Please respond based on your expectations prior to the initial FDI workshop. Your candid feedback is essential to the success of this study. Click on the gray area to select your response. Thank you.

\section{Outcomes during and/or immediately following initial FDI workshop}

1. All participating faculty would have desktop computers installed in their offices with necessary hardware and software available. Was this an outcome you expected? $\square$ Yes $\square$ No To what extent was this outcome achieved?

\begin{tabular}{|l}
$\square$ Fully Achieved \\
\hline$\square$ Somewhat Achieved \\
\hline$\square$ Not Achieved \\
\hline$\square$ Not Addressed
\end{tabular}

2. Collaborative communication regarding teaching strategies would be encouraged and facilitated during the workshop among participating faculty. Was this an outcome you expected? $\square$ Yes $\square$ No To what extent was this outcome achieved?

\begin{tabular}{|l}
$\square$ Fully Achieved \\
\hline$\square$ Somewhat Achieved \\
\hline$\square$ Not Achieved \\
\hline$\square$ Not Addressed
\end{tabular}

3. Participants would receive specific training in how to use computers more effectively in their teaching role. Was this an outcome you expected? $\square$ Yes $\square$ No To what extent was this outcome achieved?

\begin{tabular}{|l}
$\square$ Fully Achieved \\
\hline$\square$ Somewhat Achieved \\
\hline$\square$ Not Achieved \\
$\square$ Not Addressed
\end{tabular}

4. Participants would acquire an enhanced understanding of administrative classroom uses of computers. Was this an outcome you expected? $\square$ Yes $\square$ No To what extent was this outcome achieved?

\begin{tabular}{|l}
$\square$ Fully Achieved \\
\hline$\square$ Somewhat Achieved \\
\hline$\square$ Not Achieved \\
$\square$ Not Addressed
\end{tabular}

5. FDI would enhance participants' knowledge and skills to interact with students outside the classroom using computer technology. Was this an outcome you expected? $\square$ Yes $\square$ No To what extent was this outcome achieved?

\begin{tabular}{|l}
$\square$ Fully Achieved \\
\hline$\square$ Somewhat Achieved \\
\hline$\square$ Not Achieved \\
\hline$\square$ Not Addressed
\end{tabular}


6. Participants would acquire the knowledge and skills necessary to integrate computer technology into their instruction. Was this an outcome you expected? $\square$ Yes $\square$ No To what extent was this outcome achieved?

\begin{tabular}{l}
$\square$ Fully Achieved \\
\hline$\square$ Somewhat Achieved \\
\hline$\square$ Not Achieved \\
\hline$\square$ Not Addressed
\end{tabular}

7. Participants would be encouraged and motivated to re-think how they were teaching.

Was this an outcome you expected? $\square$ Yes $\square$ No To what extent was this outcome achieved?

\begin{tabular}{l}
$\square$ Fully Achieved \\
\hline$\square$ Somewhat Achieved \\
\hline$\square$ Not Achieved \\
\hline$\square$ Not Addressed
\end{tabular}

8. Participants would enhance their computer skills to make their work with students more efficient and effective.

Was this an outcome you expected? $\square$ Yes $\square$ No To what extent was this outcome achieved?

\section{$\square$ Fully Achieved Somewhat Achieved Not Achieved Not Addressed}

9. Faculty would become more productive in their jobs as a result of computer technology skills learned in the workshop.

Was this an outcome you expected? $\square$ Yes $\square$ No To what extent was this outcome achieved?

\begin{tabular}{|l}
$\square$ Fully Achieved \\
\hline$\square$ Somewhat Achieved \\
\hline$\square$ Not Achieved \\
\hline$\square$ Not Addressed
\end{tabular}

10. The computer technology workshop would help participants become more effective in their teaching role.

Was this an outcome you expected? $\square$ Yes $\square$ No To what extent was this outcome achieved?

\begin{tabular}{|l}
$\square$ Fully Achieved \\
\hline$\square$ Somewhat Achieved \\
\hline$\square$ Not Achieved \\
$\square \square$ Not Addressed
\end{tabular}

11. Following the workshop, participants would receive support with course development techniques. Was this an outcome you expected? $\square$ Yes $\square$ No To what extent was this outcome achieved?

\begin{tabular}{l}
$\square$ Fully Achieved \\
\hline$\square$ Somewhat Achieved \\
\hline$\square$ Not Achieved \\
$\square$ Not Addressed
\end{tabular}


12. Students would become more active in, and take more responsibility for, their own learning as a result of participants using computer technology skills to provide information to them inside and outside the classroom.

Was this an outcome you expected? $\square$ Yes $\square$ No To what extent was this outcome achieved?

\begin{tabular}{|l}
$\square$ Fully Achieved \\
\hline$\square$ Somewhat Achieved \\
\hline$\square$ Not Achieved \\
$\square$ Not Addressed
\end{tabular}

13. Participants would receive personalized technical support with computer technology use in instruction.

Was this an outcome you expected? $\square$ Yes $\square$ No

To what extent was this outcome achieved?

\begin{tabular}{|l}
$\square$ Fully Achieved \\
\hline$\square$ Somewhat Achieved \\
\hline$\square$ Not Achieved \\
\hline$\square$ Not Addressed
\end{tabular}

14. Participation in this workshop would be a positive experience for faculty. Was this an outcome you expected? $\square$ Yes $\square$ No To what extent was this outcome achieved?

\begin{tabular}{|l}
$\square$ Fully Achieved \\
\hline$\square$ Somewhat Achieved \\
\hline$\square$ Not Achieved \\
\hline$\square$ Not Addressed
\end{tabular}

15. Participants' ideas and needs would be addressed within FDI workshops. Was this an outcome you expected? $\square$ Yes $\square$ No To what extent was this outcome achieved?

\begin{tabular}{|l}
$\square$ Fully Achieved \\
\hline$\square$ Somewhat Achieved \\
\hline$\square$ Not Achieved \\
\hline$\square$ Not Addressed
\end{tabular}

16. More classrooms across campus would be equipped with computer technology. Was this an outcome you expected? $\square$ Yes $\square$ No To what extent was this outcome achieved?

\begin{tabular}{|l}
$\square$ Fully Achieved \\
\hline$\square$ Somewhat Achieved \\
\hline$\square$ Not Achieved \\
$\square$ Not Addressed
\end{tabular}

17. Participants would improve their communication with students by learning to use e-mail.

Was this an outcome you expected? $\square$ Yes $\square$ No To what extent was this outcome achieved?

\author{
$\square$ Fully Achieved \\ Somewhat Achieved \\ Not Achieved \\ Not Addressed
}




\section{Long-term outcomes as a result of the FDI initiative}

18. The university would provide students adequate access to computers. Was this an outcome you expected? $\square$ Yes $\square$ No To what extent was this outcome achieved?

\begin{tabular}{l}
$\square$ Fully Achieved \\
\hline$\square$ Somewhat Achieved \\
\hline$\square$ Not Achieved \\
\hline$\square$ Not Addressed
\end{tabular}

19. The university would provide the classroom computer systems needed by faculty to enhance their access to technology. Was this an outcome you expected? $\square$ Yes $\square$ No To what extent was this outcome achieved?

\begin{tabular}{|l}
$\square$ Fully Achieved \\
\hline$\square$ Somewhat Achieved \\
\hline$\square$ Not Achieved \\
\hline$\square$ Not Addressed
\end{tabular}

20. All students would have access to computer technology and know how to use it effectively. Was this an outcome you expected? $\square$ Yes $\square$ No To what extent was this outcome achieved?

\begin{tabular}{|l}
$\square$ Fully Achieved \\
\hline$\square$ Somewhat Achieved \\
\hline$\square$ Not Achieved \\
\hline$\square$ Not Addressed
\end{tabular}

21. Computer literacy requirements would be developed and required of all students across the university.

Was this an outcome you expected? $\square$ Yes $\square$ No

To what extent was this outcome achieved?

\begin{tabular}{|l}
$\square$ Fully Achieved \\
\hline$\square$ Somewhat Achieved \\
\hline$\square$ Not Achieved \\
\hline$\square$ Not Addressed
\end{tabular}

22. Improved undergraduate student education. Was this an outcome you expected? $\square$ Yes $\square$ No To what extent was this outcome achieved?

\begin{tabular}{|l}
$\square$ Fully Achieved \\
\hline$\square$ Somewhat Achieved \\
\hline$\square$ Not Achieved \\
\hline$\square$ Not Addressed
\end{tabular}

23. Curriculum change within disciplines would occur through implementation of formal course development for targeted courses. Was this an outcome you expected? $\square$ Yes $\square$ No To what extent was this outcome achieved?

\begin{tabular}{|l}
$\square$ Fully Achieved \\
\hline$\square$ Somewhat Achieved \\
\hline$\square$ Not Achieved \\
$\square$ Not Addressed
\end{tabular}


24. FDI would become a forum for faculty to re-think their teaching strategies and how they were teaching. Was this an outcome you expected? $\square$ Yes $\square$ No To what extent was this outcome achieved?

\begin{tabular}{|l}
$\square$ Fully Achieved \\
\hline$\square$ Somewhat Achieved \\
\hline$\square$ Not Achieved \\
\hline$\square$ Not Addressed
\end{tabular}

25. All faculty would become technology literate and have access to computer technology.

Was this an outcome you expected? $\square$ Yes $\square$ No To what extent was this outcome achieved?

\begin{tabular}{|l}
$\square$ Fully Achieved \\
\hline$\square$ Somewhat Achieved \\
\hline$\square$ Not Achieved \\
\hline$\square$ Not Addressed
\end{tabular}

26. Faculty could develop new ways to use technology to help students learn. Was this an outcome you expected? $\square$ Yes $\square$ No To what extent was this outcome achieved?

\begin{tabular}{|l}
$\square$ Fully Achieved \\
\hline$\square$ Somewhat Achieved \\
\hline$\square$ Not Achieved \\
\hline$\square$ Not Addressed
\end{tabular}

27. Faculty would be provided with an opportunity to explore new approaches to instruction.

Was this an outcome you expected? $\square$ Yes $\square$ No To what extent was this outcome achieved?

\begin{tabular}{l}
$\square$ Fully Achieved \\
\hline$\square$ Somewhat Achieved \\
\hline$\square$ Not Achieved \\
$\square$ Not Addressed
\end{tabular}

28. Faculty would transition smoothly from the mainframe environment to personal computing environment.

Was this an outcome you expected? $\square$ Yes $\square$ No

To what extent was this outcome achieved?

\begin{tabular}{|l}
$\square$ Fully Achieved \\
\hline$\square$ Somewhat Achieved \\
\hline$\square$ Not Achieved \\
\hline$\square$ Not Addressed
\end{tabular}

29. The mainframe computing system would be replaced with a distributive, personal computing environment. Was this an outcome you expected? $\square$ Yes $\square$ No To what extent was this outcome achieved?

\begin{tabular}{l}
$\square$ Fully Achieved \\
\hline$\square$ Somewhat Achieved \\
$\square$ Not Achieved \\
\hline$\square$ Not Addressed
\end{tabular}


30. A majority of faculty would use the computer technology in the classroom as a supplement to their teaching.

Was this an outcome you expected? $\square$ Yes $\square$ No

To what extent was this outcome achieved?

\begin{tabular}{|l}
$\square$ Fully Achieved \\
\hline$\square$ Somewhat Achieved \\
\hline$\square$ Not Achieved \\
\hline$\square$ Not Addressed
\end{tabular}

31. All faculty would develop higher levels of computer literacy and skills. Was this an outcome you expected? $\square$ Yes $\square$ No To what extent was this outcome achieved?

\begin{tabular}{|l}
$\square$ Fully Achieved \\
\hline$\square$ Somewhat Achieved \\
\hline$\square$ Not Achieved \\
\hline$\square$ Not Addressed
\end{tabular}

32. The Virginia Tech computer technology infrastructure would become leading edge technology.

Was this an outcome you expected? $\square$ Yes $\square$ No

To what extent was this outcome achieved?

\begin{tabular}{l}
$\square$ Fully Achieved \\
\hline$\square$ Somewhat Achieved \\
\hline$\square$ Not Achieved \\
\hline$\square$ Not Addressed
\end{tabular}

33. The number of courses taught online and using distance learning technology would increase. Was this an outcome you expected? $\square$ Yes $\square$ No To what extent was this outcome achieved?

\begin{tabular}{|l}
$\square$ Fully Achieved \\
\hline$\square$ Somewhat Achieved \\
\hline$\square$ Not Achieved \\
$\square$ Not Addressed
\end{tabular}

34. Enhanced instructional, research, administrative and outreach computing resources would be made available to faculty. Was this an outcome you expected? $\square$ Yes $\square$ No To what extent was this outcome achieved?

\begin{tabular}{|l}
\hline Fully Achieved \\
\hline$\square$ Somewhat Achieved \\
\hline$\square$ Not Achieved \\
\hline$\square$ Not Addressed
\end{tabular}

35. An increased number of students would be served while maintaining the quality of instruction and costs.

Was this an outcome you expected? $\square$ Yes $\square$ No To what extent was this outcome achieved?

\begin{tabular}{|l}
$\square$ Fully Achieved \\
\hline$\square$ Somewhat Achieved \\
\hline$\square$ Not Achieved \\
\hline$\square$ Not Addressed
\end{tabular}


36. Virginia Tech would become a national leader in the use and integration of computer technology in teaching and research.

Was this an outcome you expected? $\square$ Yes $\square$ No

To what extent was this outcome achieved?

\begin{tabular}{|l}
$\square$ Fully Achieved \\
\hline$\square$ Somewhat Achieved \\
\hline$\square$ Not Achieved \\
\hline$\square$ Not Addressed
\end{tabular}

37. Students would develop higher levels of computer literacy and skills. Was this an outcome you expected? $\square$ Yes $\square$ No To what extent was this outcome achieved? $\square$ Fully Achieved $\square$ Somewhat Achieved $\square$ Not Achieved $\square$ Not Addressed

38. The quality of interaction among students and faculty would improve. Was this an outcome you expected? $\square$ Yes $\square$ No To what extent was this outcome achieved?

\begin{tabular}{|l}
$\square$ Fully Achieved \\
\hline$\square$ Somewhat Achieved \\
\hline$\square$ Not Achieved \\
\hline$\square$ Not Addressed
\end{tabular}

39. The emphasis on active and independent learning strategies, problem solving and collaboration would increase. Was this an outcome you expected? $\square$ Yes $\square$ No To what extent was this outcome achieved?

\begin{tabular}{|l}
$\square$ Fully Achieved \\
\hline$\square$ Somewhat Achieved \\
\hline$\square$ Not Achieved \\
\hline$\square$ Not Addressed
\end{tabular}

40. The use of class contact hours as a determinate of credit hours would decrease. Was this an outcome you expected? $\square$ Yes $\square$ No To what extent was this outcome achieved?

\begin{tabular}{|l}
$\square$ Fully Achieved \\
\hline$\square$ Somewhat Achieved \\
\hline$\square$ Not Achieved \\
\hline$\square$ Not Addressed
\end{tabular}

41. Use of computer technology in instruction would become an important factor in promotion, tenure and salary evaluations. Was this an outcome you expected? $\square$ Yes $\square$ No To what extent was this outcome achieved?

$\square$ Fully Achieved
$\square$ Somewhat Achieved
$\square$ Not Achieved
$\square$ Not Addressed


$\underline{\text { Appendix G: Research Model }}$

Source Material

Phase I

Interviews \& Historical Documents

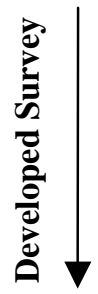

Phase II

Administered Survey to Developers and Initial Participants

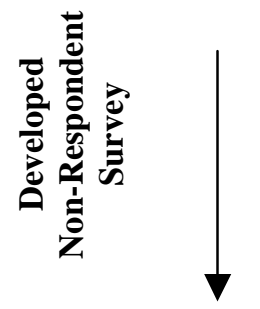

Phase III

Administered Non-Respondent Survey to Initial Participants via Telephone $\underline{\text { Study Participants }}$
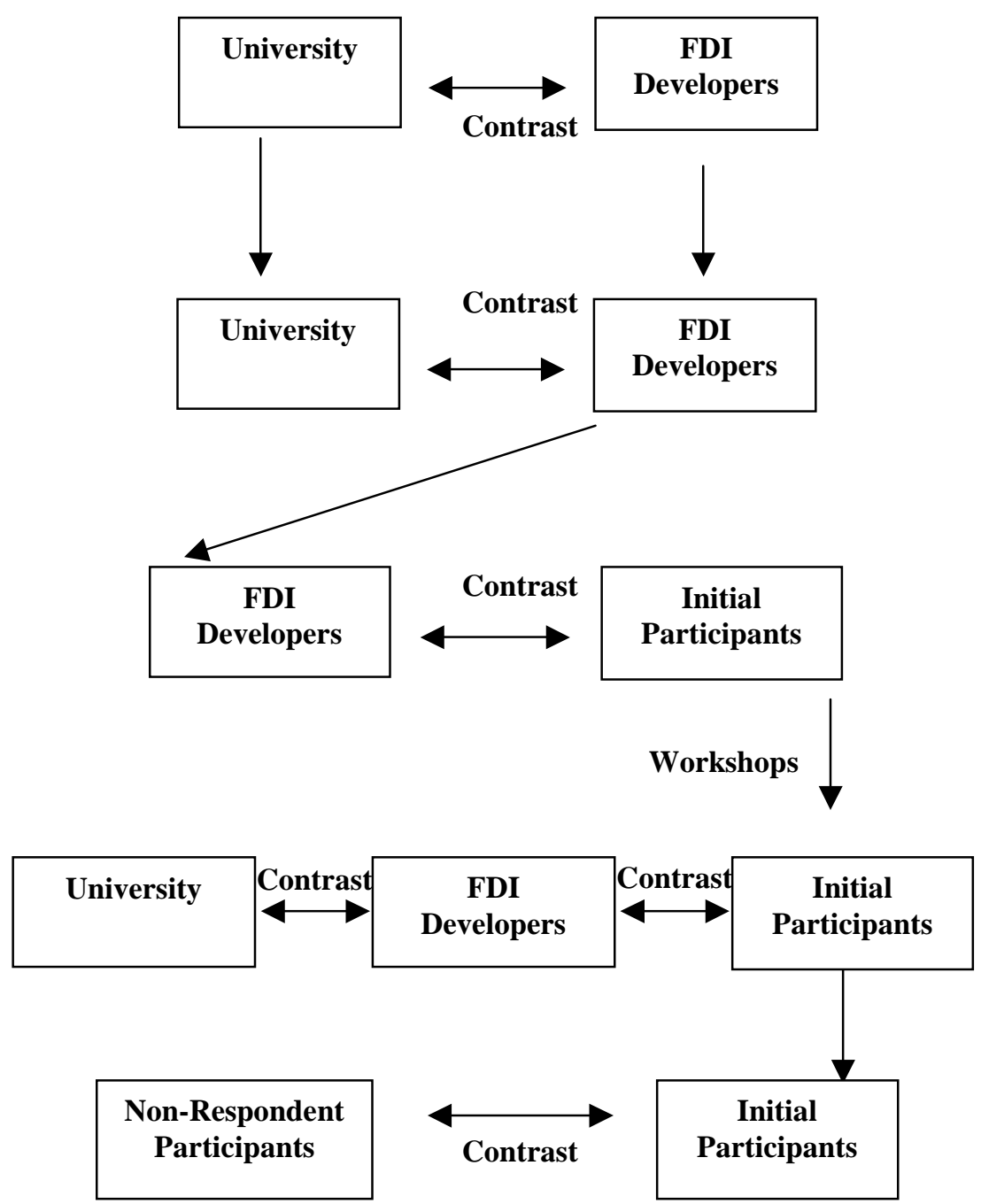

\section{Content Desired}

Expectations

Goals

Expectations

Perceived Outcomes

Expectations/ Perceived Outcomes 


\section{Appendix H: Developer Frequency Table:}

Developers' Expectations and Extent Achieved Frequency Table

\begin{tabular}{|c|c|c|c|c|c|c|c|c|}
\hline \multicolumn{9}{|c|}{ Outcomes during and/or immediately following initial FDI workshop } \\
\hline \multirow{2}{*}{ Outcomes } & \multicolumn{3}{|c|}{ Expectation \% } & \multicolumn{5}{|c|}{ Extent Achieved \% } \\
\hline & $\mathrm{n}=$ & Yes & No & $\mathbf{n}=$ & $\begin{array}{c}\text { Fully } \\
\text { Achieved }\end{array}$ & $\begin{array}{c}\text { Somewhat } \\
\text { Achieved }\end{array}$ & $\begin{array}{c}\text { Not } \\
\text { Achieved }\end{array}$ & Not Addressed \\
\hline $\begin{array}{l}\text { 1. All participating faculty } \\
\text { would have desktop } \\
\text { computers installed in their } \\
\text { offices with necessary } \\
\text { hardware and software } \\
\text { available. }\end{array}$ & 5 & 100 & & 5 & 100 & & & \\
\hline $\begin{array}{l}\text { 2.Collaborative } \\
\text { communication regarding } \\
\text { teaching strategies would be } \\
\text { encouraged and facilitated } \\
\text { during the workshop among } \\
\text { participating faculty. }\end{array}$ & 5 & 80 & 20 & 5 & 20 & 80 & & \\
\hline $\begin{array}{l}\text { 3. Participants would receive } \\
\text { specific training in how to use } \\
\text { computers more effectively in } \\
\text { their teaching role. }\end{array}$ & 5 & 100 & & 5 & 60 & 40 & & \\
\hline $\begin{array}{l}\text { 4. Participants would acquire } \\
\text { an enhanced understanding of } \\
\text { administrative classroom uses } \\
\text { of computers. }\end{array}$ & 5 & 80 & 20 & 4 & & 100 & & \\
\hline
\end{tabular}




\begin{tabular}{|c|c|c|c|c|c|c|c|c|}
\hline $\begin{array}{l}\text { 5. FDI would enhance } \\
\text { participants' knowledge and } \\
\text { skills to interact with students } \\
\text { outside the classroom using } \\
\text { computer technology. }\end{array}$ & 5 & 100 & & 5 & 40 & 60 & & \\
\hline $\begin{array}{l}\text { 6. Participants would acquire } \\
\text { the knowledge and skills } \\
\text { necessary to integrate } \\
\text { computer technology into their } \\
\text { instruction. }\end{array}$ & 5 & 100 & & 5 & 40 & 60 & & \\
\hline $\begin{array}{l}\text { 7. Participants would be } \\
\text { encouraged and motivated to } \\
\text { re-think how they were } \\
\text { teaching. }\end{array}$ & 5 & 100 & & 5 & & 100 & & \\
\hline $\begin{array}{l}\text { 8. Participants would enhance } \\
\text { their computer skills to make } \\
\text { their work with students more } \\
\text { efficient and effective. }\end{array}$ & 5 & 100 & & 5 & & 100 & & \\
\hline $\begin{array}{l}\text { 9. Faculty would become more } \\
\text { productive in their jobs as a } \\
\text { result of computer technology } \\
\text { skills learned in the workshop. }\end{array}$ & 5 & 80 & 20 & 5 & & 80 & & 20 \\
\hline $\begin{array}{l}\text { 10. The computer technology } \\
\text { workshop would help } \\
\text { participants become more } \\
\text { effective in their teaching role. }\end{array}$ & 5 & 100 & & 5 & 20 & 80 & & \\
\hline $\begin{array}{l}\text { 11. Following the workshop, } \\
\text { participants would receive } \\
\text { support with course } \\
\text { development techniques. }\end{array}$ & 5 & 80 & 20 & 5 & 20 & 60 & & 20 \\
\hline $\begin{array}{l}\text { 12. Students would become } \\
\text { more active in, and take more } \\
\text { responsibility for, their own } \\
\text { learning as a result of } \\
\text { participants using computer } \\
\text { technology skills to provide } \\
\text { information to them inside and } \\
\text { outside the classroom. }\end{array}$ & 5 & 80 & 20 & 5 & & 80 & 20 & \\
\hline
\end{tabular}




\begin{tabular}{|c|c|c|c|c|c|c|c|c|}
\hline $\begin{array}{l}\text { 13. Participants would receive } \\
\text { personalized technical } \\
\text { support with computer } \\
\text { technology use in instruction. }\end{array}$ & 5 & 60 & 40 & 4 & 25 & 75 & & \\
\hline $\begin{array}{l}\text { 14. Participation in this } \\
\text { workshop would be a positive } \\
\text { experience for faculty. }\end{array}$ & 5 & 100 & & 5 & 80 & 20 & & \\
\hline $\begin{array}{l}\text { 15. Participants' ideas and } \\
\text { needs would be addressed } \\
\text { within FDI workshops. }\end{array}$ & 5 & 100 & & 5 & 40 & 60 & & \\
\hline $\begin{array}{l}\text { 16. More classrooms across } \\
\text { campus would be equipped } \\
\text { with computer technology. }\end{array}$ & 5 & 60 & 40 & 4 & 50 & 25 & 25 & \\
\hline $\begin{array}{l}\text { 17. Participants would } \\
\text { improve their communication } \\
\text { with students by learning to } \\
\text { use e-mail. }\end{array}$ & 5 & 100 & & 5 & 80 & 20 & & \\
\hline \multicolumn{9}{|c|}{ Long term outcomes as a result of the FDI initiative } \\
\hline $\begin{array}{l}\text { 18. The university would } \\
\text { provide students adequate } \\
\text { access to computers. }\end{array}$ & 5 & 80 & 20 & 5 & 60 & 20 & 20 & \\
\hline $\begin{array}{l}\text { 19. The university would } \\
\text { provide the classroom } \\
\text { computer systems needed by } \\
\text { faculty to enhance their } \\
\text { access to technology. }\end{array}$ & 5 & 60 & 40 & 4 & & 75 & & 25 \\
\hline $\begin{array}{l}\text { 20. All students would have } \\
\text { access to computer } \\
\text { technology and know how to } \\
\text { use it effectively. }\end{array}$ & 5 & 80 & 20 & 5 & 40 & 40 & & 20 \\
\hline $\begin{array}{l}\text { 21. Computer literacy } \\
\text { requirements would be } \\
\text { developed and required of all } \\
\text { students across the } \\
\text { university. }\end{array}$ & 5 & 20 & 80 & 4 & & 75 & & 25 \\
\hline
\end{tabular}




\begin{tabular}{|c|c|c|c|c|c|c|c|}
\hline $\begin{array}{l}\text { 22. Improved undergraduate } \\
\text { student education. }\end{array}$ & 5 & 100 & & 5 & & 100 & \\
\hline $\begin{array}{l}\text { 23. Curriculum change within } \\
\text { disciplines would occur } \\
\text { through implementation of } \\
\text { formal course development for } \\
\text { targeted courses. }\end{array}$ & 5 & 100 & & 5 & 20 & 80 & \\
\hline $\begin{array}{l}\text { 24. FDI would become a forum } \\
\text { for faculty to re-think their } \\
\text { teaching strategies and how } \\
\text { they were teaching. }\end{array}$ & 5 & 100 & & 5 & 20 & 80 & \\
\hline $\begin{array}{l}\text { 25. All faculty would become } \\
\text { technology literate and have } \\
\text { access to computer } \\
\text { technology. }\end{array}$ & 5 & 80 & 20 & 5 & 60 & 40 & \\
\hline $\begin{array}{l}\text { 26. Faculty could develop new } \\
\text { ways to use technology to } \\
\text { help students learn. }\end{array}$ & 5 & 100 & & 5 & & 100 & \\
\hline $\begin{array}{l}\text { 27. Faculty would be provided } \\
\text { with an opportunity to explore } \\
\text { new approaches to } \\
\text { instruction. }\end{array}$ & 5 & 100 & & 5 & 40 & 60 & \\
\hline $\begin{array}{l}\text { 28. Faculty would transition } \\
\text { smoothly from the mainframe } \\
\text { environment to personal } \\
\text { computing environment. }\end{array}$ & 5 & 60 & 40 & 4 & 50 & 25 & 25 \\
\hline $\begin{array}{l}\text { 29. The mainframe computing } \\
\text { system would be replaced } \\
\text { with a distributive, personal } \\
\text { computing environment. }\end{array}$ & 5 & 80 & 20 & 5 & 40 & 40 & 20 \\
\hline $\begin{array}{l}\text { 30. A majority of faculty would } \\
\text { use the computer technology } \\
\text { in the classroom as a } \\
\text { supplement to their teaching. }\end{array}$ & 5 & 60 & 40 & 3 & 33.3 & 66.7 & \\
\hline $\begin{array}{l}\text { 31. All faculty would develop } \\
\text { higher levels of computer } \\
\text { literacy and skills. }\end{array}$ & 5 & 100 & & 5 & 80 & 20 & \\
\hline
\end{tabular}




\begin{tabular}{|c|c|c|c|c|c|c|c|c|}
\hline $\begin{array}{l}\text { 32. The Virginia Tech } \\
\text { computer technology } \\
\text { infrastructure would become } \\
\text { leading edge technology. }\end{array}$ & 5 & 60 & 40 & 4 & 25 & 75 & & \\
\hline $\begin{array}{l}\text { 33. The number of courses } \\
\text { taught online and using } \\
\text { distance-learning technology } \\
\text { would increase. }\end{array}$ & 5 & 80 & 20 & 5 & 40 & 60 & & \\
\hline $\begin{array}{l}\text { 34. Enhanced instructional, } \\
\text { research, administrative and } \\
\text { outreach computing resources } \\
\text { would be made available to } \\
\text { faculty. }\end{array}$ & 5 & 40 & 60 & 4 & 25 & 25 & & 50 \\
\hline $\begin{array}{l}35 \text { An increased number of } \\
\text { students would be served } \\
\text { while maintaining the quality } \\
\text { of instruction and costs. }\end{array}$ & 5 & 80 & 20 & 4 & 25 & 75 & & \\
\hline $\begin{array}{l}\text { 36. Virginia Tech would } \\
\text { become a national leader in } \\
\text { the use and integration of } \\
\text { computer technology in } \\
\text { teaching and research. }\end{array}$ & 5 & 100 & & 5 & 60 & 20 & 20 & \\
\hline $\begin{array}{l}\text { 37. Students would develop } \\
\text { higher levels of computer } \\
\text { literacy and skills. }\end{array}$ & 5 & 60 & 40 & 4 & 50 & 25 & & 25 \\
\hline $\begin{array}{l}\text { 38. The quality of interaction } \\
\text { among students and faculty } \\
\text { would improve. }\end{array}$ & 5 & 100 & & 5 & 20 & 80 & & \\
\hline $\begin{array}{l}\text { 39. The emphasis on active } \\
\text { and independent learning } \\
\text { strategies, problem solving } \\
\text { and collaboration would } \\
\text { increase. }\end{array}$ & 5 & 80 & 20 & 4 & 25 & 75 & & \\
\hline $\begin{array}{l}\text { 40. The use of class contact } \\
\text { hours as a determinate of } \\
\text { credit hours would decrease. }\end{array}$ & 5 & 60 & 40 & 4 & & 100 & & \\
\hline
\end{tabular}


41. Use of computer technology in instruction

would become an important

factor in promotion, tenure

\begin{tabular}{|l|l|l|l|}
\hline 5 & 0 & 100 & 4 \\
\hline
\end{tabular}


Appendix I: Initial Participant Frequency Table

Initial Participants' Expectation and Extent Achieved Frequency Table

\begin{tabular}{|c|c|c|c|c|c|c|c|c|}
\hline \multicolumn{9}{|c|}{ Outcomes during and/or immediately following initial FDI workshop } \\
\hline \multirow{2}{*}{ Outcomes } & \multicolumn{3}{|c|}{ Expectation \% } & \multicolumn{5}{|c|}{ Extent Achieved \% } \\
\hline & $\mathrm{n}=$ & Yes & No & $\mathbf{n}=$ & $\begin{array}{c}\text { Fully } \\
\text { Achieved }\end{array}$ & $\begin{array}{c}\text { Somewhat } \\
\text { Achieved }\end{array}$ & $\begin{array}{c}\text { Not } \\
\text { Achieved }\end{array}$ & Not Addressed \\
\hline $\begin{array}{l}\text { 1. I would earn a state of the } \\
\text { art desktop computer, } \\
\text { installed in my office, with } \\
\text { necessary hardware and } \\
\text { software to incorporate } \\
\text { computer technology in my } \\
\text { teaching. }\end{array}$ & 28 & 96.4 & 3.6 & 28 & 92.9 & 7.1 & & \\
\hline $\begin{array}{l}\text { 2.Collaborative } \\
\text { communication regarding } \\
\text { teaching strategies would be } \\
\text { encouraged and facilitated } \\
\text { during the workshop among } \\
\text { participating faculty. }\end{array}$ & 28 & 78.6 & 21.4 & 28 & 32.1 & 60.7 & & 7.1 \\
\hline $\begin{array}{l}\text { 3. I would receive specific } \\
\text { training in how to use } \\
\text { computers more effectively in } \\
\text { my teaching role. }\end{array}$ & 28 & 100 & & 28 & 42.9 & 53.6 & 3.6 & \\
\hline
\end{tabular}




\begin{tabular}{|c|c|c|c|c|c|c|c|c|}
\hline $\begin{array}{l}\text { 4. I would acquire an } \\
\text { enhanced understanding of } \\
\text { administrative classroom uses } \\
\text { of computers. }\end{array}$ & 28 & 53.6 & 46.4 & 28 & 21.4 & 39.3 & 14.3 & 25 \\
\hline $\begin{array}{l}\text { 5. I would enhance my } \\
\text { knowledge and skills to } \\
\text { interact with students outside } \\
\text { the classroom using computer } \\
\text { technology. }\end{array}$ & 28 & 75 & 25 & 28 & 42.9 & 39.3 & 7.1 & 10.7 \\
\hline $\begin{array}{l}\text { 6. I would enhance the } \\
\text { knowledge and skills } \\
\text { necessary to integrate } \\
\text { computer technology into my } \\
\text { instruction. }\end{array}$ & 28 & 96.4 & 3.6 & 28 & 35.7 & 50 & 10.7 & 3.6 \\
\hline $\begin{array}{l}\text { 7. I would be encouraged and } \\
\text { motivated to re-think how I } \\
\text { was teaching. }\end{array}$ & 28 & 75 & 25 & 28 & 35.7 & 53.6 & 7.1 & 3.6 \\
\hline $\begin{array}{l}\text { 8. I would enhance my } \\
\text { computer skills to make my } \\
\text { work with students more } \\
\text { efficient and effective. }\end{array}$ & 28 & 78.6 & 21.4 & 28 & 21.4 & 50 & 21.4 & 7.1 \\
\hline $\begin{array}{l}\text { 9. I would become more } \\
\text { productive in my job as a } \\
\text { result of computer technology } \\
\text { skills learned in the workshop. }\end{array}$ & 28 & 60.7 & 39.3 & 28 & 14.3 & 57.1 & 25 & 3.6 \\
\hline $\begin{array}{l}\text { 10. The computer technology } \\
\text { workshop would help me } \\
\text { become more effective in my } \\
\text { teaching role. }\end{array}$ & 28 & 82.1 & 17.9 & 28 & 21.4 & 64.3 & 10.7 & 3.6 \\
\hline $\begin{array}{l}\text { 11. Following the workshop, I } \\
\text { would receive support with } \\
\text { course development } \\
\text { techniques. }\end{array}$ & 28 & 78.6 & 21.4 & 28 & 32.1 & 42.9 & 17.9 & 7.1 \\
\hline
\end{tabular}




\begin{tabular}{|c|c|c|c|c|c|c|c|c|}
\hline $\begin{array}{l}\text { 12. Students would become } \\
\text { more active in, and take more } \\
\text { responsibility for, their own } \\
\text { learning as a result of my } \\
\text { using computer technology } \\
\text { skills to provide information to } \\
\text { them inside and outside the } \\
\text { classroom. }\end{array}$ & 28 & 42.9 & 57.1 & 27 & 7.4 & 48.1 & 33.3 & 11.1 \\
\hline $\begin{array}{l}\text { 13. I would receive } \\
\text { personalized technical } \\
\text { support with computer } \\
\text { technology use in instruction. }\end{array}$ & 28 & 64.3 & 35.7 & 28 & 28.6 & 42.9 & 14.3 & 14.3 \\
\hline $\begin{array}{l}\text { 14. Participating in this } \\
\text { workshop would be a positive } \\
\text { experience for me. }\end{array}$ & 27 & 96.3 & 3.7 & 27 & 63 & 37 & & \\
\hline $\begin{array}{l}\text { 15. My ideas and needs would } \\
\text { be addressed within FDI } \\
\text { workshops. }\end{array}$ & 28 & 75 & 25 & 28 & 32.1 & 50 & 7.1 & 10.7 \\
\hline $\begin{array}{l}\text { 16. More classrooms across } \\
\text { campus would be equipped } \\
\text { with computer technology. }\end{array}$ & 28 & 82.1 & 17.9 & 28 & 17.9 & 67.9 & 10.7 & 3.6 \\
\hline $\begin{array}{l}\text { 17. I would improve my } \\
\text { communication with students } \\
\text { by learning to use e-mail. }\end{array}$ & 28 & 57.1 & 42.9 & 26 & 65.4 & 15.4 & 11.5 & 7.7 \\
\hline \multicolumn{9}{|c|}{ Long term outcomes as a result of the FDI initiative } \\
\hline $\begin{array}{l}\text { 19. The university would } \\
\text { provide students adequate } \\
\text { access to computers. }\end{array}$ & 28 & 75 & 25 & 28 & 42.9 & 46.4 & 7.1 & 3.6 \\
\hline $\begin{array}{l}\text { 20. The university would } \\
\text { provide the classroom } \\
\text { computer systems needed by } \\
\text { faculty to enhance their } \\
\text { access to technology. }\end{array}$ & 28 & 85.7 & 14.3 & 28 & 21.4 & 60.7 & 17.9 & \\
\hline
\end{tabular}




\begin{tabular}{|c|c|c|c|c|c|c|c|c|}
\hline $\begin{array}{l}\text { 21. All students would have } \\
\text { access to computer } \\
\text { technology and know how to } \\
\text { use it effectively. }\end{array}$ & 28 & 67.9 & 32.1 & 27 & 22.2 & 66.7 & 7.4 & 3.7 \\
\hline $\begin{array}{l}\text { 22. Computer literacy } \\
\text { requirements would be } \\
\text { developed and required of all } \\
\text { students across the } \\
\text { university. }\end{array}$ & 28 & 50 & 50 & 25 & 24 & 52 & 16 & 8 \\
\hline $\begin{array}{l}\text { 23. Improved undergraduate } \\
\text { student education. }\end{array}$ & 28 & 57.1 & 42.9 & 26 & 7.7 & 69.2 & 19.2 & 3.8 \\
\hline $\begin{array}{l}\text { 24. Curriculum change within } \\
\text { disciplines would occur } \\
\text { through implementation of } \\
\text { formal course development for } \\
\text { targeted courses. }\end{array}$ & 27 & 51.9 & 48.1 & 26 & 7.7 & 57.7 & 19.2 & 15.4 \\
\hline $\begin{array}{l}\text { 25. FDI would become a forum } \\
\text { for faculty to re-think their } \\
\text { teaching strategies and how } \\
\text { they were teaching. }\end{array}$ & 28 & 64.3 & 35.7 & 28 & 17.9 & 64.3 & 14.3 & 3.6 \\
\hline $\begin{array}{l}\text { 26. All faculty would become } \\
\text { technology literate and have } \\
\text { access to computer } \\
\text { technology. }\end{array}$ & 28 & 60.7 & 39.3 & 26 & 19.2 & 65.4 & 15.4 & \\
\hline $\begin{array}{l}\text { 27. Faculty could develop new } \\
\text { ways to use technology to } \\
\text { help students learn. }\end{array}$ & 28 & 92.9 & 7.1 & 28 & 21.4 & 71.4 & 7.1 & \\
\hline $\begin{array}{l}\text { 28. Faculty would be provided } \\
\text { with an opportunity to explore } \\
\text { new approaches to } \\
\text { instruction. }\end{array}$ & 28 & 92.9 & 7.1 & 28 & 42.9 & 46.4 & 7.1 & 3.6 \\
\hline $\begin{array}{l}\text { 29. Faculty would transition } \\
\text { smoothly from the mainframe } \\
\text { environment to personal } \\
\text { computing environment. }\end{array}$ & 28 & 39.3 & 60.7 & 26 & 50 & 50 & & \\
\hline
\end{tabular}




\begin{tabular}{|c|c|c|c|c|c|c|c|c|}
\hline $\begin{array}{l}\text { 30. The mainframe computing } \\
\text { system would be replaced } \\
\text { with a distributive, personal } \\
\text { computing environment. }\end{array}$ & 28 & 71.4 & 28.6 & 26 & 84.6 & 11.5 & & 3.8 \\
\hline $\begin{array}{l}\text { 31. A majority of faculty would } \\
\text { use the computer technology } \\
\text { in the classroom as a } \\
\text { supplement to their teaching. }\end{array}$ & 28 & 32.1 & 67.9 & 26 & 15.4 & 46.2 & 30.8 & 7.7 \\
\hline $\begin{array}{l}\text { 32. All faculty would develop } \\
\text { higher levels of computer } \\
\text { literacy and skills. }\end{array}$ & 28 & 75 & 25 & 28 & 32.1 & 53.6 & 10.7 & 3.6 \\
\hline $\begin{array}{l}\text { 33. The Virginia Tech } \\
\text { computer technology } \\
\text { infrastructure would become } \\
\text { leading edge technology. }\end{array}$ & 28 & 50 & 50 & 24 & 41.7 & 41.7 & 4.2 & 12.5 \\
\hline $\begin{array}{l}\text { 34. The number of courses } \\
\text { taught online and using } \\
\text { distance-learning technology } \\
\text { would increase. }\end{array}$ & 28 & 64.3 & 35.7 & 27 & 29.6 & 63 & & 7.4 \\
\hline $\begin{array}{l}\text { 35. Enhanced instructional, } \\
\text { research, administrative and } \\
\text { outreach computing resources } \\
\text { would be made available to } \\
\text { faculty. }\end{array}$ & 28 & 85.7 & 14.3 & 28 & 39.3 & 53.6 & 3.6 & 3.6 \\
\hline $\begin{array}{l}36 . \text { An increased number of } \\
\text { students would be served } \\
\text { while maintaining the quality } \\
\text { of instruction and costs. }\end{array}$ & 28 & 14.3 & 85.7 & 25 & 4 & 40 & 48 & 8 \\
\hline $\begin{array}{l}37 . \text { Virginia Tech would } \\
\text { become a national leader in } \\
\text { the use and integration of } \\
\text { computer technology in } \\
\text { teaching and research. }\end{array}$ & 28 & 50 & 50 & 27 & 29.6 & 55.6 & 7.4 & 7.4 \\
\hline $\begin{array}{l}\text { 38. Students would develop } \\
\text { higher levels of computer } \\
\text { literacy and skills. }\end{array}$ & 28 & 78.6 & 21.4 & 27 & 44.4 & 51.9 & & 3.7 \\
\hline
\end{tabular}




\begin{tabular}{|c|c|c|c|c|c|c|c|c|}
\hline $\begin{array}{l}\text { 39. The quality of interaction } \\
\text { among students and faculty } \\
\text { would improve. }\end{array}$ & 28 & 42.9 & 57.1 & 27 & 22.2 & 40.7 & 29.6 & 7.4 \\
\hline $\begin{array}{l}\text { 40. The emphasis on active } \\
\text { and independent learning } \\
\text { strategies, problem solving } \\
\text { and collaboration would } \\
\text { increase. }\end{array}$ & 28 & 64.3 & 35.7 & 28 & & 61.5 & 38.5 & \\
\hline $\begin{array}{l}\text { 41. The use of class contact } \\
\text { hours as a determinate of } \\
\text { credit hours would decrease. }\end{array}$ & 28 & 14.3 & 85.7 & 24 & 8.3 & 41.7 & 37.5 & 12.5 \\
\hline $\begin{array}{l}\text { 42. Use of computer } \\
\text { technology in instruction } \\
\text { would become an important } \\
\text { factor in promotion, tenure } \\
\text { and salary evaluations. }\end{array}$ & 28 & 10.7 & 89.3 & 25 & 8 & 24 & 48 & 20 \\
\hline
\end{tabular}




\section{Appendix J: Non-respondent Frequency Table}

Non-Respondents' Expectation and Extent Achieved Frequency Table

\begin{tabular}{|c|c|c|c|c|c|c|c|c|}
\hline \multicolumn{9}{|c|}{ Outcomes during and/or immediately following initial FDI workshop } \\
\hline \multirow{2}{*}{ Outcomes } & \multicolumn{3}{|c|}{ Expectation \% } & \multicolumn{5}{|c|}{ Extent Achieved \% } \\
\hline & $\mathrm{n}=$ & Yes & No & $\mathbf{n}=$ & $\begin{array}{c}\text { Fully } \\
\text { Achieved }\end{array}$ & $\begin{array}{c}\text { Somewhat } \\
\text { Achieved }\end{array}$ & $\begin{array}{c}\text { Not } \\
\text { Achieved }\end{array}$ & Not Addressed \\
\hline $\begin{array}{l}\text { 3. I would receive specific } \\
\text { training in how to use } \\
\text { computers more effectively in } \\
\text { my teaching role. }\end{array}$ & 5 & 100 & & 5 & 60 & 20 & 20 & \\
\hline $\begin{array}{l}\text { 11. Following the workshop, I } \\
\text { would receive support with } \\
\text { course development } \\
\text { techniques. }\end{array}$ & 5 & 40 & 60 & 5 & 40 & 20 & 40 & \\
\hline $\begin{array}{l}\text { 14. Participating in this } \\
\text { workshop would be a positive } \\
\text { experience for me. }\end{array}$ & 5 & 80 & 20 & 5 & 80 & 20 & & \\
\hline \multicolumn{9}{|c|}{ Long term outcomes as a result of the FDI initiative } \\
\hline $\begin{array}{l}\text { 23. Improved undergraduate } \\
\text { student education. }\end{array}$ & 5 & 80 & 20 & 5 & 40 & 20 & 40 & \\
\hline $\begin{array}{l}\text { 32. All faculty would develop } \\
\text { higher levels of computer } \\
\text { literacy and skills. }\end{array}$ & 5 & 100 & & 5 & 60 & 40 & & \\
\hline
\end{tabular}




\begin{tabular}{|c|c|c|c|c|c|c|c|c|}
\hline \multirow[t]{2}{*}{ Outcomes } & \multicolumn{3}{|c|}{ Expectation \% } & \multicolumn{5}{|c|}{ Extent Achieved \% } \\
\hline & $\mathbf{n}=$ & Yes & No & $\mathrm{n}=$ & $\begin{array}{c}\text { Fully } \\
\text { Achieved }\end{array}$ & $\begin{array}{c}\text { Somewhat } \\
\text { Achieved }\end{array}$ & $\begin{array}{c}\text { Not } \\
\text { Achieved }\end{array}$ & Not Addressed \\
\hline $\begin{array}{l}\text { 37. Virginia Tech would } \\
\text { become a national leader in } \\
\text { the use and integration of } \\
\text { computer technology in } \\
\text { teaching and research. }\end{array}$ & 5 & 60 & 40 & 4 & 50 & 50 & & \\
\hline $\begin{array}{l}\text { 41. The use of class contact } \\
\text { hours as a determinate of } \\
\text { credit hours would decrease. }\end{array}$ & 5 & 40 & 60 & 5 & 20 & 40 & 40 & \\
\hline $\begin{array}{l}\text { 42. Use of computer } \\
\text { technology in instruction } \\
\text { would become an important } \\
\text { factor in promotion, tenure } \\
\text { and salary evaluations. }\end{array}$ & 5 & 40 & 60 & 5 & 40 & 40 & 20 & \\
\hline
\end{tabular}




\section{Appendix K: Non-respondent Survey}

Hello my name is ....

I am calling in reference to a survey that I sent you recently regarding your expectations for the initial FDI and whether they were met. I am conducting a short survey of nonrespondents to determine if their views differ from those of respondents. Do you have time to answer just eight questions now or is there another time that is more convenient?

Note: If at any point they indicate that they responded to the original survey, make a note of their name. Then say:

I appreciate you responding to the original request, thank you for your time and assistance.

\section{Outcomes during and/or immediately following initial FDI workshop}

1. I would receive specific training in how to use computers in my teaching role. Was this an outcome you expected? $\square$ Yes $\square$ No To what extent was this outcome achieved? $\square$ Fully Achieved $\square$ Somewhat Achieved $\square$ Not Achieved $\square$ Not Addressed

2. Following the workshop, I would receive support with course development techniques.

Was this an outcome you expected? $\square$ Yes $\square$ No To what extent was this outcome achieved?

\begin{tabular}{l}
$\square$ Fully Achieved \\
\hline$\square$ Somewhat Achieved \\
\hline$\square$ Not Achieved \\
\hline$\square$ Not Addressed
\end{tabular}

3. Participating in this workshop would be a positive experience for me. Was this an outcome you expected? $\square$ Yes $\square$ No To what extent was this outcome achieved?

\begin{tabular}{l}
$\square$ Fully Achieved \\
\hline$\square$ Somewhat Achieved \\
\hline$\square$ Not Achieved \\
$\square$ Not Addressed
\end{tabular}




\section{Long-term outcomes as a result of initial FDI workshop}

1. Improved undergraduate student education. Was this an outcome you expected? $\square$ Yes $\square$ No To what extent was this outcome achieved?

\section{$\square$ Fully Achieved Somewhat Achieved Not Achieved Not Addressed}

2. All faculty would develop higher levels of computer literacy and skills. Was this an outcome you expected? $\square$ Yes $\square$ No To what extent was this outcome achieved?

\begin{tabular}{|l|}
\hline Fully Achieved \\
\hline$\square$ Somewhat Achieved \\
\hline$\square$ Not Achieved \\
\hline$\square$ Not Addressed
\end{tabular}

3. Virginia Tech would become more competitive nationally in the use and integration of computer technology in teaching and research across the entire institution as a result of the FDI initiative.

Was this an outcome you expected? $\square$ Yes $\square$ No

To what extent was this outcome achieved?

\section{$\square$ Fully Achieved Somewhat Achieved Not Achieved Not Addressed}

4. The use of class contact hours as a determinate of credit hours would decrease. Was this an outcome you expected? $\square$ Yes $\square$ No To what extent was this outcome achieved?

\begin{tabular}{l}
$\square$ Fully Achieved \\
\hline$\square$ Somewhat Achieved \\
\hline$\square$ Not Achieved \\
\hline$\square$ Not Addressed
\end{tabular}

5. Use of computer technology in instruction would become an important factor in promotion, tenure and salary evaluations. Was this an outcome you expected? $\square$ Yes $\square$ No To what extent was this outcome achieved?

\begin{tabular}{l}
$\square$ Fully Achieved \\
\hline$\square$ Somewhat Achieved \\
\hline$\square$ Not Achieved \\
\hline$\square$ Not Addressed
\end{tabular}

Thank you for your time and assistance. 


\section{Appendix L: Cover Letter to Developers}

3016 Bonsall Lane

Roanoke, VA 24014

January 16, 2002

Dear :

I am conducting a study of the perceived effectiveness of Virginia Tech's Faculty Development Institute. As one of the developers, you can provide a unique perspective on the on the initial conduct of FDI. Because only a small number of persons were involved the initial development group, your participation in the study is extremely important.

You may respond by completing the printed questionnaire and returning it in the preaddressed, stamped envelope or by submitting your responses electronically. The survey will require no more than 30 minutes of your time to complete. Please respond before February 10, 2002.

If you have questions regarding this research, please contact me at 540-427-2805 or clarebanks2@worldnet.att.net.

Thank you for your participation in this study.

Sincerely,

Claretha H. Banks 
Appendix M: Cover Letter to Initial Participants

3016 Bonsall Lane

Roanoke, VA 24014

January 6, 2002

Dear

I am conducting a study of the perceived effectiveness of Virginia Tech's Faculty Development Institute. As one of the initial Institute participants, you can provide a unique perspective on the on the initial conduct of FDI. Because only a small number of persons were in the initial participant group, your participation in the study is extremely important.

You may respond by completing the printed questionnaire and returning it in the preaddressed, stamped envelope or by submitting your responses electronically. The survey will require no more than 30 minutes of your time to complete. Please respond before February 10, 2002.

If you have questions regarding this research, please contact me at 540-427-2805 or clarebanks2@ worldnet.att.net.

Thank you for your participation in this study.

Sincerely,

Claretha H. Banks 


\section{Appendix N: Follow up Reminder Letter to Initial Participants}

3016 Bonsall Lane

Roanoke, VA 24014

February 6, 2002

Dear

I am sending this as a thank you if you have completed the survey that was previously sent regarding my dissertation study of the perceived effectiveness of Virginia Tech's Faculty Development Institute. Your assistance is greatly appreciated.

If you have not completed the survey or do not intend to complete the survey, please respond to this final mailing to let me know your decision such that I can officially complete the study.

Again, as one of the initial Institute participants, you can provide a unique perspective on the initial conduct of FDI. Because only a small number of persons were in the initial participant group, your participation in the study is extremely important.

You may respond by completing the printed questionnaire and returning it in the preaddressed, stamped envelope or by submitting your responses electronically. The survey will require no more than 30 minutes of your time to complete. Please respond before February 10, 2002.

If you have questions regarding this research, please contact me at 540-427-2805 or clarebanks2@worldnet.att.net.

Thank you for your participation in this study.

Sincerely,

Claretha H. Banks 


\section{Appendix O: Follow up Reminder Postcard to Initial Participants}

Dear

This is a reminder, request for you to complete the FDI initial participant survey and return to me as soon as it is convenient for you. Your assistance is very important to the success of this study. You may contact me at 540-427-2805 or

clarebanks2@worldnet.att.net I also have a Virginia Tech e-mail address if that would be more convenient for you at llbanks@vt.edu. If you have already completed the survey, please accept my sincere thanks for your assistance with my dissertation study.

Sincerely,

Claretha H. Banks 


\section{CLARETHA H. BANKS}

\section{EDUCATION}

Ph.D., Career \& Technical Education

$5 / 02$

VIRGINIA POLYTECHNIC INSTITUTE \& STATE UNIVERSITY, Blacksburg, VA

Dissertation topic: A descriptive analysis of the perceived effectiveness of Virginia Tech's Faculty

Development Institute

Master of Textiles, Textile Technology Management

NORTH CAROLINA STATE UNIVERSITY, Raleigh, NC

B.A., Chemistry, minor in English

CLEMSON UNIVERSITY, Clemson, SC

\section{HIGHLIGHTS OF QUALIFICATIONS}

More than 10 years of diverse management and administrative experience in organizational development and workforce training. Areas of knowledge and expertise include:

- Staff Development, Training, \& Supervision \&Evaluation

- Curriculum Development \& Instruction

- e-Learning \& Computer-Based Training

- Budgeting \& Strategic Planning
•Program Development, Management,

-Recruitment \& Staffing

-Team Building \& Group Facilitation

- Competency \& Performance Management

Pioneered the integration of computer technology into workforce development and training programs at Coca-Cola that enabled students to develop transferable skills and achieve higher paying positions. Reduced turnover and slashed operating costs through developing and implementing organizational development initiatives.

Created interactive, collaborative, cross-cultural learning environments that fostered problem solving, team building, and communication skills and that yielded measurable outcomes.

Excellent analytical, communication, organizational, and problem-solving skills. Proficient in SPSS, Micros Office 2000 applications, Authorware, Crystal Reports, StatGraphics, ATrainPro, Visual Basic, Lotus Notes WordPerfect, MS Publisher, Test Construction Set.

\section{PROFESSIONAL CERTIFICATION}

Langevin Certified Training Manager

Certified Internal Auditor (ISO 9000)

\section{RESEARCH \& TEACHING INTERESTS}

- Teaching and conducting program evaluations

- Conducting research using expectancy theory in training and development

- Teaching undergraduate and graduate training and development and/or instructional design

- Promoting and evaluating workforce development and training

- Teaching, researching, and evaluating e-Learning/e-Training

- Promoting university-business partnerships.

\section{PROFESSIONAL EXPERIENCE}


Internal Training Consultant

1998-Present

\section{COCA-COLA BOTTLING COMPANY CONSOLIDATED, Roanoke, VA}

\section{Program Development \& Management}

- Initiated, developed, and directed the Skills Pay Program, a competency management system for production employees that boosted productivity, significantly improved quality, and slashed production costs.

- Evaluated effectiveness of a faculty development program at Virginia Polytechnic Institute. Developed and administered a survey to participants and analyzed data.

- Developed a cross-training matrix for production operators and supervisors.

- Created and maintained a website to facilitate communication among all departments in the Roanoke facility and a separate training website to connect the training departments of five different sites.

- Developed and administered training and labor budgets.

\section{Curriculum Development \& Training}

- Researched competency requirements for OSHA, safety, and other certifications and aligned them to organizational needs. Created testing materials, provided job-specific training, and conducted certification testing.

- Automated the Skills Pay Program using Test Construction Set and ATrainPro, a learning management system software package. Boosted efficiency ratings by $15 \%$.

- Created and presented an instructional design model for faculty development.

- Developed and delivered training curricula for management and non-management employees. Trained employees in lean manufacturing, TQM, and SOPs principles.

- Initiated, designed, implemented, and evaluated computer-based training and testing.

- Improved on-time delivery $10 \%$ by instituting specialized testing and by realigning work processes.

- Developed and delivered a training program for sales supervisors that eliminated cost of outside training and improved sales effectiveness.

- Presented an a Train-the-Trainer workshop to a large group of training professionals.

- Taught a semester-long business course to middle school students and students with learning disabilities for Junior Achievement.

- Wrote standard operating procedures, technical manuals, and newsletter articles in corporate settings.

\section{Recruitment \& Staffing}

- Created process and testing for new hire orientation.

- Created job descriptions, position requirements, and recruitment process guidelines.

- Interviewed job candidates and made selection recommendations to HR.

- Developed performance review tools to guide managers and improve consistency and accuracy of ratings.

Production Supervisor ABBOTT LABORATORIES, ROSS PRODUCT DIVISION, Altavista, VA

1997-98

\section{Program Development \& Management}

- Developed a cross-training matrix for production operators.

- Developed and administered labor budgets.

\section{Curriculum Development \& Training}

- Researched competency requirements for OSHA, FDA, safety, and other certifications and aligned them to organizational needs. Provided job-specific training to employees.

- Trained employees in lean manufacturing, TQM, SOPs, and JIT principles.

- Improved on-time delivery $10 \%$ by instituting specialized testing and by realigning work processes.

\section{Recruitment \& Staffing}

- Interviewed job candidates and made selection recommendations to HR.

- Analyzed and redefined job functions, which reduced rework orders by $20 \%$. 
- Supervised a staff of 15 and consistently attained an efficiency rating of more than $100 \%$.

Shift Supervisor

BURLINGTON INDUSTRIES, KLOPMAN DIVISION, Hurt, VA

- Promoted from a series of increasingly responsible positions, including Physical Testing Laboratory Manager and Senior Technologist.

\section{Curriculum Development \& Training}

- Researched competency requirements for OSHA, ISO 9000, safety, and other certifications and aligned them to organizational needs. Provided job-specific training for employees.

- Developed and delivered training curricula for management and non-management employees. Trained employees in lean manufacturing, TQM, ISO 9000, SOPs, and JIT principles.

- Reduced production costs $10 \%$ by instituting quality assurance training.

- Improved on-time delivery $10 \%$ by realigning work processes.

- Taught a semester-long business course to middle school students and students with learning disabilities for Junior Achievement.

- Wrote standard operating procedures, technical manuals, and newsletter articles in corporate settings

\section{Recruitment \& Staffing}

- Analyzed and redefined job functions, which reduced rework orders by $10 \%$.

- Supervised a staff of 30 and consistently attained an efficiency rating of more than $100 \%$.

\section{PROFESSIONAL AFFILIATIONS}

American Society for Training and Development (ASTD)

Association for Career and Technical Information

Valleys of Virginia Chapter, ASTD; Vice President of Communications

Manufacturing Skill Standards Council Associate

Altavista Area Chamber of Commerce; Mentor

\section{PRESENTATIONS}

A Descriptive Analysis of the Perceived Effectiveness of Virginia Tech's Faculty Development Institute, Poster Session, Research Symposium of Virginia Tech, Blacksburg, VA 2002

Career Turning Point: People as a Technology, Graduate Seminar Presentation, College of Textiles, NC State University, Raleigh, NC 2002

Developing Strategic Training Instructional Materials, Virginia Training Conference, Richmond, VA 2001

C. Hughes, J.J. Byers, W.T. Pennington, and G.H. Robinson, "Organo-aluminum Chemistry of DPPM." Presented by C. Hughes before the $23^{\text {rd }}$ Southeastern American Chemical Society Student Affiliate Research Conference (April 1991), Savannah, GA. Abstract 1. 1991

J.J. Byers, C. Hughes, W.T. Pennington, and G. H. Robinson, "Studies on the Organogallium Chemistry of Various Silazanes." Presented by J.J. Byers before the $201^{\text {st }}$ National Meeting of the American Chemical Society (April, 1991), Atlanta, GA Abstract INORG. 197. 1991

*DPPM $=$ Bisdiphenylphospinomethane

\section{HONORS}

Phi Kappa Phi

Omicron Delta Kappa

Phi Delta Kappa

International Who's Who of Professional Management

Omicron Tau Theta 